\title{
Matricellular proteins : essential modulators of cardiac remodeling
}

Citation for published version (APA):

Schellings, M. W. M. (2007). Matricellular proteins : essential modulators of cardiac remodeling. [Doctoral Thesis, Maastricht University]. Universiteit Maastricht. https://doi.org/10.26481/dis.20071123ms

Document status and date:

Published: 01/01/2007

DOI:

10.26481/dis.20071123ms

Document Version:

Publisher's PDF, also known as Version of record

\section{Please check the document version of this publication:}

- A submitted manuscript is the version of the article upon submission and before peer-review. There can be important differences between the submitted version and the official published version of record.

People interested in the research are advised to contact the author for the final version of the publication, or visit the DOI to the publisher's website.

- The final author version and the galley proof are versions of the publication after peer review.

- The final published version features the final layout of the paper including the volume, issue and page numbers.

Link to publication

\footnotetext{
General rights rights.

- You may freely distribute the URL identifying the publication in the public portal. please follow below link for the End User Agreement:

www.umlib.nl/taverne-license

Take down policy

If you believe that this document breaches copyright please contact us at:

repository@maastrichtuniversity.nl

providing details and we will investigate your claim.
}

Copyright and moral rights for the publications made accessible in the public portal are retained by the authors and/or other copyright owners and it is a condition of accessing publications that users recognise and abide by the legal requirements associated with these

- Users may download and print one copy of any publication from the public portal for the purpose of private study or research.

- You may not further distribute the material or use it for any profit-making activity or commercial gain

If the publication is distributed under the terms of Article $25 \mathrm{fa}$ of the Dutch Copyright Act, indicated by the "Taverne" license above, 


\section{Matricellular proteins:}

essential modulators of cardiac remodeling 
(๑) copyright, M.W.M. Schellings, Maastricht 2007

ISBN 13: 978-90-9021993-6

NUR: 923

Cover image: Sirius red polarization of a mouse infarct remodeled by figures from St.-Jans Cathedral, 's Hertogenbosch.

Cover Design: Mark Schellings \& Jacques van Gerven, photos with permission taken from www.brabantfoto.com, Tony Zeeuwe.

Lay-out: House of Communications, Maastricht 


\section{Matricellular proteins: essential modulators of cardiac remodeling}

\section{PROEFSCHRIFT}

ter verkrijging van de graad van doctor aan de Universiteit Maastricht, op gezag van de Rector Magnificus, Prof. Mr. G.P.M.F. Mols

volgens het besluit van het College van Decanen, in het openbaar te verdedigen

op vrijdag 23 november 2007 om 14.00 uur.

$$
\text { door }
$$

Marcus Wilhelmus Maria Schellings Geboren op 23 augustus 1980 te Berlicum 


\section{Promotor:}

Prof. dr. Y.M. Pinto

Copromotor:

Dr. S. Heymans

Beoordelingscommissie:

Prof. dr. H.J.G.M. Crijns (voorzitter)

Dr. M. van Bilsen

Dr. J.P.M. Cleutjens

Prof. dr. J.F.M. Smits

Prof. dr. G.J. van der Vusse

Financial support by the Netherlands Heart Foundation and by Stichting Hartsvrienden Rescar for the publication of this thesis is gratefully acknowledged.

Additional support was granted by the Dr. Ir. van de Laar stichting, Harlan Netherlands, AstraZeneca B.V, Sanofi-Aventis B.V., Medtronic B.V. 


\section{Table of contents}

CHAPTER 1 General introduction and Aims of the Thesis

CHAPTER 2 Matricellular proteins in the heart: possible role

during stress and remodelling

CHAPTER 3 Absence of SPARC results in increased cardiac rupture and

dysfunction after acute myocardial infarction

CHAPTER 4 Increased expression of Syndecan-1 protects against cardiac

dilatation and dysfunction after myocardial infarction

CHAPTER 5 Syndecan-1 amplifies Angiotensin II-mediated signalling and

promotes cardiac fibrosis

CHAPTER 6 Imatinib attenuates end-organ damage in hypertensive

homozygous Ren2 rats

CHAPTER 7 Another look at imatinib mesylate

CHAPTER 8 General discussion and conclusions

Summary

Samenvatting

Dankwoord

List of Publications

Curriculum Vitae
129

131

135

140

142 



\section{Chapter 1}

General introduction and aims of the thesis 
Heart failure is one of the most prevalent diseases in the Western world, and may become epidemic this century ${ }^{1}$. Myocardial infarction (MI) and chronic hypertension are two of the most important causes for heart failure, with MI accounting for approximately $62 \%$ of all heart failure cases ${ }^{2}$. The cost of treatment of acute $\mathrm{Ml}$ alone was estimated at $\$ 140$ billion in the United States in $2002^{3}$. Fortunately, new therapies arise, resulting in a decreased incidence of heart failure after $\mathrm{MI}$, and increased survival after the onset of heart failure ${ }^{4,5}$. However, despite these new insights in the development and consequence of these diseases, we are still unable to prevent and treat them sufficiently. Therefore, research investigating the underlying causes of heart failure is necessary to improve efficacy and reduce costs of treatment.

After myocardial infarction and during hypertension, the heart adapts itself to the changed conditions, by altering its shape and size, collectively termed cardiac remodeling. For instance, during hypertension the heart is subjected to an increased workload, and will adapt itself to this condition by increasing myocyte size and its ventricular mass, a process called cardiac hypertrophy (figure 1a). This adaptation initially maintains normal cardiac function, but eventually may lead to the development of heart failure. One of the most important determinants deciding whether a hypertrophic heart will fail is the amount of extracellular matrix deposition, cardiac fibrosis (figure 1b). Cardiac fibrosis is caused by a variety of factors, like fibroblast proliferation, and growth factor activation. It causes stiffening of the left ventricle, thereby disabling ventricular relaxation, which results in diastolic dysfunction.

During myocardial infarction, part of the heart is subjected to an abrupt lack of perfusion, causing myocyte necrosis (figure 2). This results in a healing response, which initiates cardiac remodeling. Grossly, infarct healing consists of three overlapping phases, an inflammatory phase, a proliferative phase, and a maturation phase ${ }^{6}$. The inflammatory phase is hallmarked by the influx of leukocytes to remove the dead myocytes. Leukocyte infiltration is followed by influx of other inflammatory cells, like macrophages, which also help to clear the infarct zone from dead cells. The onset of the proliferative phase of infarct healing is marked by new extracellular matrix deposition, especially by differentiated fibroblasts (myofibroblasts). The formed granulation tissue increases the tensile strength of the infarct, thereby preventing cardiac rupture ${ }^{7}$. Finally, the cell-rich granulation tissue evolves into a mature, collagen-based scar, characterized by the disappearance of cells and collagen cross-linking.

To find new targets and gain new insights in the development and consequences of hypertension and MI, the use of genetically modified animals is widely appreciated. 
A

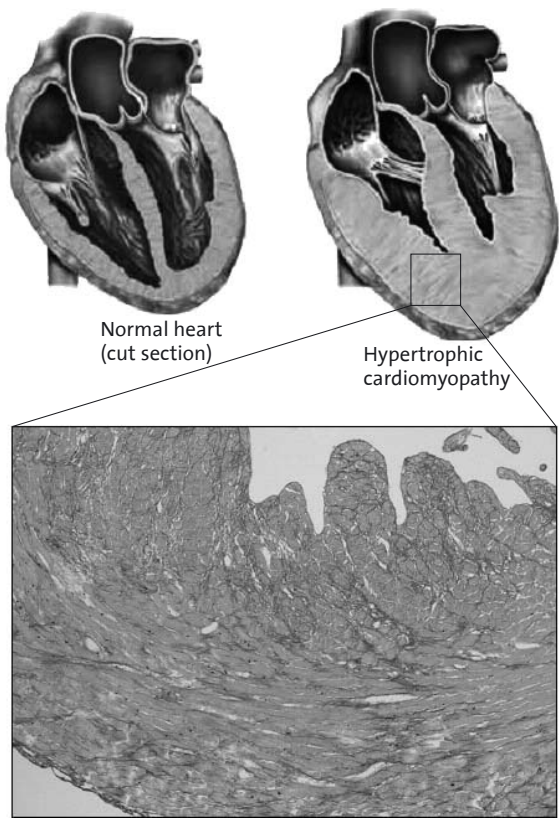

Figure 1. A, Chronic hypertension induces thickening of the ventricular wall, called cardiac hypertrophy. (Copyright (c) 2007 Nucleus Medical Art, Inc. All rights reserved. www.nucleusinc.com). B, Typical example of interstitial cardiac fibrosis during cardiac hypertrophy causing ventricular stiffness and, ultimately, cardiac dysfunction.

Gene-inactivated or knockout (KO) mice are mice that lack a certain gene, and are ideal models to study the role of the particular protein in cardiac remodeling during hypertension or after $\mathrm{MI}$, provided that they survive embryogenesis. The use of these mice has increased our knowledge about cardiovascular diseases, and remains inevitable. Also, transgenic animals overexpressing a certain gene are used in cardiovascular research. One of these is the transgenic TGR(mRen2)27 (Ren2) rat, which is used by our group to study hypertension-induced cardiac failure ${ }^{8-10}$. The studies described in this thesis all use genetic engineering to answer the specific research questions, thereby providing essential in vivo data concerning the role of investigated proteins. 
A

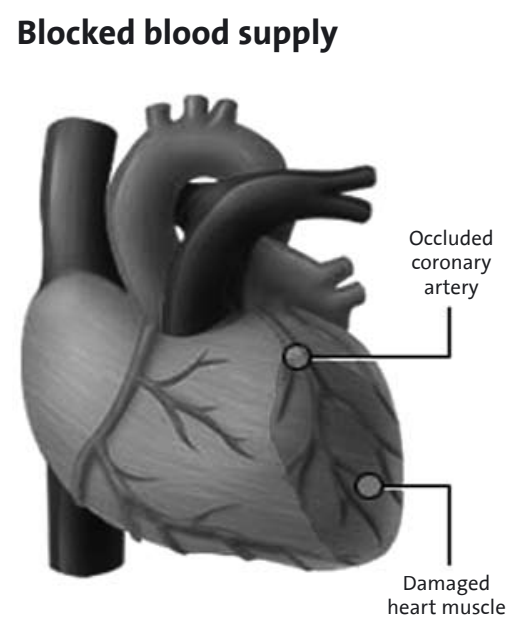

B

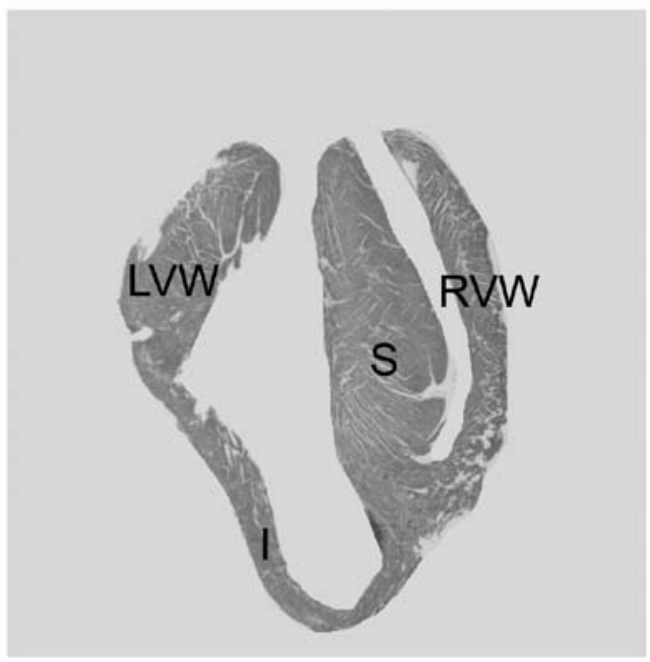

Figure 2. A, Myocardial infarction is caused by a blocked blood supply due to an occluded coronary artery. (Copyright $\odot$ FH OÖ F\&E GmbH, www.forte.fh-hagenberg.at). B, Section of an infarcted mouse heart, indicating that lack of oxygen causes myocyte necrosis and thinning of the left ventricle. LVW indicates left ventricular wall; RVW, right ventricular wall; S, septum; l, infarct.

As mentioned above, cardiac remodeling is an adaptive response occurring after Ml or hypertension. Many factors are involved in the process of cardiac remodeling, but two arise as key mediators: angiotensin II (AngII) and transforming growth factor $B_{1}$ (TGFß1). These factors are critically involved in the development of cardiac hypertrophy and regulation of infarct healing ${ }^{11,12}$. AngII and TGFß1 form a signaling network to induce cardiac remodeling, with TGFß1 usually acting as the effector molecule of Angll induced changes ${ }^{13}$.

For instance, it has been shown that Angll-induced cardiac hypertrophy and fibrosis is dependent on effective TGFß1 signaling ${ }^{14}$. Blockade of Angll by angiotensin converting enzyme (ACE) inhibitors or angiotensin type 1 receptor (AT1R) antagonists partly prevents cardiac remodeling, and improves survival in patients with heart failure. Although AngII and TGFß1 are key players in cardiac remodeling, altering their activity does not totally prevent the development of heart failure. Therefore, it is necessary to find other mediators of cardiac remodeling. Among these, matricellular proteins are emerging as possible players ${ }^{15}$, with some of them able to modify TGFß1 actions ${ }^{16,17}$. Most of the matricellular proteins are expressed at very low levels in the normal heart, but their expression reappears after injury, like Ml, suggesting an important function in the injured heart. Matricellular proteins are non-structural proteins that play a role in local signaling, and thereby provide a form of messenger function to the matrix. 
The goal of this thesis was to clarify the role of several signaling systems in cardiac remodeling, as caused by myocardial infarction or hypertension. The thesis focuses on signaling mediated via matricellular proteins, which are non-structural proteins that reside in the interstitial matrix, and regulate growth factor mechanisms. We also evaluated the role of signaling molecules by direct inhibition of growth factors like platelet-derived growth factor (PDGF). Chapter 2 summarizes then available literature regarding matricellular proteins and proposes the potential roles of a set of matricellular proteins during cardiac remodeling in the stressed heart. The following chapters will answer some of the questions raised in that initial review, concerning the functions of matricellular proteins in the injured heart.

In chapter 3, the role of secreted protein acidic and rich in cysteine (SPARC) during infarct healing is described. SPARC expression after $\mathrm{MI}$ is necessary for the deposition of a mature collagen matrix, as indicated by the increased cardiac rupture and immature collagen fibers seen in SPARC null mice after MI. Additionally, we show that SPARC is vital for signaling inside the cell, as TGFß signaling is impaired in SPARC knockdown fibroblasts.

Chapter 4 \& 5 describe the role of syndecan-1 after $\mathrm{MI}$ and during hypertension. In concordance with SPARC KO mice, syndecan-1 KO mice display cardiac dysfunction after $\mathrm{MI}$, with impaired collagen matrix formation. Interestingly, lack of syndecan1 seems to be protective during Angll-mediated hypertension, as shown by attenuated cardiac fibrosis and cardiac dysfunction in syndecan-1 null mice.

Finally, in addition we also show the importance of growth factor signaling when addressed more directly. Where the previous matricellular proteins affect signaling and cardiac structure through often unknown mechanisms, chapter 6 describes the potential beneficial effects of directly inhibiting platelet-derived growth factor (PDGF) receptor $ß$ signaling by imatinib. Directly affecting this signaling pathway during chronic hypertension also affects the cardiac matrix by inhibiting cardiac fibroblast proliferation and collagen production, which results in decreased cardiac fibrosis. This finding may have important therapeutic implications, since imatinib is already clinically used. The broader clinical implications of this research are illustrated in chapter 7.

Together, this thesis indicates the importance of matricellular proteins and growth factor signaling in regulating cardiac remodeling in the chronically overloaded heart. The findings described in this thesis provide novel insight in the functions of matricellular proteins during cardiac remodeling. While at the outset of the thesis there was very little information on this class of proteins in the heart, our studies provided highly novel findings. Matricellular proteins turned out to be necessary 
proteins for a proper cardiac adaptation to stress. While already known for years, this is the first documentation of the importance of matricellular proteins in the heart. This work highlights these proteins as potential targets for therapeutic interventions, and for large-scale clinical investigations.

\section{References}

1. Braunwald E. Shattuck lecture--cardiovascular medicine at the turn of the millennium: triumphs, concerns, and opportunities. N Engl J Med. 1997;337:1360-1369.

2. Bansal D, Chahoud G, Smith ES, Mehta JL. Prevention of heart failure. Curr Opin Cardiol. 2006;21:510-516.

3. Heart Disease and Stroke Statistics-2005 Update American Heart Association Website, 2005.

4. Hellermann JP, Goraya TY, Jacobsen SJ, Weston SA, Reeder GS, Gersh BJ, Redfield MM, Rodeheffer RJ, Yawn BP, Roger VL. Incidence of heart failure after myocardial infarction: is it changing over time? Am J Epidemiol. 2003;157:1101-1107.

5. Levy D, Kenchaiah S, Larson MG, Benjamin EJ, Kupka MJ, Ho KK, Murabito $J M$, Vasan RS. Long-term trends in the incidence of and survival with heart failure. N Engl J Med. 2002;347:1397-1402.

6. Frangogiannis NG. The mechanistic basis of infarct healing. Antioxid Redox Signal. 2006;8:1907-1939.

7. Cleutjens JP, Blankesteijn WM, Daemen MJ, Smits JF. The infarcted myocardium: simply dead tissue, or a lively target for therapeutic interventions. Cardiovasc Res. 1999;44:232-241.

8. Schroen B, Heymans S, Sharma U, Blankesteijn WM, Pokharel S, Cleutjens JP, Porter JG, Evelo CT, Duisters R, van Leeuwen RE, Janssen BJ, Debets JJ, Smits JF, Daemen MJ, Crijns HJ, Bornstein P, Pinto YM. Thrombospondin-2 is essential for myocardial matrix integrity: increased expression identifies failure-prone cardiac hypertrophy. Circ Res. 2004;95:515-522.

9. Sharma UC, Pokharel S, van Brakel TJ, van Berlo JH, Cleutjens JP, Schroen B, Andre S, Crijns HJ, Gabius HJ, Maessen J, Pinto YM. Galectin-3 marks activated macrophages in failure-prone hypertrophied hearts and contributes to cardiac dysfunction. Circulation. 2004;110:3121-3128.

10. Schellings MW, Baumann M, van Leeuwen RE, Duisters RF, Janssen SH, Schroen B, Peutz-Kootstra CJ, Heymans S, Pinto YM. Imatinib attenuates end-organ damage in hypertensive homozygous TGR(mRen2)27 rats. Hypertension. 2006;47:467-474.

11. Swynghedauw B. Molecular mechanisms of myocardial remodeling. Physiol Rev. 1999;79:215-262. 
12. Bujak M, Frangogiannis NG. The role of TGF-beta signaling in myocardial infarction and cardiac remodeling. Cardiovasc Res. 2006.

13. Rosenkranz S. TGF-beta1 and angiotensin networking in cardiac remodeling. Cardiovasc Res. 2004;63:423-432.

14. Schultz Jel J, Witt SA, Glascock BJ, Nieman ML, Reiser PJ, Nix SL, Kimball TR, Doetschman T. TGF-beta1 mediates the hypertrophic cardiomyocyte growth induced by angiotensin II. J Clin Invest. 2002;109:787-796.

15. Schellings MW, Pinto YM, Heymans S. Matricellular proteins in the heart: possible role during stress and remodeling. Cardiovasc Res. 2004;64:24-31.

16. Chen L, Klass C, Woods A. Syndecan-2 regulates transforming growth factor-beta signaling. J Biol Chem. 2004;279:15715-15718.

17. Francki A, McClure TD, Brekken RA, Motamed K, Murri C, Wang T, Sage EH. SPARC regulates TGF-beta1-dependent signaling in primary glomerular mesangial cells. J Cell Biochem. 2004;91:915-925. 



\title{
Chapter 2
}

\author{
Matricellular proteins in the heart: \\ possible role during stress and remodelling \\ Mark WM Schellings, Yigal M Pinto, Stephane Heymans \\ Cardiovascular Research \\ 2004 Oct 1;64(1):24-31
}




\section{Abstract}

Matricellular proteins are extracellular matrix proteins that modulate cellmatrix interactions and cell function, and do not seem to have a direct structural role. The family includes tenascin $C(T N-C)$, tenascin $X(T N-X)$, osteonectin, osteopontin, thrombospondin-1 (TSP1) and thrombospondin-2 (TSP2). Expression of matricellular proteins is high during embryogenesis, but almost absent during normal postnatal life. Interestingly, it reappears in response to injury.

Left ventricular remodeling is a complicated process that occurs in the stressed heart, and is still not completely understood. Several members of the matricellular protein family, like TN-C, osteopontin, and osteonectin are up-regulated after cardiac injury. Therefore, this group of proteins may have crucial functions in the heart coping with stress. This review will focus on the expression, regulation and function of these matricellular proteins, and will discuss the crucial functions that these proteins might exert during remodeling of the stressed heart. 


\section{Introduction}

A well-organized extracellular matrix is necessary to maintain strength and organization of cardiac tissue and is involved in communication between different cardiac cells. The last decade we have witnessed increasing interest in a group of 'matrix' proteins that modulate cell function but do not appear to have a direct structural role in the extracellular matrix (ECM) of the heart ${ }^{1}$. These matrix proteins have been termed 'matricellular' proteins to highlight their role in modulating cell function.

The current review will focus on the biological role of matricellular proteins in the heart, in particular tenascin $\mathrm{C}(\mathrm{TN}-\mathrm{C})$, tenascin $\mathrm{X}(\mathrm{TN}-\mathrm{X})$, thrombospondin-1 (TSP1), thrombospondin-2 (TSP2), osteonectin (also known as SPARC or BM-40) and osteopontin (OPN).

A common property of matricellular proteins is their high expression during embryogenesis, which strongly decreases after birth, when expression becomes low to absent during normal adult life. Their expression reappears at high levels during tumor growth and after tissue injury ${ }^{1}$, indicating a role for these proteins in migration and proliferation of malignant and wound healing cells, and in remodeling of the extracellular matrix. Matricellular proteins may indeed regulate cellular function and matrix production by binding to their cellular receptors ${ }^{1,2}$, and by modulating expression and activity of growth factors, cytokines, and proteinases ${ }^{1}$. A variety of knockout mice has been generated to study the role of these matricellular proteins. Surprisingly, all of the mouse models where these proteins have been deleted by gene targeting survive embryogenesis, suggesting redundancy of these proteins during embryonic development. These gene deficient mice only show a mild phenotype after birth, mainly consisting of some abnormalities of collagen formation, with resulting hyperflexibility of the skin as described in TN-X and TSP2 deficient mice ${ }^{3,4}$. Absence of matricellular proteins, however, resulted in striking abnormalities in wound healing and matrix remodeling after injury, clearly indicating that their re-expression after tissue injury is vital for normal tissue healing and remodeling ${ }^{5-9}$.

The current review will first shortly describe the overall expression and function of each matricellular protein. Subsequently, it will focus more extensively on their expression and possible function in the heart. 


\section{Tenascin C \& Tenascin-X}

TN-C is the founding member of the extracellular matrix family of tenascins. Other family members are TN-R, TN-X, TN-Y and TN-W ${ }^{10}$. Since only TN-C and TN-X are described as modulators of cell adhesion, migration and growth, the current review will focus on these two tenascins.

$\mathrm{TN}-\mathrm{C}$ is highly expressed during embryogenesis ${ }^{11}$, whereas its expression is very low after birth. TN-C, however, reappears under pathological conditions, such as infection, vascular hypertension, myocardial infarction ${ }^{12}$ or tumor formation ${ }^{8,10}$. TN-C possesses adhesive as well as counteradhesive activities, which depend on ECM and cell surface receptor binding. The counteradhesive effects of TN-C are termed "de-adhesion", meaning the induction of a transition from a strong cell-ECM adherence to an intermediate cell-ECM adhesion, as described in some excellent reviews $2,8,10,13$. De-adhesion facilitates cell migration and tissue remodeling during wound healing.

$\mathrm{TN}-\mathrm{X}$ is also widely expressed during embryogenesis, but, in contrast to TN-C, its expression persists after birth ${ }^{14,15}$. Until now, several functions of TN-X have been proposed. TN-X blocked invasion and metastasis of tumor cells ${ }^{16,17}$, enhanced cell proliferation stimulated by VEGF family proteins ${ }^{18,19}$, and modulated collagen fibrillogenesis ${ }^{3}$. TN- $X$ gene inactivation in mice caused a syndrome of cutaneous hyperflexibility of the skin ${ }^{3}$, mimicking the Ehlers-Danlos syndrome in human, which may also be caused by a mutation in the TN-X gene ${ }^{20}$.

\subsection{Tenascin- $C$ and Tenascin- $X$ in the heart}

$\mathrm{TN}-\mathrm{C}$ was only detected in the chorda tendinae of papillary muscles of the normal adult myocardium ${ }^{21}$. However, TN-C reappeared under pathological conditions, including myocarditis ${ }^{22}$, myocardial infarction ${ }^{12,}{ }^{23}$, hibernating myocardium ${ }^{24}$, and during dilated cardiomyopathy ${ }^{25}$. Its expression correlated with cardiac injury and inflammation, and level of TN-C expression has been proposed as a marker for the severity of viral myocarditis ${ }^{22}$. After myocardial infarction, $\mathrm{TN}-\mathrm{C}$ appeared at the borderzone between the infarcted area and the intact myocardium where extensive remodeling occurred ${ }^{12}$. TN-C may exert a dual role in cardiac healing after myocardial infarction. TN-C may loosen cardiomyocytes from the matrix, thereby causing slippage of cardiomyocytes, and facilitating invasion of inflammatory cells and capillaries after myocardial infarction. It may also increase matrix production, thereby strengthening the cardiac matrix. Loosening of the cardiomyocytes from the matrix may occur by TN-C mediated de-adhesion. In addition, TN-C upregulates the transcription and activity of matrix metalloproteinases (MMPs) ${ }^{26}$, promoting degradation of the extracellular matrix, 
and increasing the risk of cardiac dilatation and rupture after myocardial infarction 27-29. Increased production of matrix, in contrast, may occur by TN-C mediated recruitment of myofibroblasts ${ }^{12}$, which are the main cells involved in production of new collagen shortly after myocardial infarction ${ }^{30}$. In addition, elastic properties of TN-C ${ }^{31}$ may also help to resist the increased mechanical loading to which the borderzone of the infarct is subjected. Whether TN-C reappearance after cardiac injury is beneficial or detrimental remains unclear, considering the paradoxical functions of TN-C in matrix remodeling. Whereas TN-C mediated de-adhesion ${ }^{32}$ and increase in $\mathrm{MMPs}^{26}$ might predispose to left ventricular dilatation, recruitment of myofibroblasts by $\mathrm{TN}-\mathrm{C}$ and its elastic properties may strengthen the ventricle through accelerated fibrosis. The precise role of TN-C in matrix remodeling after cardiac injury or stress requires further investigation in mice lacking the TN-C gene.

In contrast to TN-C, TN-X is expressed in the heart during embryogenesis and adulthood, which implies a vital function for this protein in the development of the heart ${ }^{33}$. However, absence of TN-X in gene targeted mice did not result in an apparent cardiac phenotype, but resulted in reduction of collagen content in the skin with loss of tissue strength ${ }^{3}$. In addition, absence of TN-X resulted in increased activities of MMP-2 and MMP-9 ${ }^{17}$. Whether TN-X may regulate MMP activity, thereby affecting rupture or dilatation, or influence cardiac healing and remodeling after cardiac injury, requires further investigation.

\section{Osteonectin}

Osteonectin (also known as: Secreted Protein Acidic and Rich in Cysteine; SPARC or BM-40) is a 32-kDa glycoprotein that belongs to the family of matricellular proteins ${ }^{34}$. Expression of osteonectin is high during embryonic development, but very low during normal postnatal life, except in tissues undergoing continuous remodeling, such as the gut and bone ${ }^{35,}{ }^{36}$. However, osteonectin expression reappeared after pathological insults, like myocardial infarction ${ }^{37,38}$, and in malignant tumours ${ }^{39}$, indicating a role in cell migration and matrix remodeling during pathological conditions.

Its implication in remodeling may occur through binding to TSP1, vitronectin, entactin, fibrillar collagens and collagen type IV ${ }^{40}$, thereby regulating matrix organization. In addition, osteonectin is a substrate for transglutaminase, an enzyme that makes covalent cross-links between matrix proteins ${ }^{41}$, mediating matrix assembly and cell-ECM interactions. Osteonectin expression also correlated with progression of different tumours ${ }^{42-45}$. Increase in MMP-2 activity by osteonectin, as shown in invasive human breast ${ }^{46}$ and prostate cell lines ${ }^{47}$, may in part explain increased invasiveness associated with increased expression of osteonectin. 
Another important property of osteonectin is its counteradhesive activity. Addition of osteonectin to cultured endothelial cells caused dissociation of focal adhesion of endothelial cells to the matrix, resulting in modified cell shape with rounding of endothelial cells ${ }^{48}$. However, the exact mechanism of de-adhesion induced by osteonectin is incompletely understood ${ }^{48}$.

Use of osteonectin deficient mice provided new insights in the function of osteonectin regarding cell function and matrix remodeling during wound healing, as already suggested by increased expression of osteonectin after injury. Indeed, osteonectin-null mice showed an altered cutaneous wound healing ${ }^{5,6}$. Together, these data indicate a crucial role of osteonectin in matrix assembly and reorganization, and in cell-matrix interaction during tissue injury and remodelling.

\subsection{Osteonectin in the heart}

Expression of osteonectin is abundant in the heart during fetal development ${ }^{35,36}$. In contrast, its expression in the heart is almost absent during adulthood ${ }^{36}$, but reappears in the heart after myocardial infarction ${ }^{37,38}$ or adrenergic stimulation ${ }^{49}$. Absence of osteonectin in mice during embryogenesis resulted in smaller collagen fibrils that were more uniform in diameter ${ }^{50}$, with curly tails and reduced tensile strength of the skin.

Whether absence of osteonectin may also alter formation of collagen in the normal heart is unknown. Expression of osteonectin mRNA strongly increased after myocardial infarction in the infarct zone of the rat heart, reaching a peak after 14 days ${ }^{37,38}$. Its expression paralleled the up-regulation of type I collagen mRNA after myocardial infarction, suggesting an implication of osteonectin in development of fibrosis during scar formation ${ }^{37}$. Osteonectin mRNA was also up-regulated in cardiac remodeling 3 and 7 days after $ß$-adrenergic stimulation 49. Osteonectin may modulate matrix remodeling and wound healing in the heart by different ways. First, osteonectin may alter activity of growth factors, including TGF- 3 , bFGF, PDGF and VEGF, which are involved in wound healing after cardiac injury ${ }^{40,51,52}$. Secondly, osteonectin may induce de-adhesion, involved in stimulating invasion of wound healing cells, but also facilitating myocyte slippage and cardiac dilatation. Finally, osteonectin may modulate angiogenesis ${ }^{53-55}$, and might thereby influence infarct healing and function after myocardial injury. Whether osteonectin up-regulation after cardiac injury or during hemodynamic stress may be beneficial or detrimental for cardiac structure or function requires further investigation. 


\section{Osteopontin}

The matricellular protein osteopontin (OPN) is to date the most extensively studied one regarding its role in the myocardium. OPN is highly expressed during embryonic development ${ }^{56,57}$. However, OPN expression is low in normal postnatal life except for the kidney, bone, and in epithelial linings of several tissues ${ }^{58}$. As described for other matricellular proteins, OPN expression clearly increased during pathological conditions, such as cancer ${ }^{59}$, atherosclerosis ${ }^{60}$, myocardial infarction ${ }^{61}$, and focal stroke ${ }^{62}$, indicating a role of OPN in matrix remodeling and cell-matrix interaction in diseased tissue. OPN is a multifunctional protein, not only expressed by bone cells, but also by inflammatory and wound healing cells, including macrophages, endothelial cells, smooth muscle cells and fibroblasts ${ }^{63}$. It mediates wound healing by regulating cell adhesion, migration and proliferation ${ }^{7}$. OPN has both pro- and anti-inflammatory effects ${ }^{64}$ by regulating inflammatory cell adhesion ${ }^{65,66}$, migration ${ }^{65,66}$, cytokine release ${ }^{67,68}$, and differentiation state ${ }^{69}$. As a proinflammatory agent, it appears to be crucial for the recruitment of macrophages to inflamed sites ${ }^{66,70}$. Inflammatory effects of OPN were clearly shown in mice lacking OPN. Lack of OPN also resulted in impaired wound healing after skin incisions with abnormal collagen formation and pronounced disorganization of the matrix ${ }^{71}$. In conclusion, OPN appears to be a key player in matrix remodelling and wound healing.

\subsection{Osteopontin in the heart}

Based on current literature, expression of OPN has never been demonstrated in the developing heart. OPN is expressed in cultured neonatal myocytes of rats, but its expression is absent in normal human myocardium ${ }^{72}$. OPN expression reappears in response to injury. Indeed, increase of OPN was described after myocardial infarction, primarily in non-muscle cells in the interstitial space -probably infiltrating inflammatory cells- ${ }^{37,61,73}$, reaching its peak 2 to 3 days after the infarction. OPN also colocalized with interstitial fibroblasts in hypertrophic hearts of spontaneous hypertensive rats ${ }^{74}$, rat hearts undergoing thermal injury ${ }^{75}$, and in hypertrophic hearts of cardiomyopathic hamsters ${ }^{76}$. OPN expression coincided with the development of heart failure, and in situ hybridization revealed primarly interstitial cells, probably fibroblasts, as the major source of OPN. In human hearts however, OPN expression was primarly present in myocytes of explanted hearts with ischemic, hypertrophic or idiopathic dilated cardiomyopathy . In situ hybridization indeed revealed cardiomyocytes as the dominant source of OPN synthesis and expression did not correlate with inflammatory cell invasion ${ }^{72}$. Clear genetic evidence for a crucial role of OPN in cardiac healing and remodeling was provided in OPN-null mice. Absence of OPN resulted in exaggerated LV dilatation, and decreased collagen deposition in both the infarcted and remote area of 
the heart after myocardial infarction ${ }^{61}$. Up-regulation of OPN after myocardial infarction thus protected against LV dilatation, implying a beneficial role for OPN in LV remodeling when coping with cardiac stress. Whether OPN-mediated decrease in MMP activity ${ }^{77}$ may also be implicated in LV remodeling after myocardial injury has not been investigated. Taken together, OPN upregulation may be necessary to maintain cardiac structure and function during cardiac injury or stress.

\section{Thrombospondin $1 \& 2$}

Thrombospondin (TSP) 1 and 2 belong to the thrombospondin family of extracellular glycoproteins, consisting of TSPs 1-5. TSP1 and TSP2 expression is high during embryogenesis, but spatial and temporal expression of TSP1 during embryogenesis differs from TSP2 ${ }^{78-80}$. During normal postnatal life, the expression of TSP1 and TSP2 is low. TSPs exert their function at the cell surface, where they bind to membrane proteins and cytokines, thereby regulating ECM structure and cellular phenotype. The three main molecular functions of TSP1 are activation of TGF- $\beta$, inhibition of angiogenesis and de-adhesion. First, TSP1 is a major activator of TGF- $B 1$ in vivo ${ }^{81}$. Secondly, TSP1 was the first naturally occurring protein to be identified as an angiogenesis inhibitor ${ }^{82}$. TSP1 directly inhibits angiogenesis by induction of apoptosis and inhibition of migration of endothelial cells ${ }^{83}$, and may indirectly inhibit angiogenesis by modulation of inflammatory cells and myofibroblasts ${ }^{84}$. Finally, TSP1 also induces de-adhesion in a variety of cells, including fibroblasts and endothelial cells ${ }^{85}$, by stimulating the loss of focal adhesions and actin stress fibers ${ }^{85,86}$. Despite its array of functions, the TSP1 null mice showed only a subtle phenotype, including mild spinal lordosis, acute and chronic inflammatory pulmonary infiltrates and an elevated number of white blood cells in the circulation ${ }^{87}$.

As described for TSP1, TSP2 also inhibits angiogenesis and causes de-adhesion. Gene inactivation of TSP2 in mice indeed increased capillary density in various tissues at all stages of life ${ }^{4}$. Besides its anti-angiogenic function, TSP2 also inhibits focal adhesion in endothelial cells ${ }^{88,89}$. Absence of TSP2 in fibroblasts, however, caused defective attachment and spreading on matrix proteins, like fibronectin ${ }^{4,90}$. Increased levels of MMP2 activity in absence of TSP2 may in part explain the defect in fibroblast adhesion. The TSP2 null mice showed a more dramatic phenotype, as compared to TSP1 null mice, including a fragile skin associated with an abnormal collagen fibrillogenesis, increased vascularity in response to injury, increased cortical bone density, and a bleeding diathesis ${ }^{4,} 79$. In conclusion, TSP1 and TSP2 are involved in wound healing by regulating growth factor signaling, angiogenesis and cellular adhesion. 


\subsection{Thrombospondin 1 and 2 in the heart}

Both TSP1 and TSP2 are expressed in the heart during development, whereas their expression is low during normal postnatal life. However, TSP1 and TSP2 expression reappears in response to injury, implicating that, if the same occurs in the heart, these proteins could be involved in the LV remodeling during/after pathological events in the heart, such as myocardial infarction, or chronic pressure overload.

TSP1 null mice may show an interesting phenotype after pathological insults in the heart. It is known that TSP1 null mice have a delayed wound healing associated with a reduced inflammatory response ${ }^{87}$. A delayed healing after, for instance, myocardial infarction may result in a reduced LV function.

TSP2 null mice display an abnormal collagen fibrillogenesis after birth and during cutaneous wound healing ${ }^{9,87}$. An important issue is whether collagen formation may be abnormal after cardiac injury or stress, resulting in abnormal cardiac remodeling and impaired cardiac function. Preliminary results indeed demonstrated that myocardial infarction in TSP2 null mice resulted in cardiac rupture 48 hours after myocardial infarction in more than $90 \%$ of the null mice ${ }^{91}$. This striking phenotype suggests that TSP2 is essential to LV remodeling after myocardial infarction, and may have an important role to maintain matrix integrity in the heart. Preliminary, yet unpublished data indicate that altered collagen formation may in part explain increased cardiac rupture after myocardial infarction. Whether increased inflammation in absence of TSP2 may predispose to weakening of the matrix, however, remains a vital question. Together, TSP2 appears to play a pivotal role in maintenance of cardiac integrity and structure. 


\section{Are matricellular proteins essential for the heart to cope with hemodynamic stress?}

The matricellular proteins are a group of ECM binding proteins that exert their function by binding to matrix proteins, cell surface receptors or molecules such as cytokines. They do not have a direct structural role in the matrix, but modulate cell function and cell-matrix interactions ${ }^{1}$. Most of the matricellular proteins show an increased expression in the heart in response to injury or stress, which suggests a vital function of these proteins in wound healing and ventricular remodeling $12,37,61$. These matricellular proteins may alter cardiac remodeling by different ways. First, they may initiate de-adhesion between cardiomyocytes and the ECM, meaning the transformation from a strong cell-ECM adhesion to an intermediate cell-ECM adhesion, which allows cells to spread (figure 1$)^{2}$. Secondly, matricellular proteins can decrease ${ }^{17,77,92}$, or increase ${ }^{26,46,47,93}$ (figure 1, table 1) proteinases involved in cardiac remodeling and function in different cardiac diseases ${ }^{27,} 94$.

\section{Strong adhesion (focal adhesion, stress fibers)}
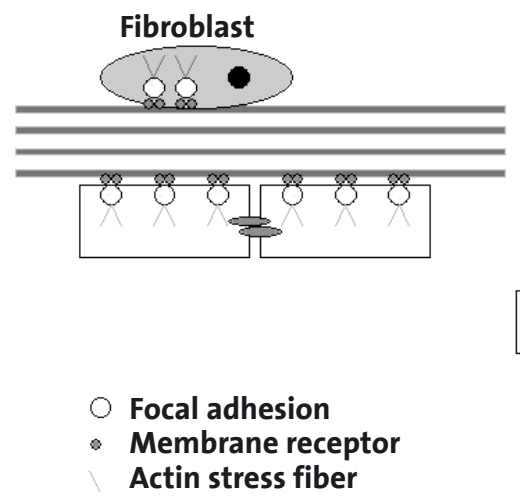

Static tissue
Intermediate adhesion (cell migration)

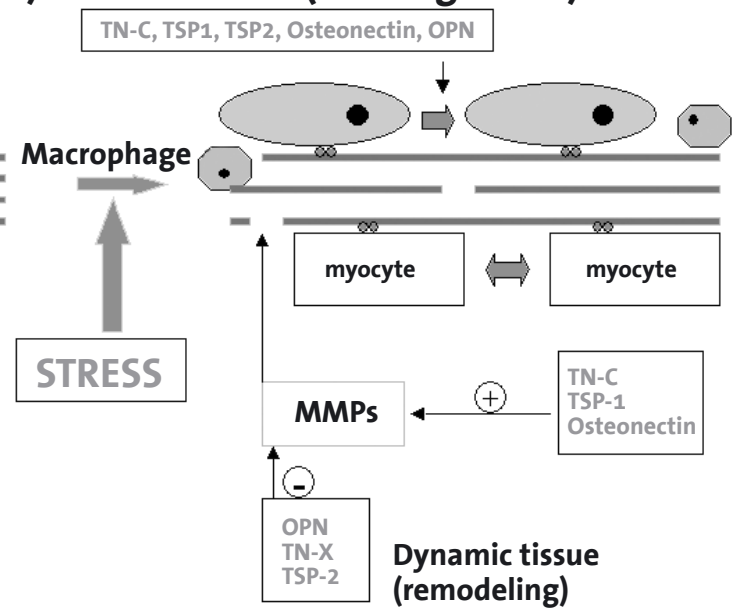

Figure 1. A hypothetical scheme showing the possible role of the matricellular proteins in during LV remodeling of the heart. Expression of matricellular proteins increases in response to stress. Matricellular proteins induce de-adhesion (loosening of cell-matrix adherence), through loss of actin fibers and focal adhesion plaques. Thereby, matricellular proteins facilitate cell migration and cell infiltration. Matricellular proteins also regulate MMP activity, involved in regulating matrix rearrangement during remodeling of the heart.

Gene inactivation in mice in combination with cardiac disease models provides a unique tool to study the role of each individual matricellular protein in the stressed or injured heart. The null mice of the matricellular proteins all survived during embryogenesis, and only showed a mild phenotype. However, most of the null mice showed an altered response to wound healing, with changes in inflammation, angiogenesis, collagen fibrillogenesis or matrix deposition (table 1). 
Table 1: MMP activity regulation by matricellular proteins and characteristics of matricellular protein null mice.

\begin{tabular}{|c|c|c|c|c|c|}
\hline & & Characteristics of & e matricellular $p$ & tein null mice & \\
\hline $\begin{array}{c}\text { Matricellular } \\
\text { protein }\end{array}$ & $\begin{array}{l}\text { MMP activity } \\
\text { regulation }\end{array}$ & $\begin{array}{c}\text { Baseline } \\
\text { matrix character }\end{array}$ & $\begin{array}{c}\text { Matrix character } \\
\text { after } \\
\text { wound healing }\end{array}$ & $\begin{array}{c}\text { Cardiac } \\
\text { phenotype after } \\
\text { MI }\end{array}$ & References \\
\hline Osteopontin & $\begin{array}{c}\text { Decreases } \\
\text { MMP-2 \& -9 }\end{array}$ & No studies & $\begin{array}{l}\text { Small regular } \\
\text { collagen fibrils }\end{array}$ & $\begin{array}{c}\text { Exaggerated LV } \\
\text { dilatation }\end{array}$ & {$[61,71,77]$} \\
\hline Osteonectin & $\begin{array}{l}\text { Increases } \\
\text { MMP- } 2\end{array}$ & $\begin{array}{c}\text { Immature } \\
\text { collagen fibrils }\end{array}$ & $\begin{array}{l}\text { Small regular } \\
\text { collagen fibrils }\end{array}$ & No studies & {$[5,46,47,50]$} \\
\hline TSP1 & $\begin{array}{l}\text { Increases } \\
\text { MMP- } 2\end{array}$ & No change & No change & No studies & {$[87,93]$} \\
\hline TSP2 & $\begin{array}{c}\text { Decreases } \\
\text { MMP-2 }\end{array}$ & $\begin{array}{c}\text { Abnormal } \\
\text { collagen fibrils }\end{array}$ & $\begin{array}{l}\text { Large irregular } \\
\text { collagen fibrils }\end{array}$ & $\begin{array}{l}\text { Cardiac rupture } \\
>90 \% \text { within } 3 \\
\text { days }\end{array}$ & {$[9,87,90,91]$} \\
\hline Tenascin-C & $\begin{array}{l}\text { Increases } \\
\text { MMP- } 9\end{array}$ & No studies & $\begin{array}{l}\text { Reduced } \\
\text { fibronectin } \\
\text { deposition }\end{array}$ & No studies & {$[26,95]$} \\
\hline Tenascin-X & $\begin{array}{c}\text { Decreases } \\
\text { MMP-2 \& -9 }\end{array}$ & $\begin{array}{l}\text { Reduced collagen } \\
\text { content in skin }\end{array}$ & No studies & No studies & {$[3,17]$} \\
\hline
\end{tabular}


Recently, the role of OPN and TSP2 after myocardial infarction has been examined in their respective null mice. Both the OPN and the TSP2 null mice showed a clear phenotype after MI. The OPN null mice had an exaggerated left ventricle dilatation 61 , whereas $>90 \%$ of the TSP2 null mice died after myocardial infarction due to cardiac rupture ${ }^{91}$. These data are striking and show that both OPN and TSP2 are necessary to maintain a normal cardiac structure and function after myocardial injury.

The multiple parallel features of the matricellular proteins suggest that, besides OPN and TSP2, also other family members may have crucial functions during ventricular remodeling of the stressed heart. More research is needed to clarify the roles of these matricellular proteins during ventricular remodeling in the injured heart.

\section{Acknowledgements}

This study was supported by a VIDI grant (016.036.346) from the Netherlands Organisation for Scientific Research (NWO) to Dr. Y. M. Pinto and a Dr. Dekkers grant of the Netherlands Heart Foundation (NHS, 2003T036) to Dr. S. Heymans. 


\section{References}

1. Bornstein P and Sage EH. Matricellular proteins: extracellular modulators of cell function. Curr Opin Cell Biol 2002; 14: 608-16.

2. Murphy-Ullrich JE. The de-adhesive activity of matricellular proteins: is intermediate cell adhesion an adaptive state? J Clin Invest 2001; 107: 78590.

3. Mao JR, Taylor G, Dean WB, et al. Tenascin-X deficiency mimics EhlersDanlos syndrome in mice through alteration of collagen deposition. Nat Genet 2002; 30: 421-5.

4. Kyriakides TR, Zhu YH, Smith LT, et al. Mice that lack thrombospondin 2 display connective tissue abnormalities that are associated with disordered collagen fibrillogenesis, an increased vascular density, and a bleeding diathesis. J Cell Biol 1998; 140: 419-30.

5. Bradshaw AD, Reed MJ, and Sage EH. SPARC-null mice exhibit accelerated cutaneous wound closure. J Histochem Cytochem 2002; 50: 1-10.

6. Basu A, Kligman LH, Samulewicz SJ, and Howe CC. Impaired wound healing in mice deficient in a matricellular protein SPARC (osteonectin, BM-40). BMC Cell Biol 2001; 2: 15.

7. Giachelli CM and Steitz S. Osteopontin: a versatile regulator of inflammation and biomineralization. Matrix Biol 2000; 19: 615-22.

8. Chiquet-Ehrismann $\mathrm{R}$ and Chiquet $M$. Tenascins: regulation and putative functions during pathological stress. J Pathol 2003; 200: 488-99.

9. Kyriakides TR, Tam JW, and Bornstein P. Accelerated wound healing in mice with a disruption of the thrombospondin 2 gene. J Invest Dermatol 1999; 113: 782-7.

10. Jones FS and Jones PL. The tenascin family of ECM glycoproteins: structure, function, and regulation during embryonic development and tissue remodeling. Dev Dyn 2000; 218: 235-59.

11. Crossin KL, Hoffman S, Grumet $M$, et al. Site-restricted expression of cytotactin during development of the chicken embryo. J Cell Biol 1986; 102: 1917-30.

12. Imanaka-Yoshida K, Hiroe $M$, Nishikawa $T$, et al. Tenascin-C modulates adhesion of cardiomyocytes to extracellular matrix during tissue remodeling after myocardial infarction. Lab Invest 2001; 81: 1015-24.

13. Jones PL and Jones FS. Tenascin-C in development and disease: gene regulation and cell function. Matrix Biol 2000; 19: 581-96.

14. Bristow J, Tee MK, Gitelman SE, et al. Tenascin-X: a novel extracellular matrix protein encoded by the human XB gene overlapping P450c21B. J Cell Biol 1993; 122: 265-78.

15. Geffrotin C, Garrido JJ, Tremet L, and Vaiman M. Distinct tissue distribution 
in pigs of tenascin-X and tenascin-C transcripts. Eur J Biochem 1995; 231 : 83-92.

16. Matsumoto K, Takahashi K, Yoshiki A, et al. Invasion of melanoma in double knockout mice lacking tenascin-X and tenascin-C. Jpn J Cancer Res 2002; 93: 968-75.

17. Matsumoto K, Takayama N, Ohnishi J, et al. Tumour invasion and metastasis are promoted in mice deficient in tenascin-X. Genes Cells 2001; 6: 1101-11.

18. Ikuta $\mathrm{T}$, Ariga $\mathrm{H}$, and Matsumoto $\mathrm{K}$. Extracellular matrix tenascin- $\mathrm{X}$ in combination with vascular endothelial growth factor B enhances endothelial cell proliferation. Genes Cells 2000; 5: 913-927.

19. Ikuta T, Ariga $\mathrm{H}$, and Matsumoto Kl. Effect of tenascin-X together with vascular endothelial growth factor $\mathrm{A}$ on cell proliferation in cultured embryonic hearts. Biol Pharm Bull 2001; 24: 1320-3.

20. Schalkwijk J, Zweers MC, Steijlen PM, et al. A recessive form of the EhlersDanlos syndrome caused by tenascin-X deficiency. N Engl J Med 2001; 345: 1167-75.

21. Sato I and Shimada K. Quantitative analysis of tenascin in chordae tendineae of human left ventricular papillary muscle with aging. Ann Anat 2001; 183: 443-8.

22. Imanaka-Yoshida $\mathrm{K}$, Hiroe $M$, Yasutomi $Y$, et al. Tenascin-C is a useful marker for disease activity in myocarditis. J Pathol 2002; 197: 388-94.

23. Willems IE, Arends JW, and Daemen MJ. Tenascin and fibronectin expression in healing human myocardial scars. J Pathol 1996; 179: 321-5.

24. Frangogiannis NG, Shimoni S, Chang SM, et al. Active interstitial remodeling: an important process in the hibernating human myocardium. J Am Coll Cardiol 2002; 39: 1468-74.

25. Tamura A, KusachiS, Nogami K, et al. Tenascin expression in endomyocardial biopsy specimens in patients with dilated cardiomyopathy: distribution along margin of fibrotic lesions. Heart 1996; 75: 291-4.

26. Tremble P, Chiquet-Ehrismann R, and Werb Z. The extracellular matrix ligands fibronectin and tenascin collaborate in regulating collagenase gene expression in fibroblasts. Mol Biol Cell 1994; 5: 439-53.

27. Heymans S, Luttun A, Nuyens D, et al. Inhibition of plasminogen activators or matrix metalloproteinases prevents cardiac rupture but impairs therapeutic angiogenesis and causes cardiac failure. Nat Med 1999; 5: 1135-42.

28. Ducharme A, Frantz S, Aikawa M, et al. Targeted deletion of matrix metalloproteinase- 9 attenuates left ventricular enlargement and collagen accumulation after experimental myocardial infarction. J Clin Invest 2000; 106: 55-62.

29. Rohde LE, Ducharme A, Arroyo LH, et al. Matrix metalloproteinase 
inhibition attenuates early left ventricular enlargement after experimental myocardial infarction in mice. Circulation 1999; 99: 3063-70.

30. Weber KT. Fibrosis and hypertensive heart disease. Curr Opin Cardiol 2000; 15: 264-72.

31. Oberhauser AF, Marszalek PE, Erickson HP, and Fernandez JM. The molecular elasticity of the extracellular matrix protein tenascin. Nature 1998; 393: 181-5.

32. Murphy-Ullrich JE, Lightner VA, Aukhil I, et al. Focal adhesion integrity is downregulated by the alternatively spliced domain of human tenascin. J Cell Biol 1991; 115: 1127-36.

33. Matsumoto K, Saga Y, Ikemura T, et al. The distribution of tenascin-X is distinct and often reciprocal to that of tenascin-C. J Cell Biol 1994; 125: 483-93.

34. Lane TF and Sage EH. The biology of SPARC, a protein that modulates cellmatrix interactions. Faseb J 1994; 8: 163-73.

35. Holland PW, Harper SJ, McVey JH, and Hogan BL. In vivo expression of mRNA for the Ca++-binding protein SPARC (osteonectin) revealed by in situ hybridization. J Cell Biol 1987; 105: 473-82.

36. Sage H, Vernon RB, Decker J, et al. Distribution of the calcium-binding protein SPARC in tissues of embryonic and adult mice. J Histochem Cytochem 1989; 37: 819-29.

37. Komatsubara I, Murakami T, Kusachi S, et al. Spatially and temporally different expression of osteonectin and osteopontin in the infarct zone of experimentally induced myocardial infarction in rats. Cardiovasc Pathol 2003; 12: 186-94.

38. Stanton LW, Garrard L, Damm D, et al. Altered patterns of gene expression in response to myocardial infarction. Circ Res 2000; 86: 939-45.

39. Porter PL, Sage EH, Lane TF, et al. Distribution of SPARC in normal and neoplastic human tissue. J Histochem Cytochem 1995; 43: 791-800.

40. Brekken RA and Sage EH. SPARC, a matricellular protein: at the crossroads of cell-matrix communication. Matrix Biol 2001; 19: 816-27.

41. Aeschlimann D, Kaupp O, and Paulsson M. Transglutaminase-catalyzed matrix cross-linking in differentiating cartilage: identification of osteonectin as a major glutaminyl substrate. J Cell Biol 1995; 129: 881-92.

42. Ledda F, Bravo Al, Adris S, et al. The expression of the secreted protein acidic and rich in cysteine (SPARC) is associated with the neoplastic progression of human melanoma. J Invest Dermatol 1997; 108: 210-4.

43. Massi D, Franchi A, Borgognoni L, et al. Osteonectin expression correlates with clinical outcome in thin cutaneous malignant melanomas. Hum Pathol 1999; 30: 339-44.

44. Rempel SA, Ge S, and Gutierrez JA. SPARC: a potential diagnostic marker of 
invasive meningiomas. Clin Cancer Res 1999; 5: 237-41.

45. Rempel SA, Golembieski WA, Ge S, et al. SPARC: a signal of astrocytic neoplastic transformation and reactive response in human primary and xenograft gliomas. J Neuropathol Exp Neurol 1998; 57: 1112-21.

46. Gilles $\mathrm{C}$, Bassuk JA, Pulyaeva $\mathrm{H}$, et al. SPARC/osteonectin induces matrix metalloproteinase 2 activation in human breast cancer cell lines. Cancer Res 1998; 58: 5529-36.

47. Jacob K, Webber M, Benayahu D, and Kleinman HK. Osteonectin promotes prostate cancer cell migration and invasion: a possible mechanism for metastasis to bone. Cancer Res 1999; 59: 4453-7.

48. Murphy-Ullrich JE, Lane TF, Pallero MA, and Sage EH. SPARC mediates focal adhesion disassembly in endothelial cells through a follistatin-like region and the $\mathrm{Ca}(2+)$-binding EF-hand. J Cell Biochem 1995; 57: 341-50.

49. Masson S, Arosio B, Luvara G, et al. Remodelling of cardiac extracellular matrix during beta-adrenergic stimulation: upregulation of SPARC in the myocardium of adult rats. J Mol Cell Cardiol 1998; 30: 1505-14.

50. Bradshaw AD and Sage EH. SPARC, a matricellular protein that functions in cellular differentiation and tissue response to injury. J Clin Invest 2001; 107: 1049-54.

51. Yan Q and Sage EH. SPARC, a matricellular glycoprotein with important biological functions. J Histochem Cytochem 1999; 47: 1495-506.

52. Kupprion C, Motamed K, and Sage EH. SPARC (BM-40, osteonectin) inhibits the mitogenic effect of vascular endothelial growth factor on microvascular endothelial cells. J Biol Chem 1998; 273: 29635-40.

53. Carmeliet $P$ and Collen $D$. Transgenic mouse models in angiogenesis and cardiovascular disease. J Pathol 2000; 190: 387-405.

54. Carmeliet P and Jain RK. Angiogenesis in cancer and other diseases. Nature 2000; 407: 249-57.

55. Edelberg JM, Cai D, and Xaymardan M. Translation of PDGF cardioprotective pathways. Cardiovasc Toxicol 2003; 3: 27-35.

56. Thayer JM, Giachelli CM, Mirkes PE, and Schwartz SM. Expression of osteopontin in the head process late in gastrulation in the rat. J Exp Zool 1995; 272: 240-4.

57. Giachelli C, Schwartz SM, and Liaw L. Molecular and Cellular Biology of Osteopontin. Trends Cardiovasc. Med. 1995; 5: 88-95.

58. Denhardt DT and Guo X. Osteopontin: a protein with diverse functions. Faseb J 1993; 7: 1475-82.

59. Tuck AB, O'Malley FP, Singhal $\mathrm{H}$, et al. Osteopontin and $\mathrm{p} 53$ expression are associated with tumor progression in a case of synchronous, bilateral, invasive mammary carcinomas. Arch Pathol Lab Med 1997; 121: 578-84.

60. Giachelli CM, Bae N, Almeida M, et al. Osteopontin is elevated during 
neointima formation in rat arteries and is a novel component of human atherosclerotic plaques. J Clin Invest 1993; 92: 1686-96.

61. Trueblood NA, Xie Z, Communal C, et al. Exaggerated left ventricular dilation and reduced collagen deposition after myocardial infarction in mice lacking osteopontin. Circ Res 2001; 88: 1080-7.

62. Ellison JA, Velier JJ, Spera P, et al. Osteopontin and its integrin receptor alpha(v)beta3 are upregulated during formation of the glial scar after focal stroke. Stroke 1998; 29: 1698-706; discussion 1707.

63. O'Brien ER, Garvin MR, Stewart DK, et al. Osteopontin is synthesized by macrophage, smooth muscle, and endothelial cells in primary and restenotic human coronary atherosclerotic plaques. Arterioscler Thromb 1994; 14: 1648-56.

64. Mazzali M, Kipari T, Ophascharoensuk V, et al. Osteopontin--a molecule for all seasons. Ojm 2002; 95: 3-13.

65. Nasu K, Ishida T, Setoguchi M, et al. Expression of wild-type and mutated rabbit osteopontin in Escherichia coli, and their effects on adhesion and migration of P388D1 cells. Biochem J 1995; 307 ( Pt 1): 257-65.

66. Giachelli CM, Lombardi D, Johnson RJ, et al. Evidence for a role of osteopontin in macrophage infiltration in response to pathological stimuli in vivo. Am J Pathol 1998; 152: 353-8.

67. Ashkar S, Weber GF, Panoutsakopoulou V, et al. Eta-1 (osteopontin): an early component of type-1 (cell-mediated) immunity. Science 2000; 287 : 860-4.

68. Nau GJ, Liaw L, Chupp GL, et al. Attenuated host resistance against Mycobacterium bovis BCG infection in mice lacking osteopontin. Infect Immun 1999; 67: 4223-30.

69. Crawford HC, Matrisian LM, and Liaw L. Distinct roles of osteopontin in host defense activity and tumor survival during squamous cell carcinoma progression in vivo. Cancer Res 1998; 58: 5206-15.

70. Denhardt DT, Noda M, O'Regan AW, et al. Osteopontin as a means to cope with environmental insults: regulation of inflammation, tissue remodeling, and cell survival. J Clin Invest 2001; 107: 1055-61.

71. Liaw L, Birk DE, Ballas CB, et al. Altered wound healing in mice lacking a functional osteopontin gene (spp1). J Clin Invest 1998; 101: 1468-78.

72. Graf K, Do YS, Ashizawa N, et al. Myocardial osteopontin expression is associated with left ventricular hypertrophy. Circulation 1997; 96: 3063-71.

73. Rocha R, Rudolph AE, Frierdich GE, et al. Aldosterone induces a vascular inflammatory phenotype in the rat heart. Am J Physiol Heart Circ Physiol 2002; 283: H1802-10.

74. Singh K, Sirokman G, Communal C, et al. Myocardial osteopontin expression coincides with the development of heart failure. Hypertension 
1999; 33: 663-70.

75. Murry CE, Giachelli CM, Schwartz SM, and Vracko R. Macrophages express osteopontin during repair of myocardial necrosis. Am J Pathol 1994; 145: 1450-62.

76. Williams EB, Halpert I, Wickline S, et al. Osteopontin expression is increased in the heritable cardiomyopathy of Syrian hamsters. Circulation 1995; 92 : 705-9.

77. Xie Z, Singh $M$, Siwik DA, et al. Osteopontin inhibits interleukin-1betastimulated increases in matrix metalloproteinase activity in adult rat cardiac fibroblasts: role of protein kinase C-zeta. J Biol Chem 2003; 278 : 48546-52.

78. Iruela-Arispe ML, Liska DJ, Sage EH, and Bornstein P. Differential expression of thrombospondin 1, 2, and 3 during murine development. Dev Dyn 1993; 197: 40-56.

79. Kyriakides TR, Zhu YH, Yang Z, and Bornstein P. The distribution of the matricellular protein thrombospondin 2 in tissues of embryonic and adult mice. J Histochem Cytochem 1998; 46: 1007-15.

80. Tooney PA, Sakai T, Sakai K, et al. Restricted localization of thrombospondin2 protein during mouse embryogenesis: a comparison to thrombospondin1. Matrix Biol 1998; 17: 131-43.

81. Crawford SE, Stellmach V, Murphy-Ullrich JE, et al. Thrombospondin-1 is a major activator of TGF-beta1 in vivo. Cell 1998; 93: 1159-70.

82. Good DJ, Polverini PJ, Rastinejad F, et al. A tumor suppressor-dependent inhibitor of angiogenesis is immunologically and functionally indistinguishable from a fragment of thrombospondin. Proc Natl Acad Sci U S A 1990; 87: 6624-8.

83. Iruela-Arispe ML, Lombardo $M$, Krutzsch HC, et al. Inhibition of angiogenesis by thrombospondin-1 is mediated by 2 independent regions within the type 1 repeats. Circulation 1999; 100: 1423-31.

84. Lawler J. Thrombospondin-1 as an endogenous inhibitor of angiogenesis and tumor growth. J Cell Mol Med 2002; 6: 1-12.

85. Murphy-Ullrich JE and Hook M. Thrombospondin modulates focal adhesions in endothelial cells. J Cell Biol 1989; 109: 1309-19.

86. Greenwood JA and Murphy-Ullrich JE. Signaling of de-adhesion in cellular regulation and motility. Microsc Res Tech 1998; 43: 420-32.

87. Agah A, KyriakidesTR, Lawler J, and Bornstein P.The lack of thrombospondin1 (TSP1) dictates the course of wound healing in double-TSP1/TSP2-null mice. Am J Pathol 2002; 161: 831-9.

88. Murphy-Ullrich JE, Gurusiddappa S, Frazier WA, and Hook M. Heparinbinding peptides from thrombospondins 1 and 2 contain focal adhesionlabilizing activity. J Biol Chem 1993; 268: 26784-9. 
89. Pellerin S, Lafeuillade B, Chambaz EM, and Feige JJ. Distinct effects of thrombospondin-1 and CISP/thrombospondin-2 on adrenocortical cell spreading. Mol Cell Endocrinol 1994; 106: 181-6.

90. Yang Z, Kyriakides TR, and Bornstein P. Matricellular proteins as modulators of cell-matrix interactions: adhesive defect in thrombospondin 2-null fibroblastsisaconsequenceofincreased levels of matrixmetalloproteinase2. Mol Biol Cell 2000; 11: 3353-64.

91. Cleutjens J, Huynen F, Smits J, et al. Thrombospondin-2 deficiency in mice results in cardiac rupture early after myocardial infarction. Circ Res 1999; 100 (Suppl.): 156.

92. Yang Z, Strickland DK, and Bornstein P. Extracellular matrix metalloproteinase 2 levels are regulated by the low density lipoproteinrelated scavenger receptor and thrombospondin 2. J Biol Chem 2001; 276: 8403-8.

93. Lee T, Esemuede N, Sumpio BE, and Gahtan V. Thrombospondin-1 induces matrix metalloproteinase-2 activation in vascular smooth muscle cells. J Vasc Surg 2003; 38: 147-54.

94. Spinale FG. Matrix metalloproteinases: regulation and dysregulation in the failing heart. Circ Res 2002; 90: 520-30.

95. Forsberg E, Hirsch E, Frohlich L, et al. Skin wounds and severed nerves heal normally in mice lacking tenascin-C. Proc Natl Acad Sci U S A 1996; 93: 6594-9. 



\section{Chapter 3}

\section{Absence of SPARC results in increased cardiac rupture and dysfunction after acute myocardial infarction}

Mark WM Schellings, Davy Vanhoutte, Melissa Swinnen, Jack PM Cleutjens, Jacques JM Debets, Mirjam van Loon,

E. Helene Sage, Yigal M Pinto, Stephane Heymans

Submitted 


\section{Abstract}

Background The matricellular protein SPARC (secreted protein acidic and rich in cysteine, also known as osteonectin) mediates cell-matrix interactions during wound healing and tumorigenesis. The current study investigated whether SPARC also regulates cardiac remodeling and matrix maturation after myocardial infarction (MI).

Methods and Results. SPARC protein expression after MI increased from 3 days on, reaching its maximum at day 14 . Targeted deletion of SPARC in mice resulted in increased mortality compared with wild type (WT) mice after MI. About $41 \%$ of the SPARC knockout mice (13/32) succumbed within 5 days after MI due to cardiac rupture, in contrast to $8.8 \%$ rupture (3/34) in WT. The absence of SPARC resulted in the formation of a disorganized granulation tissue and dismature collagen matrix in the infarcted area, leading to increased cardiac dysfunction after hemodynamic stress. This crucial involvement of SPARC in infarct healing is in part due to its regulatory role in transforming growth factor- $B$ (TGFß) signaling. In vitro, lentiviral mediated knockdown of SPARC by short hairpin RNA attenuated phosphorylation of SMAD2 after TGFß stimulation, whereas infusion of TGFß in SPARC KO mice rescued cardiac rupture and infarct healing.

In conclusion, SPARC is essential for normal infarct healing and cardiac integrity after MI, partly via regulation of TGFß signaling. 


\section{Introduction}

Secreted Protein, Acidic and Rich in Cysteine (SPARC, also called osteonectin or BM-40) belongs to the family of matricellular proteins, which are non-structural proteins in the matrix capable of modulating cellular responses. As for other matricellular proteins, SPARC is involved in tumor formation and wound healing by modulating cell-matrix interaction ${ }^{1,2}$. However, evidence on a specific role for SPARC in formation of granulation and scar tissue after myocardial infarction (MI) is lacking.

Healing after $\mathrm{MI}$ requires a tightly regulated process of wound healing and scar formation. Alteration in this well-orchestrated response to myocardial necrosis leads to adverse infarct healing, cardiac rupture and dysfunction ${ }^{3}$. Expression of SPARC is increased after $\mathrm{MI}$, and is spatially and temporally related to the formation of a fibrous scar ${ }^{4,5}$. SPARC may modulate extracellular matrix turnover through its effect on collagen, extracellular proteases and growth factors ${ }^{1}$.

Transforming growth factor $-\beta$ (TGFß) is a cytokine involved in wound healing and collagen production, and has an important role in LV remodeling after MI. SPARC is able to modulate TGFß signaling by binding to the TGFß receptor type II, and the absence of SPARC resulted in decreased SMAD phosphorylation ${ }^{6,7}$. We hypothesized that its local expression after MI acts as a modulator of scar maturation, partly through TGFß signaling, and thereby protects against cardiac rupture and dysfunction.

Here, we show that loss of SPARC results in abnormal collagen formation and increased cardiac rupture and dysfunction after MI. Increased matrix metalloproteinase (MMP) activity and reduced TGFß signaling in the absence of SPARC contributed to the formation of an immature scar, as indicated by increased MMP- 2 and MMP-9 activity in SPARC deficient mice and by shRNA-mediated SPARC knockdown in cardiac (myo)fibroblasts. In concordance, exogenous administration of TGFß in SPARC deficient mice rescued increased infarct rupture after MI.

In conclusion, increased expression of SPARC after MI is essential for proper infarct healing and collagen maturation, thereby protecting against cardiac rupture, dilatation and dysfunction. 


\section{Methods}

\section{Mouse model of myocardial infarction}

All described study protocols were approved by the Animal care and use committee of the Universiteit Maastricht. Experiments were performed according to the official rules formulated in the Dutch law on care and use of experimental animals. Ten to eighteen weeks old male and female SPARC KO and WT with a C57/BL6 x Sv129 background were used in this study. Experimental myocardial infarction and sham operation was performed as described previously ${ }^{8}$. Three days, one week and two weeks after surgery, cardiac function was assessed before euthanasia. Hearts were perfused with phosphate saline buffer, taken out and prepared for molecular, histological and ultrastructural analysis.

\section{Histology and Electron Microscopy}

Cardiac tissue was processed as described previously ${ }^{8}$. Sections were stained with hematoxylin/eosin for detection of infarct size and thickness. Next, collagen was stained on cardiac sections using Sirius red, and the amount of collagen was quantified ${ }^{8,9}$. Quality of collagen fibers was investigated by Sirius red polarization microscopy, allowing to quantify tightly packed collagen fibers as orange-red, and loosely assembled fibers as yellow-green ${ }^{10}$.

Ultrastructural analysis was performed as described previously ${ }^{9}$. Immunohistochemistry on paraffin sections was performed using antibodies against CD45 (leukocytes), SPARC (R\&D, Abingdon, UK) and alpha-smooth muscle cell actin (SMA, coronary vessels) (Dako, Leuven, Belgium) ${ }^{8,9}$. CD45-staining leukocytes, and SMA-staining vessels and myofibroblasts were quantified in the area of infarction as described previously ${ }^{8,9}$.

\section{Cardiac fibroblast culture \& Lentiviral constructs}

Cardiac fibroblasts were isolated from 2-day-old neonatal Lewis rats. All the experiments were performed on cells from the second passage. Cells were maintained in DMEM supplemented with $10 \% \mathrm{FBS}$ along with $0.1 \%$ gentamycin, and were incubated at $37^{\circ} \mathrm{C}$ in a humidified chamber. Small interfering RNA (siRNA) against SPARC was designed by Eurogentec, Liège, Belgium. From this design oligo's with one hairpin loop were created (shRNA, table 5). The oligo's were cloned into Xhol and Hpal site of the vector pLenti Lox 3.7 puro. This vector was modified from the pLenti Lox $3.7^{11}$ by replacing the eGFP gene by puromycin. Constructs were verified by sequencing. Lentiviral production was performed by co-transfection of $3 \mu \mathrm{g}$ shSPARC/pLL3.7 puro or empty pLL3.7 puro and packaging vectors into 293FT cells by Lipofectamine 2000 (Invitrogen) and virus-containing supernatant was harvested after 48 hours. SPARC knockdown in cardiac fibroblasts 
was established by treating cells with lentivirus containing shRNA against SPARC for 48 hours. After puromycin selection, cells were placed in low-serum medium (0.4\% FBS) for 24 hours. Thereafter, cells received TGFß $(1 \mathrm{ng} / \mathrm{ml})$ for 15 minutes, and were harvested for Western blotting.

Table 1. Functional analysis of SPARC WT and KO mice after MI

\begin{tabular}{|c|c|c|c|c|c|c|}
\hline & \multicolumn{2}{|c|}{ Sham } & \multicolumn{2}{|c|}{7 days } & \multicolumn{2}{|c|}{14 days } \\
\hline & WT & KO & WT & KO & WT & KO \\
\hline & $n=11$ & $n=11$ & $n=8$ & $n=7$ & $n=10$ & $n=11$ \\
\hline $\mathrm{FS}, \%$ & $26 \pm 1.3$ & $30 \pm 1.9$ & $18 \pm 3.1 \dagger$ & $15 \pm 7 \dagger$ & $12 \pm 1.4 \dagger$ & $12 \pm 1.2 \dagger$ \\
\hline LVIDd, mm & $3.7 \pm 0.1$ & $3.6 \pm 0.1$ & $4.7 \pm 0.2 \dagger$ & $4.9 \pm 0.5 \dagger$ & $5.0 \pm 0.3 \dagger$ & $5.3 \pm 0.2 \dagger$ \\
\hline LVIDs, mm & $2.8 \pm 0.1$ & $2.6 \pm 0.1$ & $3.9 \pm 0.3 \dagger$ & $4.3 \pm 0.6 \dagger$ & $4.4 \pm 0.3 \dagger$ & $4.7 \pm 0.3 \dagger$ \\
\hline IVSd, mm & $0.9 \pm 0.1$ & $1.0 \pm 0.1$ & $1.0 \pm 0.2$ & $0.9 \pm 0.1$ & $0.8 \pm 0.1$ & $0.8 \pm 0.1$ \\
\hline IVSs, mm & $1.2 \pm 0.1$ & $1.4 \pm 0.1$ & $1.4 \pm 0.1$ & $1.2 \pm 0.2$ & $1.0 \pm 0.2$ & $0.9 \pm 0.1$ \\
\hline HR, bpm & $698 \pm 18$ & $659 \pm 6$ & $699 \pm 9$ & $717 \pm 16$ & $698 \pm 19$ & $644 \pm 21$ \\
\hline LVW/BW & $4.4 \pm 0.2$ & $4.2 \pm 0.2$ & $5.6 \pm 0.2 \dagger$ & $6.7 \pm 1.2 \dagger$ & $5.0 \pm 0.2 \dagger$ & $5.8 \pm 0.2^{*} \dagger$ \\
\hline LW/BW & $6.6 \pm 0.4$ & $6.0 \pm 0.2$ & $9.7 \pm 1.3 \dagger$ & $10.4 \pm 1.2 \dagger$ & $10.1 \pm 1.3 \dagger$ & $9.8 \pm 1.2 \dagger$ \\
\hline
\end{tabular}

FS, fractional shortening; LVIDd, left ventricular diameter diastole; LVIDs, left ventricular diameter systole; IVSd, intraventricular septum diastole; IVSs, intraventricular septum systole; HR, heart rate; LVW, left ventricular weight; BW, body weight and LW, lung weight.

$+P<0.05$ in infarcted vs. sham

${ }^{*} P<0.05$ in SPARC KO vs WT infarcts

\section{Western Blotting and MMP Zymography}

Western blotting was performed as described previously. Cell lysates were applied to SDS-PAGE and immunoblotted for the detection of phosphorylated and total SMAD2, as described by others ${ }^{12}$. Zymographic activity of matrix metalloproteinase (MMP)-2 and -9 in infarcted and sham hearts were performed as described previously ${ }^{8,13}$. 


\section{RNA isolation and expression}

RNA was isolated from infarcted and sham tissue using the RNeasy Mini Kit (Qiagen) and stored in $-80^{\circ} \mathrm{C}$. RNA was reverse transcribed into CDNA using the iScript $^{\text {TM }}$ CDNA synthesis kit (BioRad). Real-time quantitative PCR was performed using iQ $^{\mathrm{TM}}$ SYBR green supermix (BioRad) and primers designed with Primer Express Software (PE Applied Biosystems, Foster City, CA). Cyclophilin was used as a housekeeping gene. Primers used are shown in table 5.
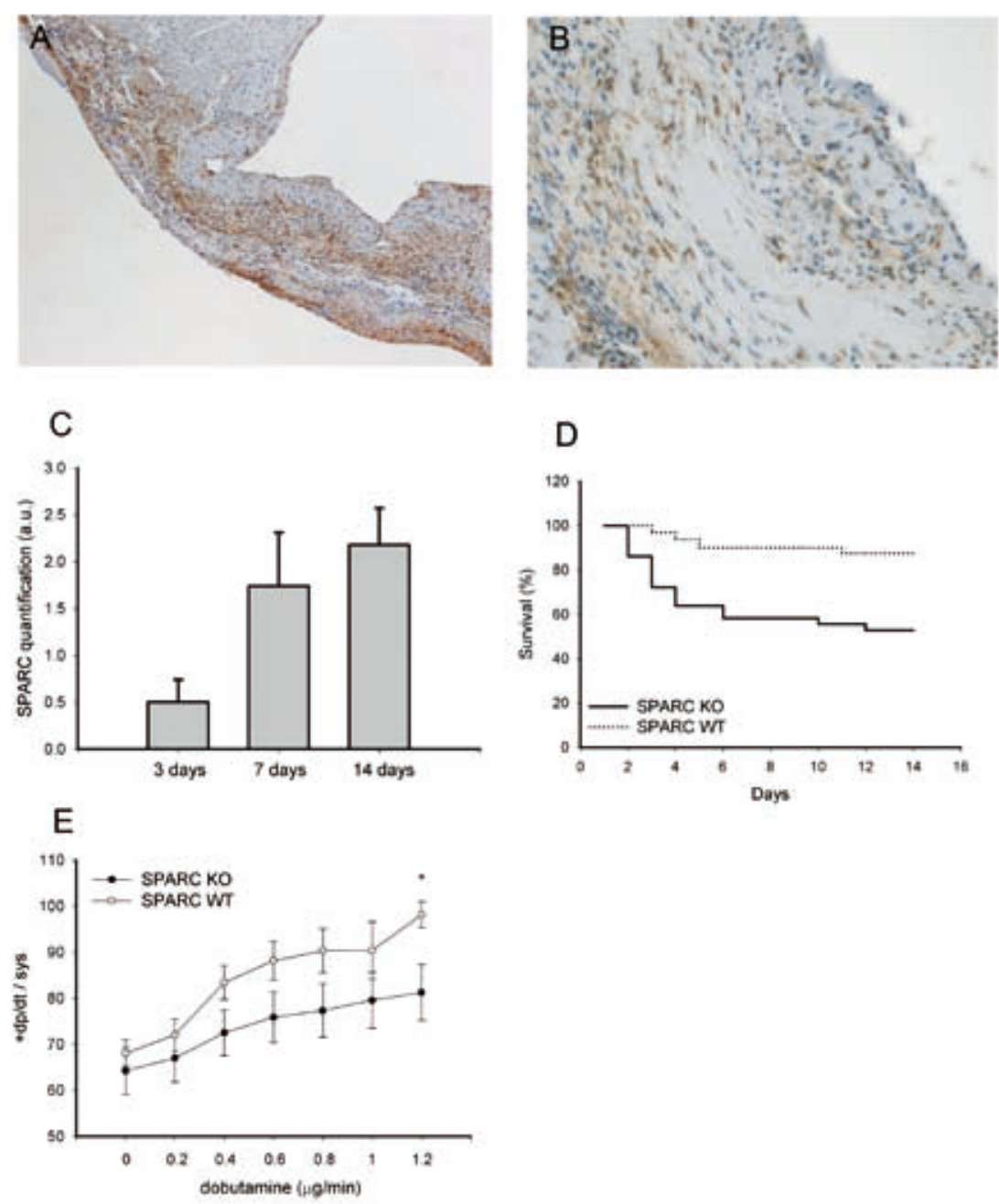

D

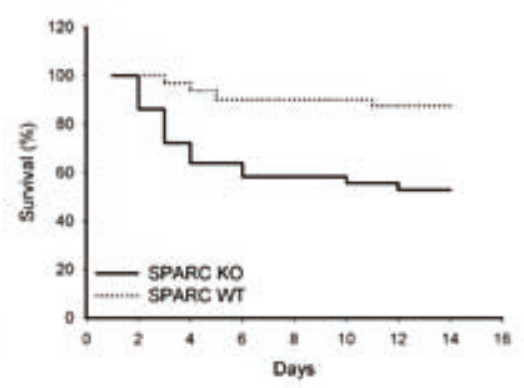

Figure 1. SPARC expression after MI. Immunostaining of SPARC increased from 3 days after MI, while peaking at 14 days. A: Typical example of SPARC expression 14 days after MI. B: SPARC is produced by (myo)fibroblasts surrounding the necrotic cardiomyocytes. C: Quantification of SPARC staining. D: Survival curve of SPARC KO and WT mice after myocardial infarction. E: SPARC KO mice display cardiac dysfunction after hemodynamic stress. ${ }^{*} P<0.05$ 


\section{Echocardiography \& Functional assessments}

Standard views were obtained in 2-D as well as $M$-mode by transthoracic echocardiography with a $12-\mathrm{MHz}$ transducer (Hewlett Packard, Amsterdam, The Netherlands) on a Sonos 5500 (Hewlett Packard) echocardiograph. Cardiac contractility was measured using a $2 \mathrm{~F}$ Millar microtip catheter (Millar instruments) as described before ${ }^{14}$.

\section{TGFß infusion}

To investigate whether exogenous administration of TGFß may rescue increased cardiac rupture after MI, SPARC KO mice were treated with TGFß (250 ng/day) versus saline using osmotic minipumps for 7 days, starting 1 day before the induction of MI.

\section{Statistical analysis}

Data were expressed as mean \pm SEM. No repeated measures were performed. Echocardiographic measurements and histological and molecular analysis in sham-operated and infarcted groups at 3, 7 and 14 days were all performed in independent groups. Normal distribution of all continuous variables was tested using the method of Kolmogorov and Smirnov. An unpaired t-test was used in most of the comparisons when groups passed the normality test. However, a MannWhitney test was used when the standard deviations of two groups significantly differed. A two sided P value $<0.05$ was considered statistically significant. 
Table 2. Histological analysis and determination of collagen in infarcted area.

\begin{tabular}{|c|c|c|c|c|c|c|}
\hline & $\begin{array}{l}\text { SPARC WT, } \\
\text { MI, } 3 \text { days } \\
n=11\end{array}$ & $\begin{array}{c}\text { SPARC KO, } \\
\text { MI, } 3 \text { days, } \\
n=11\end{array}$ & $\begin{array}{l}\text { SPARC WT, } \\
\text { MI, } 7 \text { days } \\
n=8\end{array}$ & $\begin{array}{c}\text { SPARC KO, } \\
\text { MI, } 7 \text { days } \\
n=7\end{array}$ & $\begin{array}{c}\text { SPARC WT, } \\
\text { MI, } 14 \text { days } \\
n=10\end{array}$ & $\begin{array}{c}\text { SPARC KO } \\
\text { MI, } 14 \text { days } \\
n=11\end{array}$ \\
\hline Infarct size, \% & $49 \pm 2.3$ & $44 \pm 3.3$ & $43 \pm 3.6$ & $46 \pm 4.1$ & $42 \pm 2.6$ & $43 \pm 2.7$ \\
\hline $\begin{array}{l}\text { Residual necrotic } \\
\text { area, \% }\end{array}$ & N.D. & N.D. & $9.6 \pm 1.8$ & $9.6 \pm 2.2$ & $2.7 \pm 0.7$ & $1.0 \pm 0.3^{*}$ \\
\hline $\begin{array}{l}\text { Infarct thickness, } \\
\mu \mathrm{m}\end{array}$ & $384 \pm 25$ & $390 \pm 38$ & $377 \pm 61$ & $291 \pm 22$ & $390 \pm 27$ & $379 \pm 27$ \\
\hline $\begin{array}{l}\text { Leukocyte } \\
\text { infiltration, cells/ } \\
\mathrm{mm}^{2}\end{array}$ & $964 \pm 186$ & $1097 \pm 101$ & $874 \pm 182$ & $821 \pm 143$ & $659 \pm 131$ & $272 \pm 68^{*}$ \\
\hline $\begin{array}{l}\text { Coronary growth, } \\
\text { vessels } / \mathrm{mm}^{2}\end{array}$ & N.D. & N.D. & $42.1 \pm 3.7$ & $44.9 \pm 4.8$ & $53.6 \pm 9.7$ & $42.8 \pm 4.8$ \\
\hline $\begin{array}{l}\text { Myofibroblast, \% } \\
\text { area }\end{array}$ & N.D. & N.D. & $2.1 \pm 0.37$ & $3.8 \pm 0.84^{*}$ & $0.76 \pm 0.37$ & $1.61 \pm 0.16^{*}$ \\
\hline $\begin{array}{l}\text { Collagen } \\
\text { depostion, \% }\end{array}$ & N.D. & N.D. & $26 \pm 2.5$ & $20 \pm 3.6$ & $36 \pm 2.4$ & $37 \pm 2.0$ \\
\hline $\begin{array}{l}\text { Ratio O-R thick/Y-G } \\
\text { thin collagen fibers }\end{array}$ & N.D. & N.D. & $11 \pm 2.3$ & $2.5 \pm 0.5^{*}$ & $17.2 \pm 1.8$ & $8.1 \pm 1.8^{*}$ \\
\hline
\end{tabular}

ND indicates not detected; $O-R$, orange-red; $Y-G$, yellow-green. ${ }^{*}<0.05$ in SPARC KO vs WT infarcts of corresponding time after MI

\section{Results}

\section{Increased SPARC protects against cardiac rupture and dysfunction}

Immunostaining revealed increased expression of SPARC at 3 days after MI, progressively increasing 7 and 14 days after $\mathrm{MI}$ (figure 1C), concordant with previous findings 4,5 . SPARC immunostaining was mainly located in (myo)fibroblasts, surrounding the necrotic cardiomyocytes (Figure 1A,B). Absence of SPARC resulted in a significantly increased cardiac rupture after myocardial infarction: $41 \%$ (13/32) of SPARC KO mice (males: 8/12; females: 5/20) compared to $8.8 \%$ (3/34) of WT mice (males: 2/14; females: 1/20) died due to cardiac rupture (Figure 1D). Male SPARC KO mice that survived cardiac rupture displayed severe shortness of breath within 7 days and died prematurely. Left ventricular pressure (LVP) and heart rate were similar in sham operated and infarcted WT and SPARC KO mice in baseline conditions. Contractility ( $\mathrm{dP} / \mathrm{dt} \max$ corrected for systolic pressure) was reduced in infarcted compared with sham-operated mice at 14 days, but to a similar extent in both genotypes. Hemodynamic stress induced by dobutamine increased contractility in WT mice after MI, but significantly less in SPARC KO mice (Figure 1E). 


\section{Disorganized granulation tissue and impaired collagen quality in SPARC KO animals after MI}

Infarct size did not differ between SPARC WT and KO mice (Table 2). Histological analysis of infarcts revealed a disorganized granulation tissue with increased red blood cell infiltration in SPARC deficient infarcts (figure 2). Adverse infarct healing in SPARC KO mice was not related to significant differences in inflammation or vascular density compared to WT mice, but to formation of an immature matrix in the absence of SPARC. Sirius red-polarization microscopy of collagen fibers revealed a predomination of loosely assembled -yellow green- collagen fibers in SPARC KO infarcts at 14 days (ratio of orange-red/yellow-green birefringent collagen), in contrast to the well-aligned and thick tightly packed -orange redfibers in WT infarcts. Ultrastructural analysis confirmed a disorganized and fragmented collagen matrix in SPARC KO infarcts, in contrast to the well-organized collagen matrix in WT infarcts (Figure 3). Absence of SPARC did not affect collagen synthesis, as indicated by similar transcript levels of collagen type I and III and amount of collagen SPARC KO compared with WT infarcts (Table 3, Figure 3). Thus, increased cardiac rupture and dysfunction in SPARC KO mice is caused by deficient maturation of the collagen matrix after MI.

Table 3. Transcript levels of extracellular matrix genes after MI.

\begin{tabular}{lll}
\hline & $\begin{array}{c}\text { SPARC WT, } \\
\mathrm{n}=4-6\end{array}$ & $\begin{array}{c}\text { SPARC KO, } \\
\mathrm{n}=4-6\end{array}$ \\
& & \\
\hline Sham & & \\
Collagen I & $0.12 \pm 0.01$ & $0.10 \pm 0.01$ \\
Collagen III & $0.05 \pm 0.007$ & $0.07 \pm 0.007$ \\
Fibronectin & $0.05 \pm 0.01$ & $0.08 \pm 0.01$ \\
& & \\
MI, 7 days & $1.18 \pm 0.23 \dagger$ & $1.14 \pm 0.08 \dagger$ \\
Collagen I & $0.91 \pm 0.16 \dagger$ & $0.97 \pm 0.08 \dagger$ \\
Collagen III & $0.81 \pm 0.14 \dagger$ & $0.87 \pm 0.13 \dagger$ \\
Fibronectin & & \\
\hline MI, 14 days & & $1.81 \pm 0.32 \dagger$ \\
Collagen I & $2.03 \pm 0.36 \dagger$ & $1.79 \pm 0.23 \dagger$ \\
Collagen III & $1.50 \pm 0.26 \dagger$ & $1.49 \pm 0.14 \dagger$ \\
Fibronectin & $1.58 \pm 0.32 \dagger$ & \\
\hline & & \\
\hline
\end{tabular}




\section{SPARC modulates MMP-activity.}

Since SPARC mediates wound healing and matrix maturation by interaction with growth factors and matrix proteins ${ }^{1,2}$, activity of MMP-2 and -9 was investigated. MMP zymography revealed significantly increased activity of MMP-2- and MMP-9, both involved in cardiac rupture ${ }^{8,15}$, in SPARC KO compared with WT infarcts at 3 days (Figure 4C and 4D).

Table 4. Histological analysis and determination of collagen in infarcted area.

\begin{tabular}{|c|c|c|c|}
\hline & $\begin{array}{c}\text { SPARC WT, } 7 \\
\text { days, } \mathrm{n}=8\end{array}$ & $\begin{array}{c}\text { SPARC KO, } 7 \\
\text { days, } n=9\end{array}$ & $\begin{array}{c}\text { SPARC KO + TGF } ß, \\
7 \text { days, } n=6\end{array}$ \\
\hline Infarct size, \% & $42.7 \pm 3.6$ & $45.9 \pm 4.1$ & $36 \pm 4$ \\
\hline Residual necrotic area, \% & $9.6 \pm 1.8$ & $9.6 \pm 2.2$ & $3.9 \pm 1.7$ \\
\hline Infarct thickness, $\mu \mathrm{m}$ & $376.7 \pm 61$ & $321.5 \pm 26$ & $558.3 \pm 71.7^{*}$ \\
\hline Collagen depostion, $\%$ & $25.93 \pm 2.5$ & $20.04 \pm 3.6$ & $30.3 \pm 2.0^{*}$ \\
\hline $\begin{array}{l}\text { Ratio O-R thick/Y-G thin } \\
\text { collagen fibers }\end{array}$ & $11 \pm 2.3$ & $2.5 \pm 0.5 \dagger$ & $4.5 \pm 1.2^{*}$ \\
\hline LVW/BW & $5.6 \pm 0.2$ & $6.6 \pm 1.0$ & $6.3 \pm 0.6$ \\
\hline LW/BW & $9.7 \pm 1.3$ & $10.9 \pm 1.4$ & $9.8 \pm 0.6$ \\
\hline
\end{tabular}

O-R indicates orange-red; Y-G, yellow green; LVW, left ventricular weight; BW, body weight and LW, lung weight.

${ }^{*} P<0.05$ in TGF $\beta$ treated vs. control

$+P<0.05$ in SPARC KO vs WT infarcts

\section{SPARC modulates TGF $\beta$ signaling in cardiac fibroblasts}

To evaluate the role of SPARC in activating TGFß signaling, we examined SMAD2 phosphorylation in fibroblasts in vitro, with downregulation of SPARC by adding short hairpin (sh)-RNA against SPARC. This resulted in a significant $80 \%$ decrease in protein expression of SPARC compared with control. TGFß treatment (1ng/ml) resulted in a significant increase of phosphorylated SMAD2/SMAD2 ratio in wild type fibroblasts, but significantly less after SPARC downregulation (Figure 4A and $4 B$ ). These data indicate a crucial role for SPARC in regulating TGFß signaling in cardiac fibroblasts. 

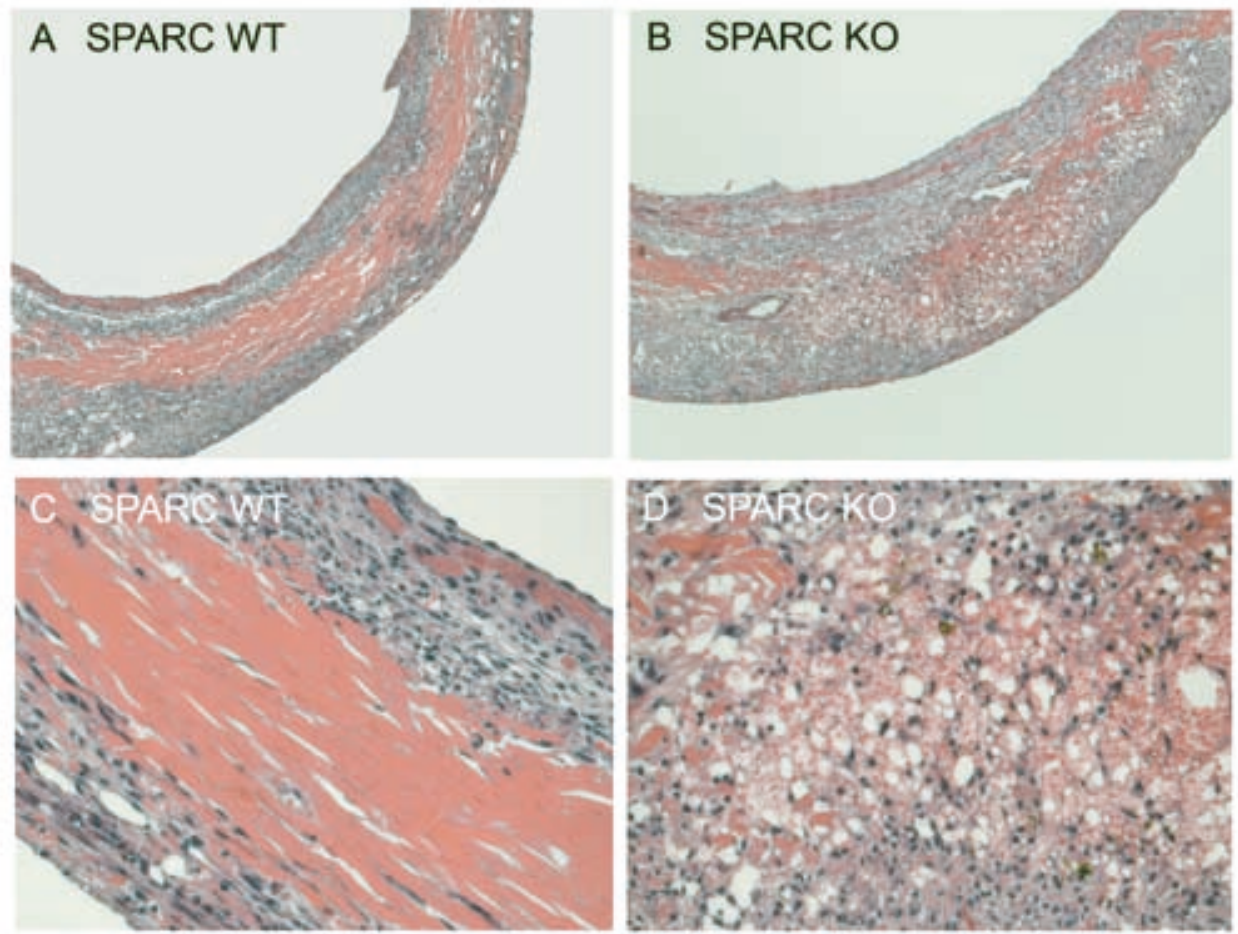

Figure 2. Adverse wound healing in SPARC KO mice. A, B: Hematoxylin and eosin staining revealed disorganized infarct healing in SPARC KO (B) vs. WT (A) infarcts. C, D: Increased red blood cell infiltration in SPARC KO infarcts (D) as compared to WT infarcts (C). 

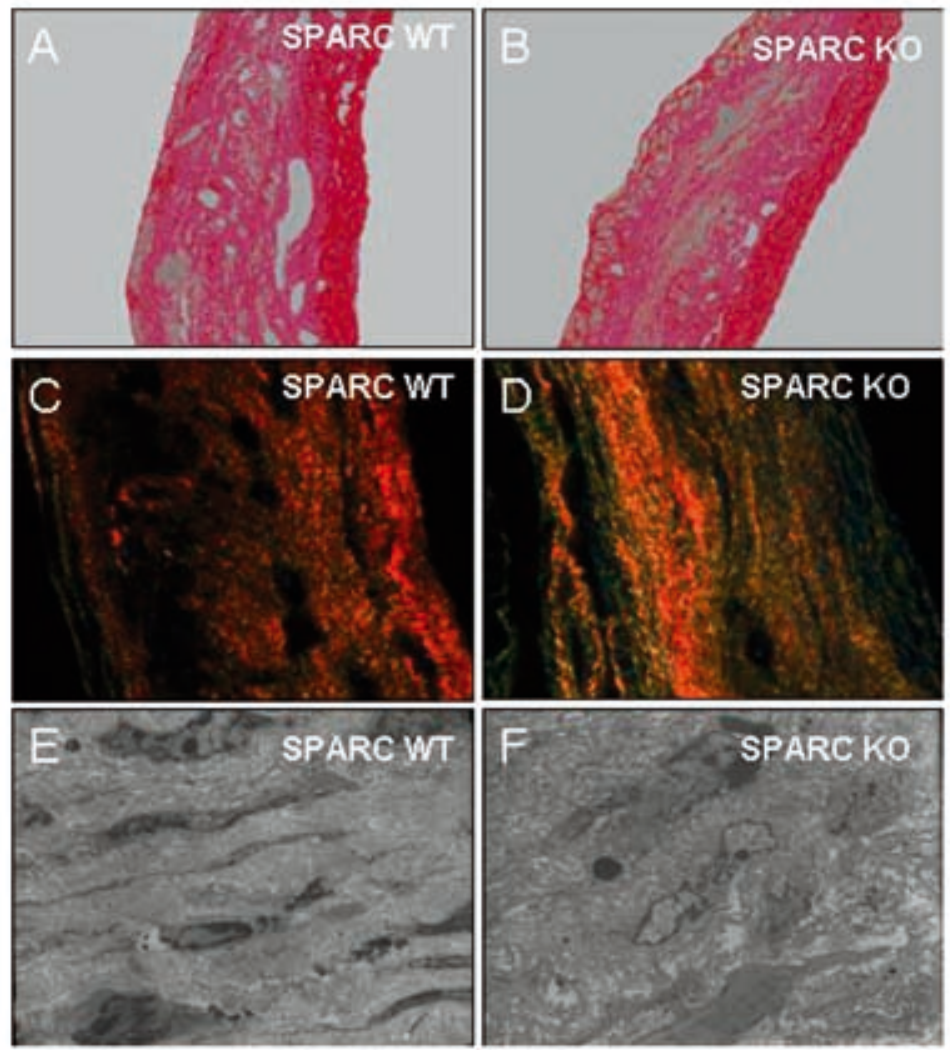

Figure 3. Abnormal collagen formation in SPARC KO infarcts. A, B: Sirius red analysis revealed no differences in collagen deposition between $W T(A)$ and $K O(B)$ infarcts at 14 days. C,D: Sirius red polarization microscopy revealed mainly wellaligned and tightly packed (orange-red) collagen fibers in WT infarcts (C), but loosely assembled fibers (yellow-green) predominating in SPARC KO infarcts (D). E, F: Ultrastructural analysis confirmed a disorganized matrix in SPARC KO (F) vs WT (E) infarcts.

\section{Infusion of TGF $\beta$ protects against cardiac rupture in SPARC KO mice}

TGFß is strongly implicated in infarct healing and remodeling after $M I$. To investigate whether aberrant TGFß signaling in absence of SPARC may be involved in adverse infarct healing and increased cardiac rupture after MI, SPARC KO mice were treated with TGFß. TGFß-treatment in SPARC KO significantly improved survival by decreasing cardiac rupture (cardiac rupture: 1 out of 7 in TGFß- compared with 8 out of 12 in saline-treated SPARC KO mice) (Figure 6). Histological analysis revealed increased deposition of collagen in TGFß- compared with saline-treated SPARC KO mice (Table 4, Figure 5). 


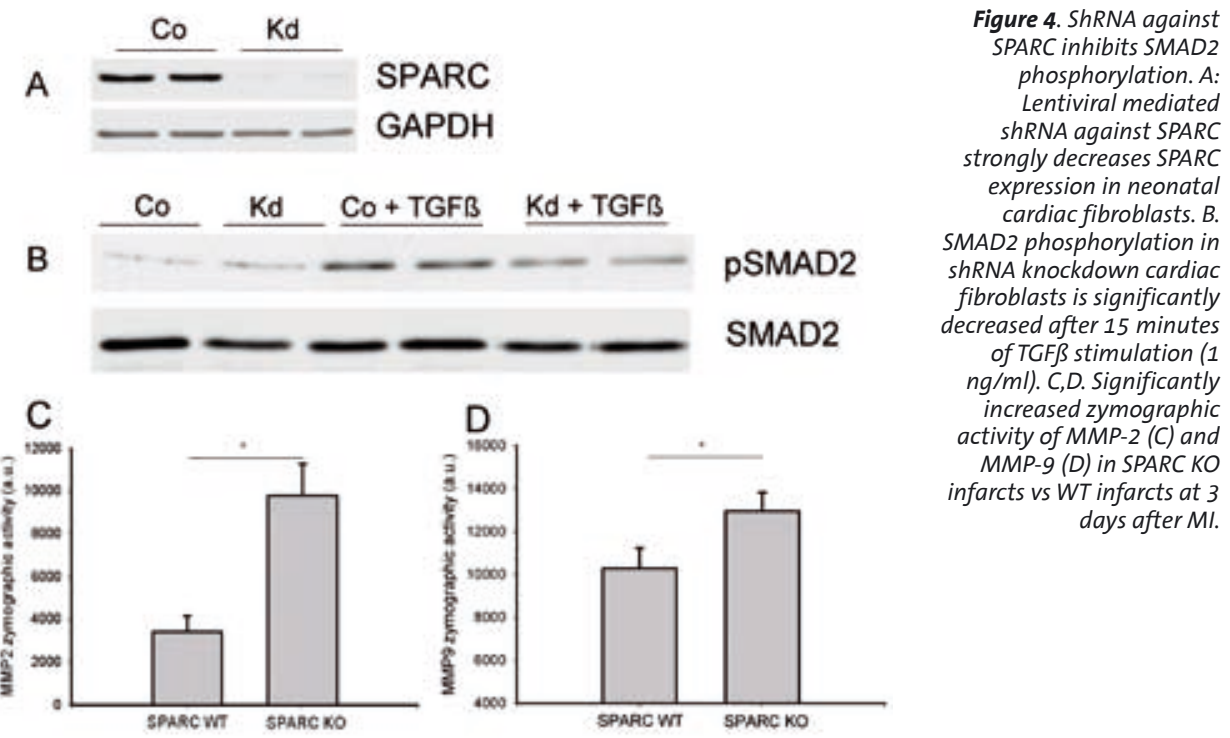

\section{Discussion}

The present study unveils a crucial role for SPARC in regulating infarct healing and collagen maturation after myocardial infarction. Absence of SPARC resulted in adverse infarct healing, deficient maturation of collagen and decreased TGFß signaling, leading to increased cardiac rupture and dysfunction. Treatment with TGFß prevented cardiac rupture in SPARC KO infarcted mice, underscoring an important role for SPARC -mediated TGFß signaling in infarct healing.

Table 5. Primers and shRNA sequence

\begin{tabular}{lll}
\hline Gene & Fw primer $\mathbf{5}^{\prime} \mathbf{-} \mathbf{3}^{\prime}$ & $\mathbf{R e v}$ primer $\mathbf{5}^{\mathbf{*}} \mathbf{-} \mathbf{3}^{\prime}$ \\
\hline Collagen I & CTTCACCTACAGCACCCTTGTG & CTTGGTGGTTTTGTATTCGATGAC \\
Collagen III & TCGGAACTGCAGAGACCTAAA & CCCCAGTTTCCATGTTACAGA \\
Fibronectin & ATGTGGACCCCTCCTGATAGT & GCCCAGTGATTTCAGCAAAGG \\
Cyclophilin & CAAATGCTGGACCAAACACAA & GCCATCCAGCCATTCAGTCT \\
\hline
\end{tabular}

\section{ShRNA SPARC}

sequence

Sense 5'- 3'

Antisense 5'- 3' ggtggaaatgggagagtttttcaagagaaaactctcccatttccacctttttc

tcgagaaaaaggtggaaatgggagagttttctcttgaaaaactctcccatttccacc 
Expression of SPARC progressively increases after MI in rats and dogs 4,5 and is mainly expressed by fibroblasts, suggesting a role for SPARC in maturation of the infarct scar. Here, gene inactivation of SPARC resulted in increased cardiac rupture and dysfunction, due to a disorganized and fragmented granulation, and abnormal collagen maturation. These findings are consistent with a role for SPARC in cutaneous wound healing ${ }^{16}$, cataract formation and -foreign body reaction. ${ }^{17}$
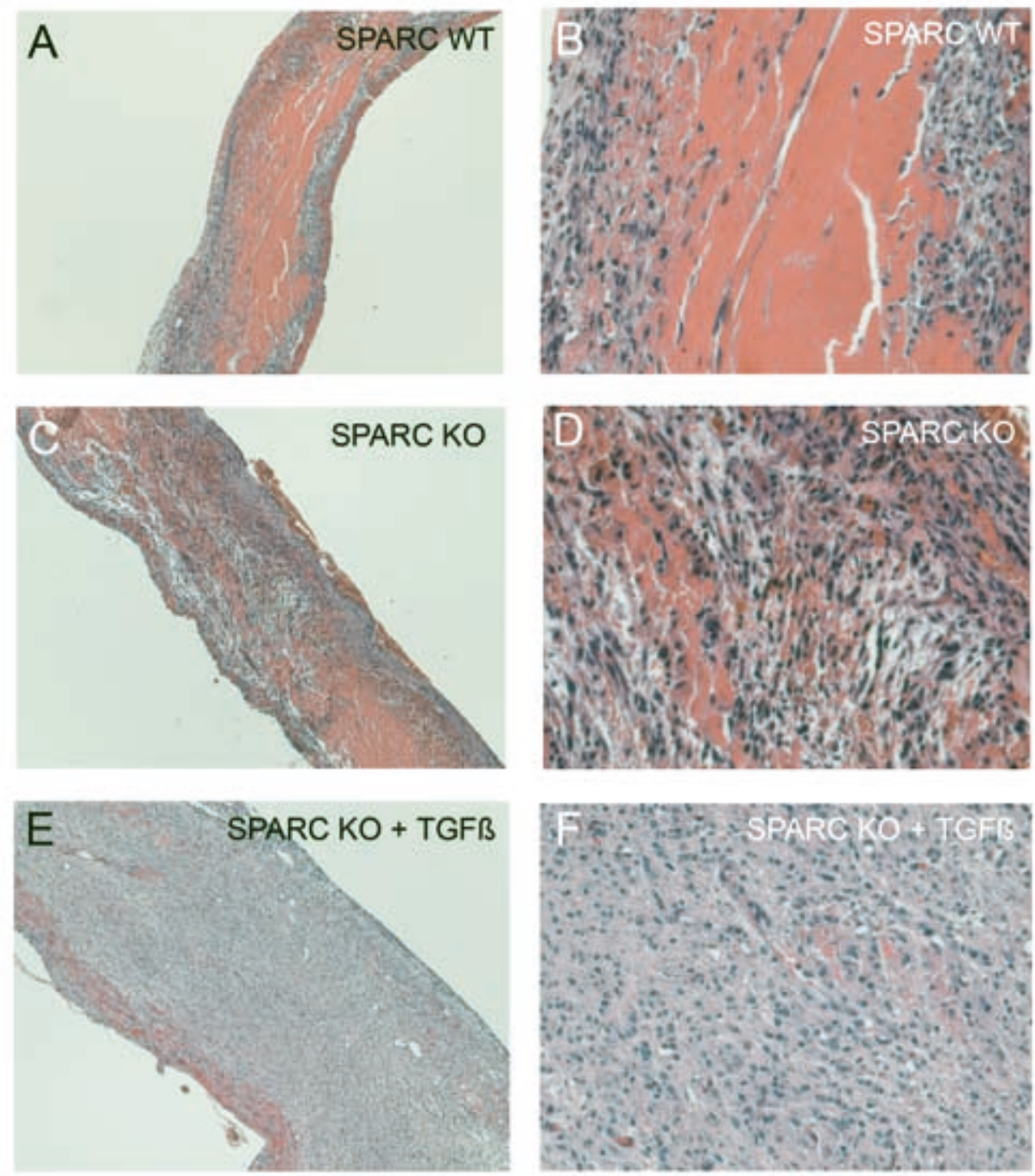

Figure 5. TGF $\beta$ infusion in SPARC KO mice protects against cardiac rupture after MI, due to increased ECM deposition. A-D: Hematoxylin and eosin staining reveals striking differences between SPARC WT and KO mice 7 days after MI. E, F: In SPARC KO mice TGF $\beta$ infusion accelerates infarct healing and stimulates ECM production to strengthen the infarct zone. 
In the present study, amount of collagen did not differ between SPARC KO and WT infarcts, but ultrastructural analysis revealed a disorganized and immature collagen matrix. SPARC may regulate infarct healing and collagen maturation by different ways. First, SPARC directly interacts with collagen type I fibers ${ }^{18}$ and thereby regulates their assembly. Variation in the structure of SPARC will directly alter its affinity to collagen type I. Lack of SPARC also results in formation of immature collagen fibers during wound healing in the $\operatorname{skin}^{16}$ and in response to a foreign body ${ }^{17}$.

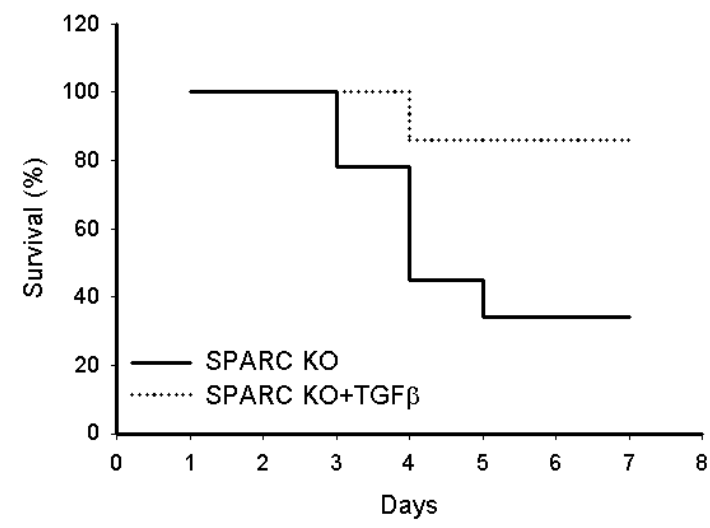

Figure 6. Survival curve showing that TGF $\beta$ infusion protected against cardiac rupture in SPARC KO mice.

Secondly, SPARC regulates TGFß signaling in cardiac fibroblasts, as revealed by our in vitro experiments showing reduced TGFß-Smad2 signaling by SPARC downregulation. These findings are concordant with previous observation in epithelial $^{19}$ and mesangial ${ }^{6}$ cells. The latter study showed that SPARC directly binds to the TGFß receptor type II, and that, consequently, SPARC null mesengial cells displayed less SMAD2 phosphorylation. Another study revealed that siRNAmediated down-regulation of SPARC attenuates SMAD3 phosphorylation and collagen production in skin fibroblasts. ${ }^{7}$ TGF $\beta$ is a cytokine involved in wound healing and collagen production, and has an important role in LV remodeling after $\mathrm{MI}^{20}$ : inhibition of TGFß in the first day after MI has detrimental effects on cardiac performance ${ }^{21}$. Our findings that treatment with TGFß prevented infarct rupture in SPARC KO mice provide strong in vivo evidence on a crucial role of SPARC-mediated TGFß signaling in infarct healing. Finally, absence of SPARC resulted in increased activity of MMP-2 and -9 , both facilitating fatal cardiac rupture ${ }^{8,22,23}$. SPARC is able to induce activation of both MMP-2 and MMP-9 (reviewed in ${ }^{24}$ ). In turn, MMP-2 proteolytically cleaves SPARC, which increases the affinity of SPARC for collagen and thereby promotes maturation of collagen by SPARC. Their increase did not result from a difference in inflammatory response in SPARC KO infarcts, but may evolve from increased presence of myofibroblasts that produce both $\mathrm{MMPs}^{25}$. 
SPARC KO animals showed increased accumulation of myofibroblasts. A paradoxal increase in myofibroblasts density despite decreased TGFß signaling was also reported in mice lacking thrombospondin-1, another matricellular protein modulating TGFß signaling ${ }^{26}$. Increased myofibroblast presence may have resulted from increased migration of myofibroblasts in the absence of SPARC ${ }^{27}$, resulting in an impaired scar maturation.

Lately, evidence on a central role of matricellular proteins in cardiac wound healing and remodeling is increasingly appreciated. These proteins, which are hardly expressed in the normal, intact heart, are highly upregulated in the injured heart. Recent publications revealed the importance of other matricellular proteins including thrombospondin- $-^{26}$, osteopontin ${ }^{28}$, tenascin- $\mathrm{C}^{29}$ and syndecan- $1^{30}$ in wound healing of the infarcted heart ${ }^{26,28}$. Thrombospondin-1 and syndecan-1 are expressed early after MI and serve as a "barrier" limiting influx of inflammatory cells, thereby regulating proper infarct healing and preventing infarct expansion and cardiac dilatation. In contrast, osteopontin, tenascin- $C$ and SPARC are mainly expressed during the formation of granulation tissue and fibrous scar, and are implicated in arrangement and maturation of collagen fibers.

Taken together, SPARC expression after MI is essential for the proper healing of the infarct, by mediating TGFß signaling and regulating collagen matrix maturation. These results emphasize a crucial role for matricellular proteins during infarct healing, indicating that these proteins are well-fit candidates for therapeutic interventions to prevent heart failure after myocardial infarction. 


\section{References}

1. Framson PE, Sage EH. SPARC and tumor growth: where the seed meets the soil? J Cell Biochem. 2004;92:679-690.

2. Bradshaw AD, Sage EH. SPARC, a matricellular protein that functions in cellular differentiation and tissue response to injury. J Clin Invest. 2001;107:1049-1054.

3. Lindsey ML, Mann DL, Entman ML, Spinale FG. Extracellular matrix remodeling following myocardial injury. Ann Med. 2003;35:316-326.

4. Dobaczewski M, Bujak M, Zymek P, Ren G, Entman ML, Frangogiannis NG. Extracellular matrix remodeling in canine and mouse myocardial infarcts. Cell Tissue Res. 2006;324:475-488.

5. Komatsubara I, Murakami T, Kusachi S, Nakamura K, Hirohata S, Hayashi J, Takemoto S, Suezawa C, Ninomiya Y, Shiratori Y. Spatially and temporally different expression of osteonectin and osteopontin in the infarct zone of experimentally induced myocardial infarction in rats. Cardiovasc Pathol. 2003;12:186-194.

6. Francki A, McClure TD, Brekken RA, Motamed K, Murri C, Wang T, Sage EH. SPARC regulates TGF-beta1-dependent signaling in primary glomerular mesangial cells. J Cell Biochem. 2004;91:915-925.

7. Zhou X, Tan FK, Guo X, Arnett FC. Attenuation of collagen production with small interfering RNA of SPARC in cultured fibroblasts from the skin of patients with scleroderma. Arthritis Rheum. 2006;54:2626-2631.

8. Heymans S, Luttun A, Nuyens D, Theilmeier G, Creemers E, Moons L, Dyspersin GD, Cleutjens JP, Shipley M, Angellilo A, Levi M, Nube O, Baker A, Keshet E, Lupu F, Herbert JM, Smits JF, Shapiro SD, Baes M, Borgers M, Collen D, Daemen MJ, Carmeliet P. Inhibition of plasminogen activators or matrix metalloproteinases prevents cardiac rupture but impairs therapeutic angiogenesis and causes cardiac failure. Nat Med. 1999;5:1135-1142.

9. Heymans S, Lupu F, Terclavers S, Vanwetswinkel B, Herbert JM, Baker A, Collen D, Carmeliet P, Moons L. Loss or inhibition of UPA or MMP-9 attenuates $\mathrm{LV}$ remodeling and dysfunction after acute pressure overload in mice. Am J Pathol. 2005;166:15-25.

10. Whittaker P, Kloner RA, Boughner DR, Pickering JG. Quantitative assessment of myocardial collagen with picrosirius red staining and circularly polarized light. Basic Res Cardiol. 1994;89:397-410.

11. Rubinson DA, Dillon CP, Kwiatkowski AV, Sievers C, Yang L, Kopinja J, Rooney DL, Ihrig MM, McManus MT, Gertler FB, Scott ML, Van Parijs L. A lentivirusbased system to functionally silence genes in primary mammalian cells, stem cells and transgenic mice by RNA interference. Nat Genet. 2003;33:401-406. 
12. Negre-Aminou P, van Leeuwen RE, van Thiel GC, van den IP, de Jong WW, Quinlan RA, Cohen LH. Differential effect of simvastatin on activation of $\operatorname{Rac}(1)$ vs. activation of the heat shock protein 27-mediated pathway upon oxidative stress, in human smooth muscle cells. Biochem Pharmacol. 2002;64:1483-1491.

13. Schroen B, Heymans S, Sharma U, Blankesteijn WM, Pokharel S, Cleutjens JP, Porter JG, Evelo CT, Duisters R, van Leeuwen RE, Janssen BJ, Debets JJ, Smits JF, Daemen MJ, Crijns HJ, Bornstein P, Pinto YM. Thrombospondin-2 is essential for myocardial matrix integrity: increased expression identifies failure-prone cardiac hypertrophy. Circ Res. 2004;95:515-522.

14. Schellings MW, Baumann M, van Leeuwen RE, Duisters RF, Janssen SH, Schroen B, Peutz-Kootstra CJ, Heymans S, Pinto YM. Imatinib attenuates end-organ damage in hypertensive homozygous TGR(mRen2)27 rats. Hypertension. 2006;47:467-474.

15. Matsusaka H, Ikeuchi M, Matsushima S, Ide T, Kubota T, Feldman AM, Takeshita A, Sunagawa K, Tsutsui $H$. Selective disruption of MMP-2 gene exacerbates myocardial inflammation and dysfunction in mice with cytokine-induced cardiomyopathy. Am J Physiol Heart Circ Physiol. 2005;289:H1858-1864.

16. Bradshaw AD, Reed MJ, Sage EH. SPARC-null mice exhibit accelerated cutaneous wound closure. J Histochem Cytochem. 2002;50:1-10.

17. Puolakkainen P, Bradshaw AD, Kyriakides TR, Reed M, Brekken R, Wight T, Bornstein P, Ratner B, Sage EH. Compromised production of extracellular matrix in mice lacking secreted protein, acidic and rich in cysteine (SPARC) leads to a reduced foreign body reaction to implanted biomaterials. Am J Pathol. 2003;162:627-635.

18. Kaufmann B, Muller S, Hanisch FG, Hartmann U, Paulsson M, Maurer P, Zaucke F. Structural variability of BM-40/SPARC/osteonectin glycosylation: implications for collagen affinity. Glycobiology. 2004;14:609-619.

19. Schiemann BJ, Neil JR, Schiemann WP. SPARC inhibits epithelial cell proliferation in part through stimulation of the transforming growth factor-beta-signaling system. Mol Biol Cell. 2003;14:3977-3988.

20. Bujak M, Frangogiannis NG. The role of TGF-beta signaling in myocardial infarction and cardiac remodeling. Cardiovasc Res. 2006.

21. Ikeuchi M, Tsutsui H, Shiomi T, Matsusaka H, Matsushima S, Wen J, Kubota T, Takeshita A. Inhibition of TGF-beta signaling exacerbates early cardiac dysfunction but prevents late remodeling after infarction. Cardiovasc Res. 2004;64:526-535.

22. Matsumura S, Iwanaga S, Mochizuki S, Okamoto H, Ogawa S, Okada Y. Targeted deletion or pharmacological inhibition of MMP-2 prevents cardiac rupture after myocardial infarction in mice.J Clin Invest. 2005;115:599-609. 
23. Ducharme A, Frantz S, Aikawa M, Rabkin E, Lindsey $M$, Rohde LE, Schoen FJ, Kelly RA, Werb Z, Libby P, Lee RT. Targeted deletion of matrix metalloproteinase- 9 attenuates left ventricular enlargement and collagen accumulation after experimental myocardial infarction. J Clin Invest. 2000;106:55-62.

24. Brekken RA, Sage EH. SPARC, a matricellular protein: at the crossroads of cell-matrix communication. Matrix Biol. 2001;19:816-827.

25. SiwikDA,ChangDL,ColucciWS. Interleukin-1betaandtumornecrosisfactoralpha decrease collagen synthesis and increase matrix metalloproteinase activity in cardiac fibroblasts in vitro. Circ Res. 2000;86:1259-1265.

26. Frangogiannis NG, Ren G, Dewald O, Zymek P, Haudek S, Koerting A, Winkelmann K, Michael LH, Lawler J, Entman ML. Critical role of endogenous thrombospondin-1 in preventing expansion of healing myocardial infarcts. Circulation. 2005;111:2935-2942.

27. Wu RX, Laser M, Han H, Varadarajulu J, Schuh K, Hallhuber M, Hu K, Ertl $\mathrm{G}$, Hauck CR, Ritter O. Fibroblast migration after myocardial infarction is regulated by transient SPARC expression. J Mol Med. 2006;84:241-252.

28. Trueblood NA, Xie Z, Communal C, Sam F, Ngoy S, Liaw L, Jenkins AW, Wang J, Sawyer DB, Bing OH, Apstein CS, Colucci WS, Singh K. Exaggerated left ventricular dilation and reduced collagen deposition after myocardial infarction in mice lacking osteopontin. Circ Res. 2001;88:1080-1087.

29. Tamaoki M, Imanaka-Yoshida K, Yokoyama K, Nishioka T, Inada H, Hiroe M, Sakakura T, Yoshida T. Tenascin-C regulates recruitment of myofibroblasts during tissue repair after myocardial injury. Am J Pathol. 2005;167:71-80.

30. Vanhoutte D, Schellings MW, Gotte M, Swinnen M, Herias V, Wild MK, Vestweber D, Chorianopoulos E, Cortes V, Rigotti A, Stepp MA, Van de Werf F, Carmeliet P, Pinto YM, Heymans S. Increased expression of syndecan1 protects against cardiac dilatation and dysfunction after myocardial infarction. Circulation. 2007;115:475-482. 



\section{Chapter 4}

Increased expression of Syndecan-1 protects against cardiac dilatation and dysfunction after acute myocardial infarction

Mark WM Schellings*, Davy Vanhoutte*, Martin Götte, Melissa Swinnen, Veronica Herias, Martin K Wild, Dietmar Vestweber, Emmanuel Chorianopoulos, Victor Cortés, Attilio Rigotti, Mary-Ann Stepp, Frans van de Werf, Peter Carmeliet, Yigal M Pinto, Stephane Heymans

\section{Circulation}

2007 Jan 30;115(4):475-82 


\section{Abstract}

Background. The cell-associated proteoglycan Syndecan-1 (Synd1) closely regulates inflammation and cell-matrix interactions during wound healing and tumorigenesis. The current study investigated whether Synd1 may also regulate cardiac inflammation, matrix remodeling, and function after myocardial infarction (MI).

Methods and Results. First, we showed increased protein and mRNA expression of Synd 1 from 24 hours on, reaching its maximum at 7 days after $\mathrm{MI}$ and declining thereafter. Targeted deletion of Synd1 resulted in increased inflammation and accelerated, yet functionally adverse, infarct healing after MI. In concordance, adenoviral gene expression of Synd 1 protected against exaggerated inflammation after $\mathrm{MI}$, mainly by reducing transendothelial adhesion and migration of leukocytes, as shown in vitro. Increased inflammation in the absence of Synd1 resulted in increased monocyte chemoattractant protein-1 expression, increased activity of matrix metalloproteinase- 2 and -9 , and decreased activity of tissue transglutaminase, associated with increased collagen fragmentation and disorganisation. Exaggerated inflammation and adverse matrix remodeling in the absence of Synd 1 increased cardiac dilatation and impaired systolic function, whereas gene overexpression of Synd1 reduced inflammation and protected against cardiac dilatation and failure.

Conclusions. Increased expression of Synd 1 in the infarct protects against exaggerated inflammation and adverse infarct healing, thereby reducing cardiac dilatation and dysfunction after MI in mice. 


\section{Introduction}

Syndecan-1 (Synd1) is a member of a conserved family of 4 heparan and chondroitin sulfate-carrying transmembrane proteins (Synd1, 2, 3, and 4). Synd1 is emerging as a central regulator of inflammation and matrix remodeling during wound healing ${ }^{1,2}$, infection ${ }^{3}$, and tumour formation ${ }^{4}$ (reviewed elsewhere ${ }^{5-7}$ ). Well-orchestrated interactions between inflammation, extracellular matrix components, and cytokines are essential for normal cardiac healing and functional recovery after myocardial infarction (MI). However, clear evidence on a specific role for Synd1 after MI is lacking.

Expression of Synd1 is low in normal cardiac tissue, but its expression reappears at high levels after $\mathrm{Ml}$ in rats $\mathrm{s}^{8,9}$ and mice ${ }^{10}$. Considering an essential role of Synd 1 for proper wound healing ${ }^{5-7}$, we hypothesized that increased expression of Synd 1 after MI may regulate inflammation and normal infarct healing after MI. We postulated that absence of Synd1 would increase inflammation, which in turn results in increased activity of matrix metalloproteinases (MMPs). Increased MMP activity favors degradation of collagen ${ }^{11}$ and decreases cross-linking of collagens by inactivation of tissue-transglutaminase (tTG), ${ }^{12}$ both resulting in increased cardiac dilatation ${ }^{13-16}$. To address these issues, we investigated infarct healing and cardiac function in Synd1-gene-inactivated mice and after adenoviral Synd1-gene overexpression.

Our data reveal that loss of Synd 1 resulted in exaggerated inflammation, collagen disorganization, and increased cardiac dilatation and failure after MI. In line with these findings, overexpression of Synd1 protected against adverse infarct remodeling and cardiac failure after $\mathrm{Ml}$, indicating a potential therapeutic benefit of increased Synd1.

\section{Methodology}

\section{Transgenic mice and model of $M I$}

The present study was approved by our Institutional Animal Research Committee, and all experiments were performed according to the official rules formulated in the Dutch and German laws on care and use of experimental animals. We used 10- to 14-week-old male and female inbred BALB/c Synd1 knockout (KO) (backcrossed for 11 generations) and their wild type (WT) littermates weighing 20-30 g. Synd1 mice were a gift from M.A. Stepp, PhD, Washington, DC. MI was induced by permanent ligation of the left coronary artery ${ }^{17}$. Sham-operation included all procedures except permanent ligation. Hearts were taken out at indicated time points and prepared for molecular, histological, and ultrastructural analysis ${ }^{17,18}$. 
Perioperative mortality rates (24 hours) were $23 \%$ and $25 \%$ in WT and Synd 1 KO mice, respectively $(P=N S)$.

\section{Histology and electron microscopy of infarcts}

After the study period, infarcted or sham-operated mice were anesthetized, and hearts were removed and prepared for further histological and molecular analyses. Lungs and the left and right ventricles were dissected, blotted dry, and weighted ${ }^{18}$. Immunostaining on paraffin sections was performed using antibodies against CD31 (capillaries), CD45 (leukocytes), $\alpha$-smooth muscle cell actin (coronaryvessels) (Dako, Leuven, Belgium), $\epsilon$-lysyl Y-glutaminyl cross-links (Abcam, Cambridge, Mass) and Synd1 (CD138; Pharmingen, Erembodegem, Belgium) as previously described ${ }^{17,18}$. CD31-staining capillaries, CD45-staining leukocytes, and smooth muscle actinstaining vessels and myofibroblasts were counted and quantified in the different areas through the infarcted left ventricle as described ${ }^{17,18}$. Morphometric analysis was performed with a Leitz DMRXE microscope (Leica Imaging Systems Ltd, Solms, Germany), a 3CCD color video camera (DXC-93OP, Sony, New York, NY), and a Leica Owin software system by persons unaware of the genotype.

\section{Syndecan expression}

First, in situ hybridization of Synd 1 mRNA was performed on cardiac sections at 1, 4, 7, and 14 days after MI (online Data Supplement, Section I). Synd1 mRNAstaining cells were counted per square millimeter. Next, Synd1 dot-blot analysis was performed in cardiac extracts with determination of total and shed protein of Synd $1^{2}$. Finally, to investigate whether absence of Synd 1 may result in a compensatory increase of other syndecans, mRNA levels of Synd1, 2, 3, and 4 were determined by real-time polymerase chain reaction using iO SYBR green supermix (BioRad Laboratories, Hercules, Calif) in infarcts and sham heart at 7 days after MI (Online Data Supplement, Section II).

\section{In vitro leukocyte adhesion and transmigration assays}

To obtain polymorphonuclear cells (PMNs), bone marrow was flushed out of the hindlimbs of Synd $1 \mathrm{KO}$ and WT mice with PBS/1\% fetal calf serum, and PMNs were purified on Histopaque 1077/1119 gradients (Sigma, Deisenhofen, Germany). Purity of the preparation was controlled by flow cytometry or cytospin ${ }^{19}$.

Static assays measuring the adhesion of PMNs to the murine bEnd.3 endothelial cell line were performed essentially as described ${ }^{19}$. In short, PMNs were fluorescently labeled with 2'7'-bis-(2 carboxyethyl)-5-carboxyfluorescein acetoxymethyl ester (Molecular Probes, Eugene, Ore), washed, and incubated in triplicates to sextuplets $\left(2 \times 10^{6}\right.$ cells $/ \mathrm{ml}, 50 \mu \mathrm{l} /$ well $)$ with confluent bEnd.3 monolayers in 96 -well plates $\left(10 \mathrm{~min}, 37^{\circ} \mathrm{C}\right)$. After washing with PBS, adhering 
cells were lysed ${ }^{19}$. The fluorescence signal was quantified in a Spectramax (MTX Lab Systems, Inc, Vienna, Va) fluorimeter (excitation 485nm, emission 535nm).

For transendothelial migration assays, $5 \times 10^{5} \mathrm{PMNs}$ in RPMI 1640 medium containing $0.5 \%$ BSA were added in triplicate to bEnd. 3 cells grown for 2 days in laminin-coated $6.5 \mathrm{~mm}$ Transwells ( 5 - $\mu \mathrm{m}$ pore size, Costar, Bodenheim, Germany). The lower chambers contained Dulbecco's modified Eagle's medium/10\% Fetal calf serum. bEnd. 3 cells were stimulated for 16 hours with $5 \mathrm{nmol} / \mathrm{L}$ human tumor necrosis factor- $\alpha$ (R\&D Systems, Wiesbaden, Germany) before PMNs were added. Transmigrating PMNs were counted in a CASY cell counter (Schärfe System, Reutlingen, Germany).

Table 1. Transcript levels of syndecans, cytokines and collagens after MI.

\begin{tabular}{|c|c|c|c|c|}
\hline & $\begin{array}{c}\text { Synd1 WT, sham, } \\
\mathrm{n}=4\end{array}$ & $\begin{array}{c}\text { Synd } 1 \mathrm{KO} \text {, sham, } \\
\mathrm{n}=5\end{array}$ & $\begin{array}{c}\text { Synd1 WT, MI, } \\
n=7\end{array}$ & $\begin{array}{c}\text { Synd1 } \mathrm{KO}, \mathrm{MI}, \\
\mathrm{n}=7\end{array}$ \\
\hline \multicolumn{5}{|l|}{ MI, 7 days } \\
\hline Synd1 & $1.6 \pm 0.13$ & N.D. & $14 \pm 1.3$ & ND \\
\hline Synd2 & $0.40 \pm 0.02$ & $0.35 \pm 0.06$ & $0.96 \pm 0.08 \dagger$ & $0.92 \pm 0.10 \dagger$ \\
\hline Synd3 & $0.48 \pm 0.03$ & $0.39 \pm 0.03$ & $1.1 \pm 0.17 \dagger$ & $0.73 \pm 0.07 \dagger$ \\
\hline Synd4 & $0.43 \pm 0.05$ & $0.39 \pm 0.06$ & $1.2 \pm 0.12 \dagger$ & $1.0 \pm 0.16 \dagger$ \\
\hline MCP-1 & $0.06 \pm 0.01$ & $0.09 \pm 0.03$ & $0.36 \pm 0.08 \dagger$ & $0.77 \pm 0.15^{*} \dagger$ \\
\hline RANTES & $0.17 \pm 0.02$ & $0.18 \pm 0.03$ & $1.6 \pm 0.45 \dagger$ & $0.80 \pm 0.16 \dagger$ \\
\hline TNF- $\alpha$ & $0.10 \pm 0.03$ & $0.22 \pm 0.10$ & $1.0 \pm 0.12 \dagger$ & $0.98 \pm 0.21 \dagger$ \\
\hline SDF-1 & $0.07 \pm 0.01$ & $0.08 \pm 0.02$ & $0.15 \pm 0.02 \dagger$ & $0.13 \pm 0.01 \dagger$ \\
\hline \multicolumn{5}{|l|}{ MI, 14 days } \\
\hline Collagen $\mid \alpha 1$ & $0.07 \pm 0.005$ & $0.05 \pm 0.001$ & $1.2 \pm 0.06 \dagger$ & $2.1 \pm 0.3^{*} \dagger$ \\
\hline Collagen III & $0.03 \pm 0.01$ & $0.03 \pm 0.003$ & $0.37 \pm 0.03 \dagger$ & $0.68 \pm 0.07^{*} \dagger$ \\
\hline tTG & $0.39 \pm 0.06$ & $0.23 \pm 0.05$ & $0.88 \pm 0.13 \dagger$ & $0.76 \pm 0.11 \dagger$ \\
\hline
\end{tabular}

ND indicates not detectable; MCP-1, monocyte chemoattractant protein; RANTES, regulated-on-activation, normal Tcell-expressed and -secreted chemokine; TNF, tumor necrosis factor; and SDF-1, stromal cell-derived factor 1.

${ }^{*} P<0.05$ in Synd 1 KO vs WT mice; $+P<0.05$ in infarcted (MI) vs sham-operated mice. 


\section{Transcript levels of cytokines in vivo}

Transcript levels of the cytokines monocyte chemoattractant protein-1; regulatedon-activation, normal T-cell-expressed and-secreted chemokine: tumor necrosis factor- $\alpha$; and stromal cell-derived factor were investigated in infarcted and sham tissue of Synd1 KO compared with WT mice with acidic ribosomal phosphoprotein PO (ARBP) as the housekeeping gene. Methodology and a list of the primers used are presented in online Data Supplement, Section II.

\section{Collagen content}

First, transcript levels of collagen type I and III were investigated in infarcted and sham hearts of Synd1 KO compared with WT mice (online Data Supplement, Section II). Next, collagen was stained on cardiac sections using Sirius red, and the amount of collagen was quantified ${ }^{17,18}$. In addition, a microplate reader-based quantification of collagens was performed as described by others ${ }^{16,20}$. Previously, this test has been shown to be comparable to the colorimetric hydroxyproline assay ${ }^{20}$. Quality of collagen fibers was further investigated by Sirius red polarization microscopy, allowing to quantify the thick, tightly packed collagen fibers as orange-red, and the thin, loosely assembled fibers appearing as yellowgreen $^{21}$. Ultrastructural analysis was done as described ${ }^{18}$.

\section{tTG and MMP activity in infarcts}

Zymographic activity of MMP- 2 and -9 in infarcted and sham hearts was performed as described ${ }^{17,22}$.

Because MMP-2 is able to inactivate tTG, activity of tTC in the infarcted area was measured by incorporating biotinylated cadaverine into fibronectin ${ }^{12}$. Next, transcript levels and protein expression of tTG were measured by realtime polymerase chain reaction (online Data Supplement, Section II) and immunoblotting (ab2972-500, Abcam) ${ }^{22}$. 


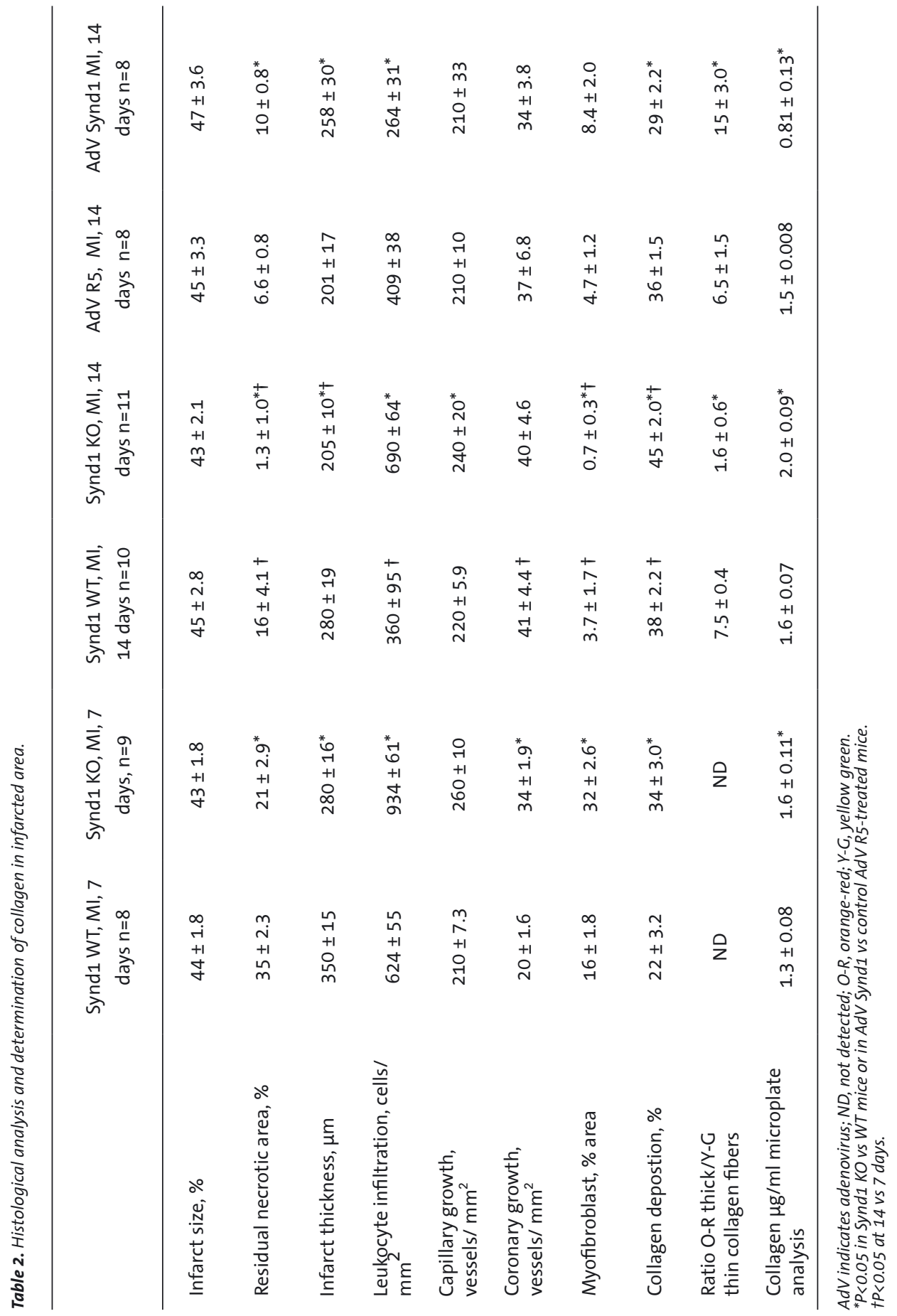




\section{Adenoviral gene transfer of Synd1}

Replication deficient adenoviruses containing rat Synd1 cDNA (AdSynd1) or the control R5 gene ${ }^{17}$ (AdR5), both under control of the cytomegalovirus promoter, were generated by homologous DNA recombination in bacteria, followed by viral particle generation and large-scale production in HEK293 cells as described ${ }^{23}$.

Then, $100 \mu \mathrm{l}$ of $1.0 \times 10^{9}$ plaque-forming units AdSynd 1 or control AdR5 diluted in saline was injected into the tail vein of Synd 1 WT mice, followed by induction of MI. Synd1 plasma levels were semiquantitatively measured in $100 \mu$ blood sampled from the retro-orbital plexus by Synd1 immunoblotting (Sc-5632, Santa Cruz Biotechnology, Santa Cruz, Calif) at 7 days after gene transfer. Echocardiography was performed in Synd 1 and control R5-treated at 14 days after MI, followed by histological and molecular analysis of infarcted hearts.

A
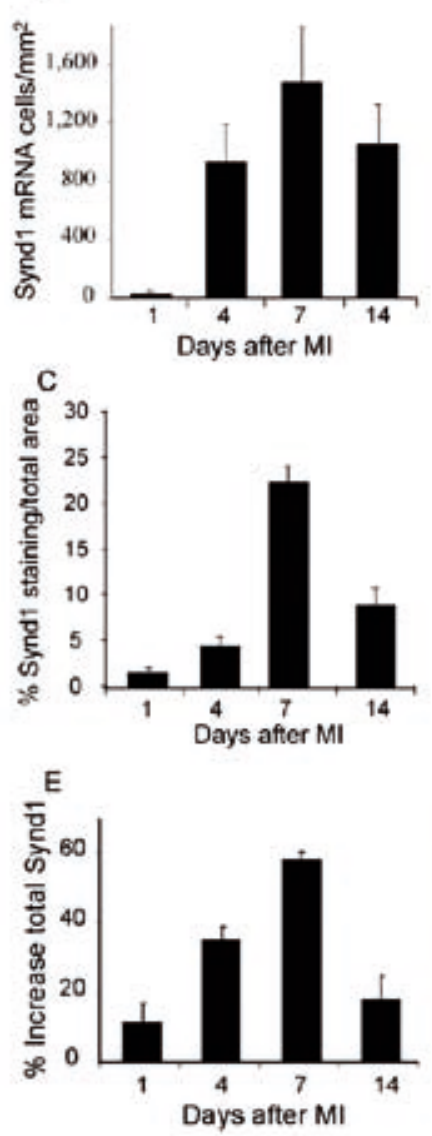

B

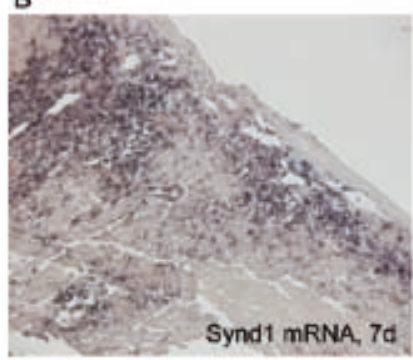

D
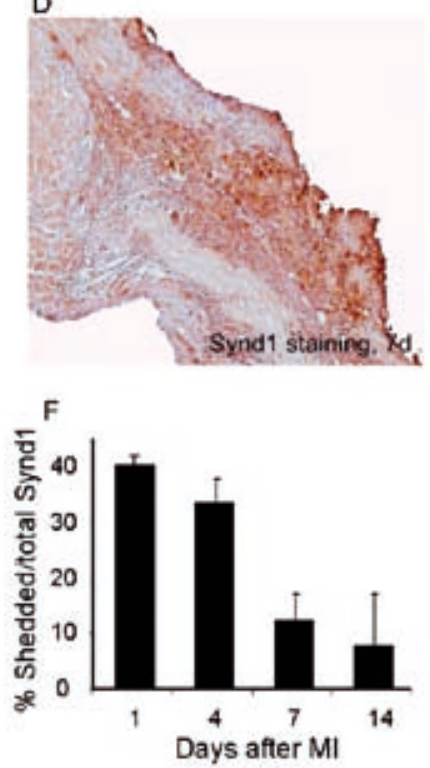

Figure 1. Synd1 expression after MI. In situ hybridization $(A, B)$, immunostaining $(C, D)$ and immunodot blot analysis $(E, F)$ of Synd 1 in infarcted WT hearts revealing minimal Synd 1 expression 1 day after $M I(A, C, E)$, and a progressive increase at 4 days $(A, C, E)$, reaching its maximum at 7 days $(A-E)$ and decreasing again at 14 days $(A, C, E)$ after $M I$, all relative to sham levels. Synd 1 mRNA was low to absent in sham-operated hearts. Ratio of shed to total Synd 1 significantly increased in the infarcted myocardium at 1 and 4 days but declined at 7 and 14 days vs sham levels (F). 


\section{Echocardiographic measurements}

Transthoracic echocardiography with a $12-\mathrm{mHz}$ probe (Hewlett Packard, Amsterdam, The Netherlands) on a sonos 5500 echocardiograph (Hewlett Packard, Palo Alto, Calif) was performed as described before ${ }^{18,22}$.

\section{Statistical Analysis}

Data were expressed as mean \pm SEM. No repeated measures were performed. Echocardiographic measurements and histological and molecular analysis in sham-operated and infarcted groups at 7 and 14 days were all performed in independent groups. Normal distribution of all continuous variables was tested using the method of Kolmogorov and Smirnov. An unpaired $t$ test was used most of the comparisons when groups passed the normality test. A Mann-Whitney test was used, however, when the standard deviations of 2 groups differed significantly. A 2-sided value of $\mathrm{P}<0.05$ was considered statistically significant.

The authors had full access to the data and take responsibility for the integrity of the data. All authors have read and agree to the manuscript as written.

\section{Results}

\section{Increased expression of Synd 1 after MI}

In situ hybridization of Synd1 revealed minimal Synd1 mRNA expression in the infarcted myocardium of WT mice at 1 day after $M I(n=7)$, with a progressive increase in Synd 1 mRNA from 4 days $(n=6)$ (Figure $1 A)$, reaching its maximum at 7 days $(n=8)$ (Figure $1 A$ and $1 B$ ) and decreasing again at 14 days after $M I(n=10)$ (Figure 1A). Synd1 mRNA was absent in sham-operated hearts. Expression was located primarily in inflammatory cells, endothelial cells and (myo)fibroblasts in the infarcted and peri-infarct region.

Concordant with in situ hybridization, Synd 1 immunostaining and dot-blot analysis revealed significantly increased expression of Synd 1 in the infarct region, with a maximal expression at day 7, again declining at day 14 (Figure 1C through E). Ratio of shed to total Synd 1 increased significantly in the infarcted myocardium at 1 and 4 days but declined at 7 and 14 days compared with sham levels (Figure 1F). To investigate whether the absence of Synd 1 may result in compensatory changes in expression of other syndecans, transcript levels of Synd1, 2, 3, and 4 were determined in Synd1 KO compared with WT hearts at 7 days after MI or sham surgery. Transcript levels of Synd2, 3, and 4 were significantly increased in WT and KO infarcts at 7 days after MI compared with sham hearts, concordant with previous findings by Finsen et al ${ }^{10}$ (Table 1). Lack of Synd1, however, did not result in a compensatory increase of Synd2, 3, or 4 after MI, nor did levels of Synd2, 3, or 4 differ in sham hearts of Synd1 KO compared with WT mice (Table 1). 
Figure 2. Adverse infarct wound healing in Synd1 $\mathrm{KO}$ mice. A, B, Hematoxylin and eosin staining revealed a higher degree of removal of necrotic cardiomyocytes in the Synd 1 KO vs WT infarcts at 14 days. C, D, Significantly increased number of CD45-immunoreactive inflammatory cells at 14 days in Synd1 KO vs WT infarcts.

A

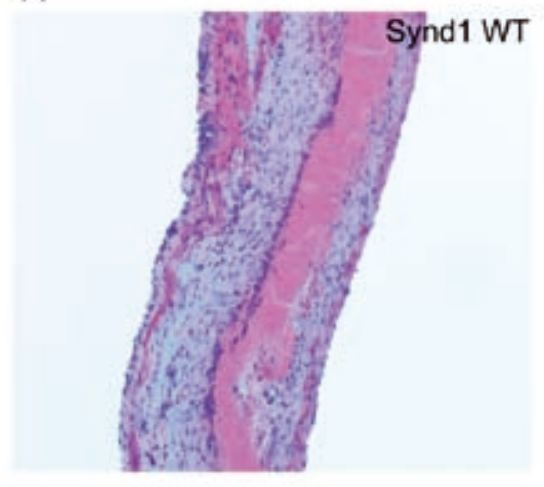

C

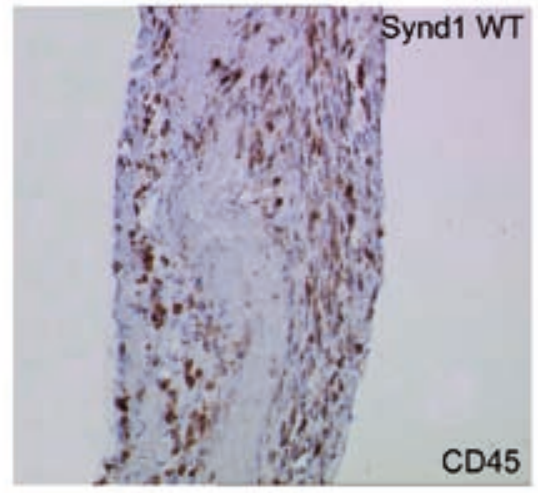

B

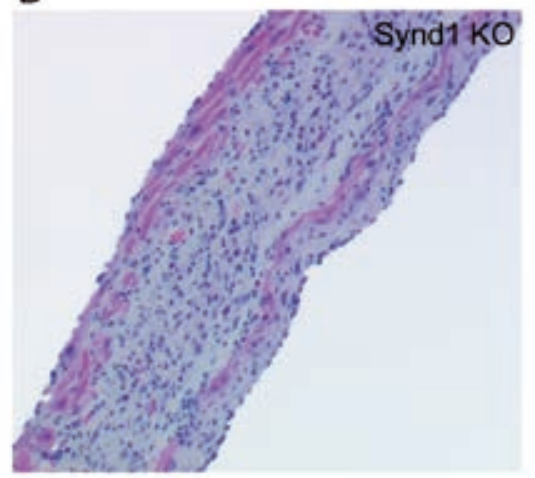

D

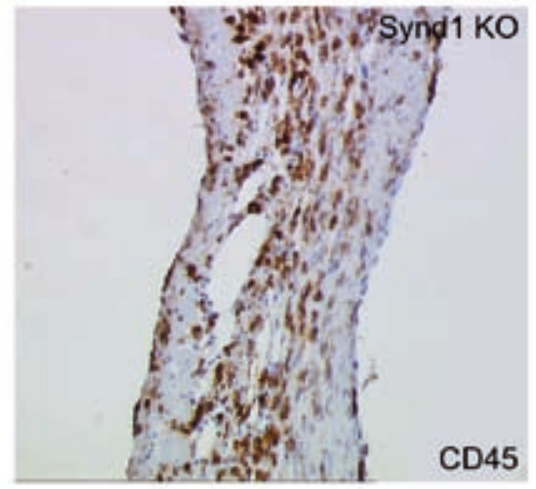

\section{Increased recruitment of inflammatory cells in Synd1 KO mice}

Infarct size did not differ significantly between Synd1 WT and KO mice (Table 2). The number of CD45-immunoreactive inflammatory cells (Figure 2C and 2D, Table 2) was significantly increased in Synd1 KO compared with WT infarcts at 7 and 14 days. Increased inflammation in the absence of Synd1 resulted in accelerated replacement of injured cardiomyocytes by granulation tissue, as indicated by significantly decreased amount of residual myocardial necrosis, increased smooth-muscle cell actin-immunoreactive myofibroblasts and coronary vessels, and increased CD31-immunoreactive capillaries in Synd1 KO compared with WT infarcts at 7 days after MI (Table 2 and Figure 2A and 2B).

Increased inflammation in the infarct was associated with significantly increased transcript levels of monocyte chemoattractant protein-1 (Table 1), involved in adverse infarct healing and increased cardiac dilatation and dysfunction after 
$\mathrm{Ml}^{24,25}$. Increased inflammation in Synd1 KO infarct was related to significantly increased adhesion and transmigration of PMNs through bEnd.3 murine endothelial cells in vitro in Synd1 KO compared with WT PMNs (adhesion, $n=6$, $\mathrm{P}<0.05$; transmigration, $\mathrm{n}=4, \mathrm{P}<0.001$ ) (Figure $3 \mathrm{~A}$ through $3 \mathrm{D}$ ).

Together, these data show that lack of Synd1 results in increased influx of inflammatory cells in the infarcted myocardium with accelerated wound healing and reveal a direct role for Synd1 in regulating transendothelial adhesion and transmigration of inflammatory cells in vitro.
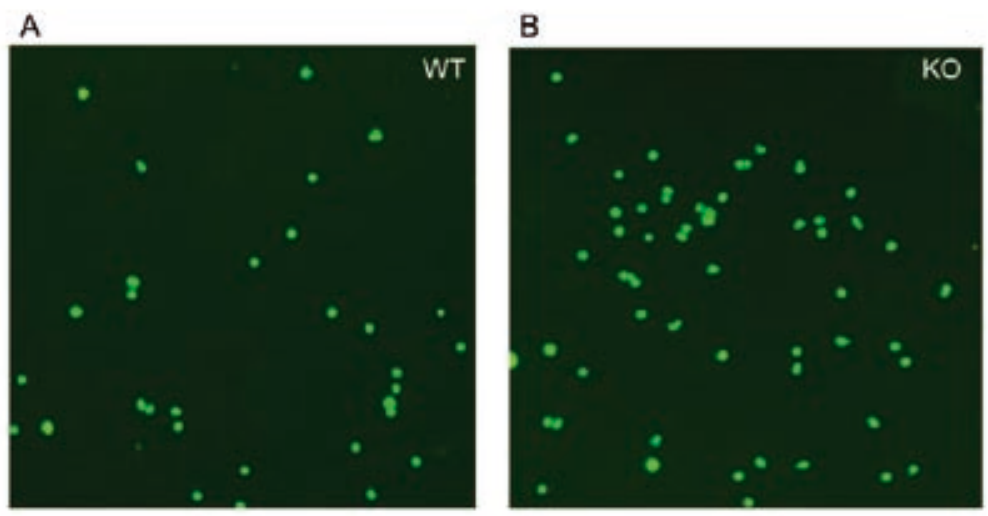

Figure 3. In vitro experiments.

A-C. Increased adhesion of fluorescently labeled PMNs to endothelial cells in Synd $1 \mathrm{KO}$ vs WT mice $\left({ }^{*} P<0.05\right)$.

D. Transendothelial migration of PMNs is increased in Synd 1 KO vs WT mice $\left({ }^{*} P<0.001\right)$.

C

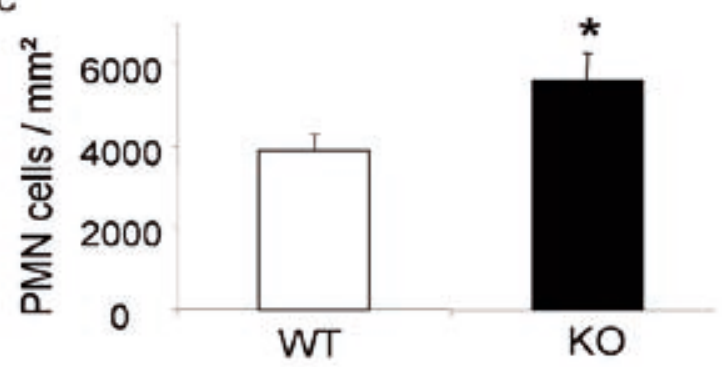

D
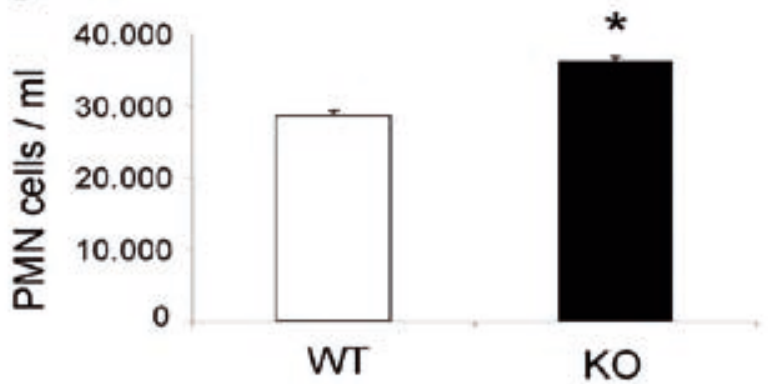
A

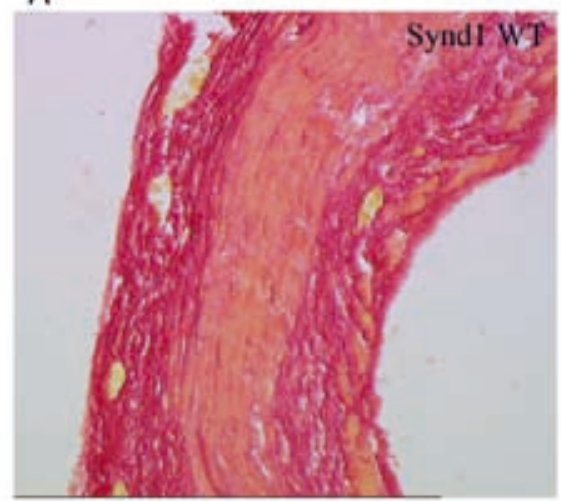

C

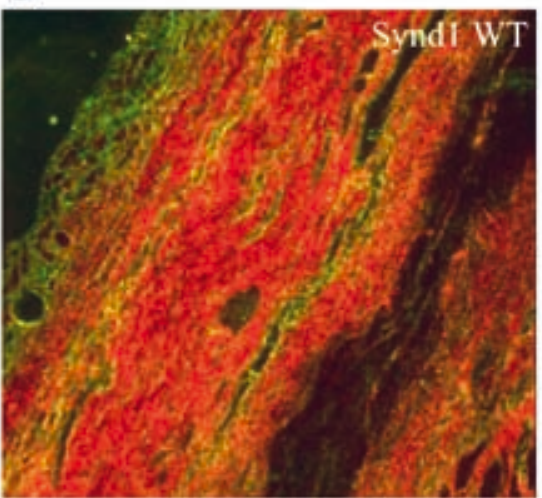

E

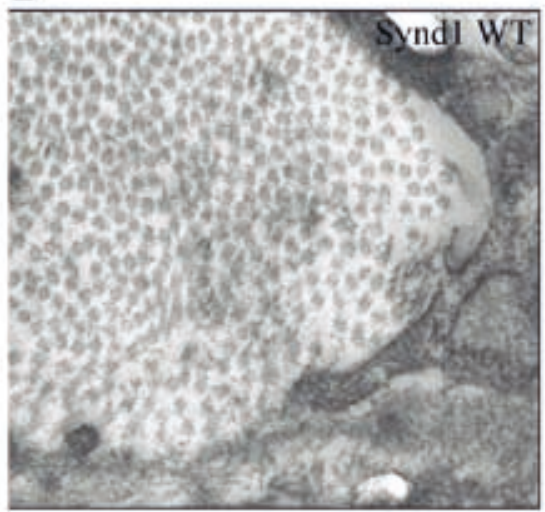

B

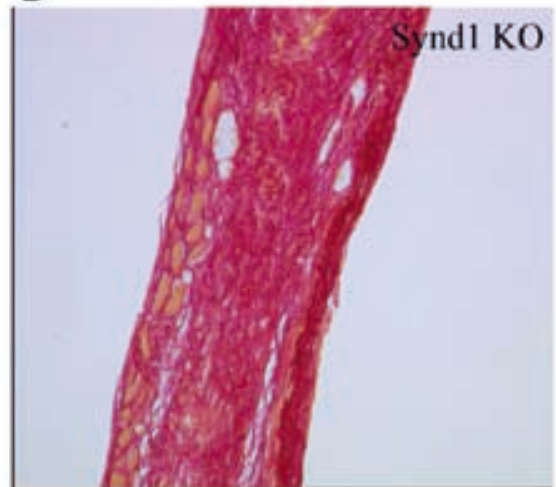

D

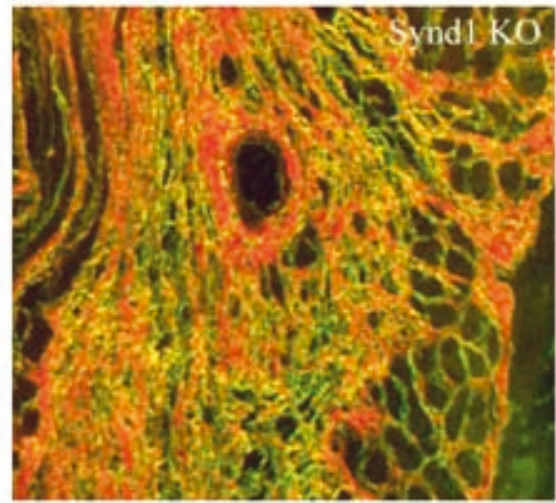

F

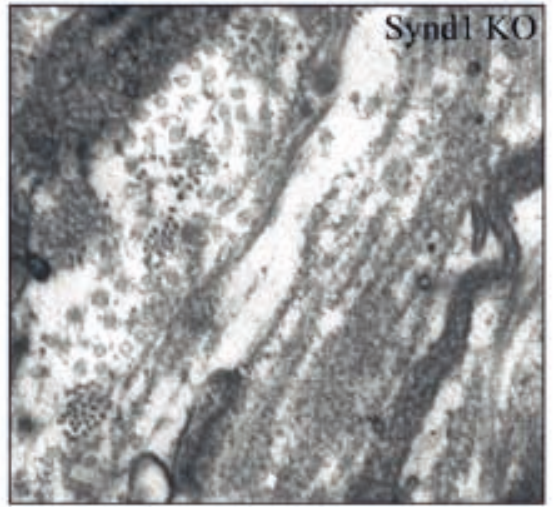

Figure 4. Abnormal collagen formation in Synd1 KO infarcts. A, B, Sirius red analysis revealed significantly increased collagen deposition in Synd1 KO vs WT infarcts. C, D, Sirius red polarization microscopy revealed mainly well-aligned and thick, tightly packed (orange-red) collagen fibers in WT infarcts but loosely assembled fibers (yellow-green) predominating in Synd1 KO infarcts. E, F, Ultrastructural analysis confirmed a disorganized collagen matrix with a predominance of smaller, less qualitative collagen fibers in Synd1 KO infarcts (F) in contrast to the well-organized collagen matrix with uniform and sharply delineated collagen fibers in WT infarcts (E). 


\section{Deficient collagen maturation and organization in the absence of Synd1}

Next, we investigated whether accelerated infarct healing in absence of Synd1 affected collagen remodeling. Transcript levels of collagen type I $\alpha 1$ and III and amount of collagen were significantly increased in Synd1 KO compared with WT infarcts but did not differ between sham-operated hearts (Figure $4 \mathrm{~A}$ and $4 \mathrm{~B}$, Tables 1 and 2). Sirius red polarization microscopy revealed mainly well-aligned and thick, tightly packed (orange-red) collagen fibers in WT infarcts (Figure 4C). In contrast, loosely assembled (yellow-green) collagen fibers predominated in Synd 1 $\mathrm{KO}$ infarcts at 14 days (ratio of orange-red to yellow-green birefringent collagen in the infarct area at 14 days; Figure 4C and 4D, Table 2).

Ultrastructural analysis confirmed a disorganized matrix with a predominance of smaller and fragmented collagen fibers in Synd $1 \mathrm{KO}$ infarcts, in contrast to the wellorganized collagen matrix with uniform and sharply delineated collagen fibers in WT infarcts (Figure 4E and 4F). Thus, increased inflammation and accelerated infarct healing in the absence of Synd1 resulted in increased collagen deposition, but of impaired quality.

\section{Increased activity of MMPs in the absence of Synd1}

Inflammatory cells in the infarct are the main source of MMP-2 and -9, proteolytic enzymes involved in cardiac dilatation and dysfunction after $\mathrm{MI}^{16,17,26}$. Increased inflammation in the absence of Synd 1 was related to significantly enhanced levels of pro-MMP-2 and -9 enzyme activity in Synd1 KO compared with WT infarcts at 14 days after $\mathrm{MI}$ ( $\mathrm{n}=5$ per group; $P<0.05$; Figure $5 \mathrm{~A}$ ). Immunoblotting confirmed the identity of the proform of MMP-2 and MMP-9, and semi-quantitative analysis showed increased expression of pro-MMP-2 and -9 in Synd1 KO compared with WT infarcts (Figure 5B). Baseline pro-MMP-2 or -9 protein and activity levels did not significantly differ between Synd 1 WT and KO mice (online Data Supplement, Section III).

MMP-2 inactivates $\mathrm{TTG}^{12}$, an enzyme known to stabilize the $\mathrm{ECM}^{27}$ and protect against cardiac dilatation ${ }^{13,14}$. The activity level of tTG was significantly decreased in infarcts of Synd 1 KO compared with WT mice at 14 days ( $n=6$ per group; $P<0.05$; Figure $5 C$ ), whereas total protein levels determined by immunoblotting did not significantly differ (Figure 5D). Decreased tTC activity resulted in decreased collagen cross-linking, as suggested by a decrease in immunoreactivity of $\epsilon$-lysyl $\gamma$-glutaminyl cross-links in infarcts ${ }^{12}$ (Figure $5 \mathrm{E}$ and $5 \mathrm{~F}$ ). Baseline protein or activity levels of tTG did not differ significantly in Synd1 WT compared with KO sham mice (online Data Supplement, Section III). Thus increased collagen fragmentation and cardiac dilatation in mice lacking Synd1 were related to increased MMP activity and decreased tTC activity. 
A
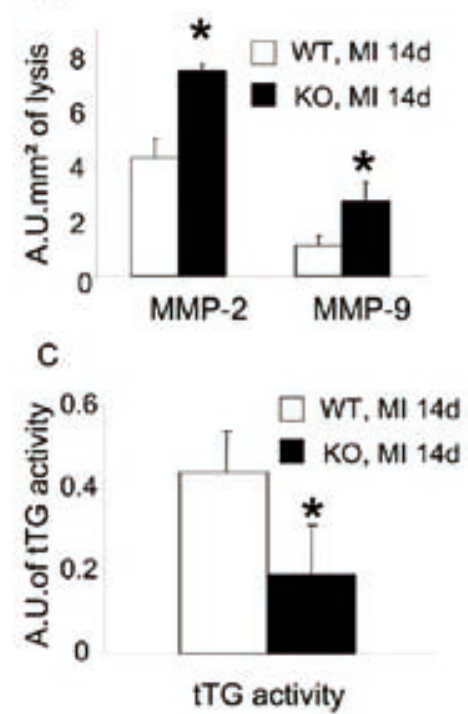

E

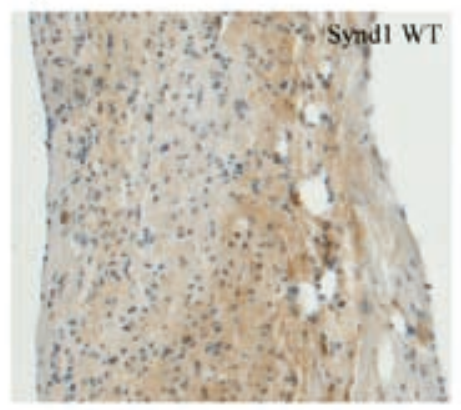

B

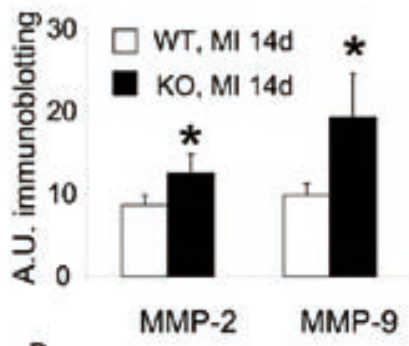

D

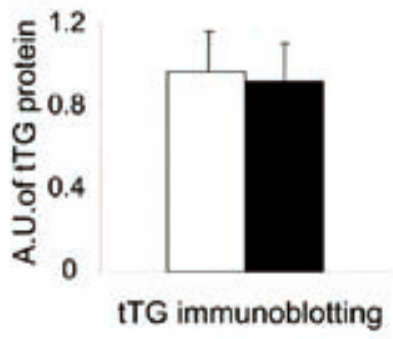

$\mathrm{F}$

Figure 5. Increased MMP and decreased tTG cross-linking in Synd1 KO infarcts. A, B, Significantly increased zymographic activity (A) and protein expression (B) of pro-MMP-2 and -9 in Synd1 KO vs WT mice at 14 days after MI. C, D, Significantly decreased activity (C) of tTG but unchanged protein expression (D) in infarcts of Synd1 KO vs WT mice at 14 daxys. E, $F$, Decreased collagen cross-linking in Synd $1 \mathrm{KO}$, as suggested by a consistent decrease in immunoreactivity of $\mathrm{\epsilon}-\mathrm{lysyl}$ Y-glutaminyl cross-links in Synd1 KO (F) compared with WT (E) infarcts.

\section{Increased cardiac dilatation and systolic dysfunction in the absence of Synd1}

Echocardiographic analysis revealed increased cardiac dilatation and impaired systolic function in Synd1 KO compared with WT infarcted hearts at 14 days (Table 3). Increased cardiac dilatation was accompanied by significantly decreased infarct thickness in Synd1 KO mice (Table 3), indicating increased infarct expansion. Increased cardiac failure after MI in Synd1 KO mice was further confirmed by a significant increase of $\sim 110 \%$ in the ratio of lung to body weight in Synd1 KO compared with a nonsignificant increase of $\sim 25 \%$ in WT mice at 14 days after MI (Table 3). Heart rate did not significantly differ between both groups (Table 3). 


\begin{tabular}{|c|c|c|c|c|c|c|}
\hline & $\begin{array}{c}\text { Synd1 WT, } \\
\text { sham, 14d } \\
n=7\end{array}$ & $\begin{array}{c}\text { Synd1 KO, } \\
\text { sham, 14d } \\
n=8\end{array}$ & $\begin{array}{c}\text { Synd1 WT, } \\
\text { infarct, 14d } \\
n=10\end{array}$ & $\begin{array}{c}\text { Synd1 KO, } \\
\text { infarct, 14d } \\
n=11\end{array}$ & $\begin{array}{c}\text { AdV R5 } \\
\text { infarct, } 14 d, \\
n=8\end{array}$ & $\begin{array}{c}\text { AdV Synd1, } \\
\text { infarct, 14d } \\
n=8\end{array}$ \\
\hline $\begin{array}{l}\text { LV/BW } \\
\text { ratio, mg/g }\end{array}$ & $3.7 \pm 0.2$ & $3.5 \pm 0.1$ & $4.4 \pm 0.2 \dagger$ & $4.2 \pm 0.3^{\dagger}$ & $4.5 \pm 0.1 \dagger$ & $4.3 \pm 0.2 \dagger$ \\
\hline $\begin{array}{l}\text { Lung/BW } \\
\text { ratio }\end{array}$ & $6.0 \pm 0.6$ & $5.9 \pm 0.3$ & $8.0 \pm 0.8$ & $13.4 \pm 1.9^{*} \dagger$ & $6.5 \pm 0.4$ & $7.8 \pm 0.3^{*}$ \\
\hline $\begin{array}{l}\text { PW diast., } \\
\mathrm{mm}\end{array}$ & $0.73 \pm 0.03$ & $0.74 \pm 0.03$ & $0.82 \pm 0.1$ & $0.84 \pm 0.08$ & $0.81 \pm 0.05$ & $0.78 \pm 0.02$ \\
\hline $\begin{array}{l}\text { SW diast., } \\
\mathrm{mm}\end{array}$ & $0.82 \pm 0.02$ & $0.81 \pm 0.03$ & $0.92 \pm 0.1$ & $0.91 \pm 0.07$ & $0.93 \pm 0.04$ & $0.94 \pm 0.03 \dagger$ \\
\hline $\begin{array}{l}\text { LV EDD, } \\
\mathrm{mm}\end{array}$ & $4.3 \pm 0.1$ & $4.1 \pm 0.2$ & $5.5 \pm 0.2 \dagger$ & $6.6 \pm 0.3^{*} \dagger$ & $4.9 \pm 0.03^{\dagger}$ & $4.1 \pm 0.2^{*}$ \\
\hline LV ESD, mm & $3.2 \pm 0.1$ & $3.0 \pm 0.1$ & $4.6 \pm 0.3^{\dagger}$ & $5.6 \pm 0.4 \dagger$ & $3.8 \pm 0.1$ & $3.0 \pm 0.1^{*}$ \\
\hline $\mathrm{FS}, \%$ & $27 \pm 2.1$ & $26 \pm 2.4$ & $18 \pm 2.6 \dagger$ & $10 \pm 1.0^{*} \dagger$ & $22 \pm 0.8 \dagger$ & $28 \pm 1.2^{*}$ \\
\hline $\begin{array}{l}\text { Heart rate, } \\
\text { beats/min. }\end{array}$ & $480 \pm 31$ & $490 \pm 22$ & $450 \pm 25$ & $470 \pm 29$ & $490 \pm 20$ & $500 \pm 12$ \\
\hline
\end{tabular}

$A d V$ indicates adenovirus; $A d V$, adenoviral gene overexpression of a control (R5) gene compared with syndecan-1 (Synd1) gene; LV, left ventricular; BW, body weight; PW, noninfarcted posterior wall; diast, diastolic; SW, noninfarcted septal wall; $E D D$, end-diastolic diameter; ESD, end-systolic diameter; and FS, fractional shortening. ${ }^{*} P<0.05$ in Synd 1 KO vs WT mice and in AdV Synd1-treated vs control AdV R5-treated WT mice. $+P<0.05$ in infarcted vs sham mice.

\section{Synd1 gene overexpression prevents cardiac dilatation and dysfunction}

To investigate whether overexpression of Synd1 may prevent increased cardiac inflammation, dilatation, and dysfunction after Ml, a replication- deficient adenovirus overexpressing Synd1 was injected in Synd1 WT mice, resulting in an 30-fold increase in Synd 1 immunoblotting in blood at 7 days after MI (online Data Supplement, Section IV). Overexpression of Synd1 significantly reduced cardiac inflammation in the infarct, improved quality of collagen (Figure 6A through 6F, Table 2), and prevented cardiac dilatation and dysfunction at 14 days after MI (Table 3).

Thus, overexpression of Synd1 clearly protects against adverse infarct healing, thereby reducing ventricular dilatation and failure after $\mathrm{MI}$. 
A

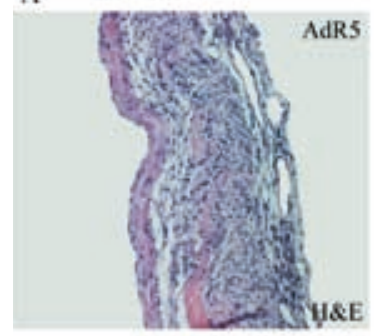

C

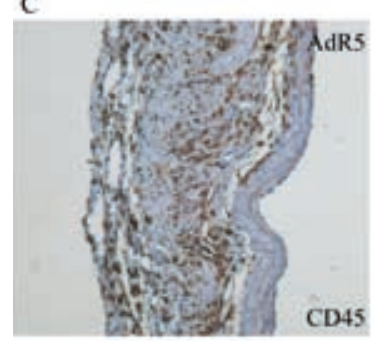

E

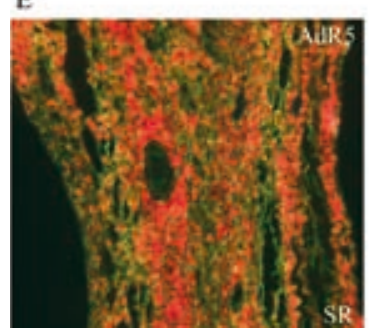

B

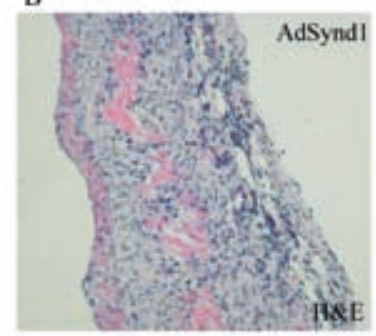

D

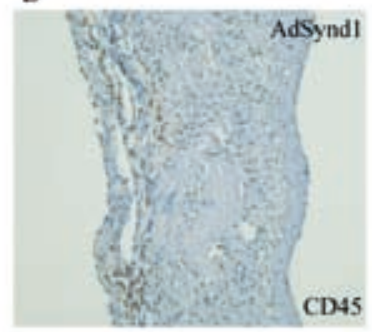

F

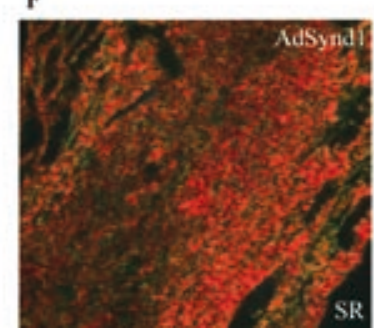

Figure 6. Synd1 overexpression improves infarct healing. A, B, Hematoxylin and eosin staining revealed a lower degree of removal of necrotic cardiomyocytes in Synd1treated vs control R5-treated infarcts at 14 days. C, D, Significantly decreased number of CD45-immunoreactive inflammatory cells in Synd1-treated vs control R5-treated infarcts at 14 days. $E, F$, Increased ratio of well-aligned and thick, tightly packed (orange-red) collagen fibers to loosely assembled (yellow-green) fibers in Synd1-treated infarcts.

\section{Discussion}

The present study unveils a novel role for Synd1 in protecting against adverse cardiac remodeling and dysfunction after MI. Whereas the absence of Synd1 in mice resulted in accelerated infarct healing with increased cardiac dilatation and dysfunction after Ml, adenoviral gene overexpression of Synd1 reduced cardiac inflammation and protected against cardiac dilatation and dysfunction after MI. Influx of inflammatory cells into the necrotic area is the earliest event in infarct healing. These inflammatory cells degrade the extracellular matrix surrounding the cardiomyocytes, alter the expression and activity of growth factors and chemokines, and thereby clear the way for the influx of other wound healing cells. Expression of Synd 1 is most pronounced in the periinfarct region, spatially and temporally related to inflammation ${ }^{8,9}$. Expression of Synd2, 3, and 4 also significantly increases after $\mathrm{MI}^{10}$, but lack of Synd 1 did not result in compensatory 
changes in Synd2, 3, or 4 after Ml, as observed in the present study.

The absence of Synd1 resulted in increased cardiac inflammation and failure, whereas overexpression of Synd1 protected against cardiac dilatation and failure after MI. Increased inflammation in the absence of Synd1 resulted in increased expression of monocyte chemoattractant protein-1 and increased activity of MMP-2 and -9, factors involved in aggravating cardiac dilatation and dysfunction after $\mathrm{Ml}^{15-17,24,25}$. Histological and molecular analyses revealed formation of a less qualitative collagen matrix in absence of Synd1, which was associated with increased MMP-2 and -9 activity and decreased tTC activity. These findings indicate a central role for Synd1 in regulating infarct inflammation and healing and in preventing cardiac dilatation and dysfunction after MI.

Increased Synd1 may reduce cardiac inflammation after MI by functioning as a barrier against invading inflammatory cells. In our present in vitro study, we observed increased adhesion and transendothelial transmigration of leukocytes lacking Synd1. Previous reports (reviewed elsewher ${ }^{28}$ ) demonstrated that Synd1 decreases leukocyte-endothelial interactions by masking adhesion ligands on endothelial cells and by competing with chemokines that mediate recruitment of inflammatory cells. Of additional interest in this regard are the findings that Synd 1 increases adhesion of inflammatory cells to collagens and limits their invasion into collagen gels ${ }^{29}$.

Synd 1 also may modulate matrix assembly (reviewed previously, ${ }^{5,6}$ ). The absence of Synd 1 resulted in the formation of less qualitative collagen fibers after $\mathrm{MI}$, whereas overexpression of Synd 1 improved collagen quality and protected against cardiac dilatation. Increased inflammation in infarcts of mice lacking Synd1 resulted in increased MMP- 2 and -9 activity and decreased tTG activity, both contributing to abnormal collagen formation and increased cardiac dilatation and dysfunction after $\mathrm{Ml}^{13,15,17}$. Although a downregulation of MMP-9 expression has previously been linked to increased Synd1 expression in myeloma cells, increased MMP activity in our experiments most likely resulted from increased inflammation, whereas decreased tTG activity may arise from increased degradation by MMP$2^{12}$. A link between increased MMP activity and changes in collagen composition is suggested by different studies ${ }^{11,14-16}$, revealing that thick type I collagen fibers are degraded by increased MMPs and replaced by fibrous interstitial deposits of poorly crosslinked collagen. Reduced levels of tTG also contribute to abnormal collagen fibrillogenesis and parallels cardiac dilatation and dysfunction ${ }^{13,14}$. tTG mediates the assembly of collagen monomers into fibers, which occurs in close association with the cell surface and involves collagen-binding $B 1$ integrins ${ }^{27}$. tTC also stabilizes the interstitial matrix by introducting $\epsilon$-lysyl $\gamma$-glutaminyl crosslinks into collagens ${ }^{27}$. 
The present study demonstrates the importance and therapeutic potential of Synd1 in ventricular remodeling after Ml. Our observations are concordant with previous findings indicating a general role for glycoproteins and matricellular proteins in preventing adverse infarct healing and dysfunction after $\mathrm{Ml}^{30}$, as described for osteopontin ${ }^{31}$ and thrombospondin- $1^{32}$. Although we show that a reduction in inflammation by Synd 1 is a putative mechanism, the present study cannot definitively answer which processes modulated by Synd 1 are pivotal in its protective role.

Our study reveals a novel role for Synd1 in protecting against infarct healing, cardiac dilatation, and dysfunction after MI. Therefore, Synd1 deserves further investigation as a novel therapeutic tool to reduce cardiac dilatation and failure after MI.

\section{Acknowledgements}

We would like to thank R. Goez and B. Pers for technical assistance.

\section{Sources of funding}

This study was supported by a research grant of the Leuven University, Belgium (OT-0346) to Dr Heymans, a Dr Dekkers grant of the Netherlands Heart Foundation (NHS, 2003T036) to Dr Heymans, a Muenster University Hospital Innovative Medizinische Forschung grant (IMF GÖ 1204 15) to Dr Götte, and a VIDI grant of the Netherlands Organisation for Scientific Research to Dr Pinto (016.036.346). Dr Pinto is an established investigator of the Netherlands Heart Foundation.

\section{References}

1. Gotte M, Joussen AM, Klein C, Andre P, Wagner DD, Hinkes MT, Kirchhof B, Adamis AP, Bernfield M. Role of syndecan-1 in leukocyte-endothelial interactions in the ocular vasculature. Invest Ophthalmol Vis Sci. 2002;43:1135-41.

2. Elenius V, Gotte $M$, Reizes $O$, Elenius K, Bernfield M. Inhibition by the soluble syndecan-1 ectodomains delays wound repair in mice overexpressing syndecan-1. J Biol Chem. 2004;279:41928-35.

3. Park PW, Pier GB, Hinkes MT, Bernfield M. Exploitation of syndecan1 shedding by Pseudomonas aeruginosa enhances virulence. Nature. 2001;411:98-102.

4. Alexander CM, Reichsman F, Hinkes MT, Lincecum J, Becker KA, Cumberledge $S$, Bernfield $M$. Syndecan-1 is required for Wnt-1-induced mammary tumorigenesis in mice. Nat Genet. 2000;25:329-32. 
5. Woods A. Syndecans: transmembrane modulators of adhesion and matrix assembly. J Clin Invest. 2001;107:935-41.

6. Tkachenko E, Rhodes JM, Simons M. Syndecans: new kids on the signaling block. Circ Res. 2005;96:488-500.

7. Gotte M. Syndecans in inflammation. Faseb J. 2003;17:575-91.

8. Li J, Brown LF, Laham RJ, Volk R, Simons M. Macrophage-dependent regulation of syndecan gene expression. Circ Res. 1997;81:785-96.

9. Endo C, Kusachi S, Ninomiya Y, Yamamoto K, Murakami M, Murakami T, Shinji T, Koide N, Kondo J, Tsuji T. Time-dependent increases in syndecan1 and fibroglycan messenger RNA expression in the infarct zone after experimentally induced myocardial infarction in rats. Coron Artery Dis. 1997;8:155-61.

10. Finsen AV, Woldbaek PR, Li J, Wu J, Lyberg T, Tonnessen T, Christensen G. Increased syndecan expression following myocardial infarction indicates a role in cardiac remodeling. Physiol Genomics. 2004;16:301-8.

11. Lindsey ML, Mann DL, Entman ML, Spinale FG. Extracellular matrix remodeling following myocardial injury. Ann Med. 2003;35:316-26.

12. Agah A, Kyriakides TR, Bornstein P. Proteolysis of cell-surface tissue transglutaminase by matrix metalloproteinase-2 contributes to the adhesive defect and matrix abnormalities in thrombospondin-2-null fibroblasts and mice. Am J Pathol. 2005;167:81-8.

13. Woodiwiss AJ, Tsotetsi OJ, Sprott S, Lancaster EJ, Mela T, Chung ES, Meyer TE, Norton GR. Reduction in myocardial collagen cross-linking parallels left ventricular dilatation in rat models of systolic chamber dysfunction. Circulation. 2001;103:155-60.

14. Klotz S, Foronjy RF, Dickstein ML, Gu A, Garrelds IM, Danser AH, Oz MC, D'Armiento J, Burkhoff D. Mechanical unloading during left ventricular assist device support increases left ventricular collagen cross-linking and myocardial stiffness. Circulation. 2005;112:364-74.

15. Hayashidani S, Tsutsui H, Ikeuchi M, Shiomi T, Matsusaka H, Kubota T, Imanaka-Yoshida K, Itoh T, Takeshita A. Targeted deletion of MMP2 attenuates early LV rupture and late remodeling after experimental myocardial infarction. In: Am J Physiol Heart Circ Physiol; 2003:H122935.

16. Ducharme A, Frantz S, Aikawa M, Rabkin E, Lindsey M, Rohde LE, Schoen FJ, Kelly RA, Werb Z, Libby P, Lee RT. Targeted deletion of matrix metalloproteinase- 9 attenuates left ventricular enlargement and collagen accumulation after experimental myocardial infarction. In: J Clin Invest; 2000:55-62.

17. Heymans S, Luttun A, Nuyens D, Theilmeier G, Creemers E, Moons L, Dyspersin GD, Cleutjens JP, Shipley M, Angellilo A, Levi M, Nube O, Baker A, 
Keshet E, Lupu F, Herbert JM, Smits JF, Shapiro SD, Baes M, Borgers M, Collen D, Daemen MJ, Carmeliet P. Inhibition of plasminogen activators or matrix metalloproteinases prevents cardiac rupture but impairs therapeutic angiogenesis and causes cardiac failure. In: Nat Med; 1999:1135-42.

18. Heymans S, Lupu F, Terclavers S, Vanwetswinkel B, Herbert JM, Baker A, Collen D, Carmeliet P, Moons L. Loss or Inhibition of UPA or MMP-9 Attenuates LV Remodeling and Dysfunction after Acute Pressure Overload in Mice. Am J Pathol. 2005;166:15-25.

19. Gotte $M$, Bernfield $M$, Joussen AM. Increased leukocyte-endothelial interactions in syndecan-1-deficient mice involve heparan sulfatedependent and -independent steps. Curr Eye Res. 2005;30:417-22.

20. Walsh BJ, Thornton SC, Penny R, Breit SN. Microplate reader-based quantitation of collagens. Anal Biochem. 1992;203:187-90.

21. Whittaker P, Kloner RA, Boughner DR, Pickering JG. Quantitative assessment of myocardial collagen with picrosirius red staining and circularly polarized light. Basic Res Cardiol. 1994;89:397-410.

22. Schroen B, Heymans S, Sharma U, Blankesteijn WM, Pokharel S, Cleutjens JPM, Porter JG, Evelo CTA, Duisters R, van Leeuwen REW, Janssen BJA, Debets JJM, Smits JFM, Daemen MJAP, Crijns HJGM, Bornstein P, Pinto YM. Thrombospondin-2 Is Essential for Myocardial Matrix Integrity: Increased Expression Identifies Failure-Prone Cardiac Hypertrophy. Circ Res. 2004;95:515-522.

23. He TC, Zhou S, da Costa LT, Yu J, Kinzler KW, Vogelstein B. A simplified system for generating recombinant adenoviruses. Proc Natl Acad Sci U S A. 1998;95:2509-14.

24. Hayashidani S, Tsutsui H, Shiomi T, Ikeuchi M, Matsusaka H, Suematsu N, Wen J, Egashira K, Takeshita A. Anti-monocyte chemoattractant protein1 gene therapy attenuates left ventricular remodeling and failure after experimental myocardial infarction. Circulation. 2003;108:2134-40.

25. Dewald O, Zymek P, Winkelmann K, Koerting A, Ren G, Abou-Khamis T, Michael LH, Rollins BJ, Entman ML, Frangogiannis NG. CCL2/Monocyte Chemoattractant Protein-1 regulates inflammatory responses critical to healing myocardial infarcts. Circ Res. 2005;96:881-9.

27. Lorand L, Graham RM. Transglutaminases: crosslinking enzymes with pleiotropic functions. Nat Rev Mol Cell Biol. 2003;4:140-56.

28. Parish CR. The role of heparan sulphate in inflammation. Nat Rev Immunol. 2006;6:633-43.

29. Liu W, Litwack ED, Stanley MJ, Langford JK, Lander AD, Sanderson RD. Heparan sulfate proteoglycans as adhesive and anti-invasive molecules. Syndecans and glypican have distinct functions. J Biol Chem. 1998;273:22825-32. 
30. Schellings MWM, Pinto YM, Heymans S. Matricellular proteins in the heart: possible role during stress and remodeling. Cardiovascular Research. 2004;64:24-31.

31. Trueblood NA, Xie Z, Communal C, Sam F, Ngoy S, Liaw L, Jenkins AW, Wang J, Sawyer DB, Bing OH, Apstein CS, Colucci WS, Singh K. Exaggerated left ventricular dilation and reduced collagen deposition after myocardial infarction in mice lacking osteopontin. Circ Res. 2001;88:1080-7.

32. Frangogiannis NG, Ren G, Dewald O, Zymek P, Haudek S, Koerting A, Winkelmann K, Michael LH, Lawler J, Entman ML. Critical role of endogenous thrombospondin-1 in preventing expansion of healing myocardial infarcts. Circulation. 2005;111:2935-42. 


\section{Online supplemental Section I. In situ hybridization}

Primers for Synd 1 were designed (forward primer: 5'-TCC GTA CAA CAG GGT ATG GA- 3' and reverse primer: 5'-CCT CCC CTC CAC TCC TAC AC- 3 '), that amplified a 217 bp sequence that was cloned into pGEM-T Easy (Promega, Madison, WI). The cloned product was sequenced to assure its identity (ABI Prism 310, Molecular Genetics, Maastricht University). The plasmid DNA was purified, linearized and RNA sense and anti-sense probes were obtained. RNA labeling was performed by in vitro transcription with Digoxigenin (DIG) (Roche Applied Science). Probes were applied on four micrometer cardiac sections which were previously deparaffined, permeabilized with $25 \mu \mathrm{g} / \mathrm{ml}$ proteinase $\mathrm{K}$ (Ambion, Austin TX), acetylated with $0.25 \%$ acetic anhydride (Merck) in $0.1 \mathrm{M} \mathrm{pH} 8$ triethanolamine (Riedel-de Haën, $\mathrm{GmbH}$, Seeize, Germany). The slides were hybridized overnight at $50^{\circ} \mathrm{C}$ and the hybridized probe detected using an anti-DIG antibody conjugated with alkalinephosphatase, visualized by nitroblue tetrazolium/5-bromo-4-chloro-3-indolyl phosphate (Roche Applied Science). The sense probe and RNAse pre-treatment of slides were used both as negative controls.

\section{Online supplemental Section II}

RNA was isolated from infarcted and sham tissue using the RNeasy Mini Kit (Qiagen) and stored in $-80^{\circ} \mathrm{C}$. RNA was reverse transcribed into CDNA using the iScript $^{\text {TM }}$ CDNA synthesis kit (BioRad). Real-time quantitative PCR was performed using $\mathrm{iQ}^{\mathrm{T}}{ }^{\mathrm{M}}$ SYBR green supermix (BioRad) and primers designed with Primer Express Software (PE Applied Biosystems, Foster City, CA). Acidic ribosomal phosphoprotein PO (ARBP) was used as the housekeeping gene.

Primers used were:

\begin{tabular}{lll}
\hline Gene & Forward primer 5' - 3' $^{\prime}$ & Reverse primer 5' $-\mathbf{3}^{\prime}$ \\
\hline Syndecan 1 & CCTTTTGGACAGGAAGGAAGTG & TCCTTCTTCTTCATCCGGTACAG \\
Syndecan 2 & ACAGAAGTTCTAGCAGCCGTCATT & CGGTACACCAATAGCAGGATGAG \\
Syndecan 3 & TGCTCGTAGCCGTGATCGT & GGTGTAGCTGCCTTCGTCCTT \\
Syndecan 4 & CCCAGGGCAGCAACATCTT & AGGATCAGGAAAACGGCAAA \\
MCP-1 & ACCAGCAGCAGGTGTCCC & GCACAGACCTCTCTCTTGAGCTT \\
RANTES & TCCAATCTTCCAGTCGTGTTTC & TCTGGGTTGGCACACACTTG \\
TNF- $\alpha$ & CATCTTCTCAAAATTCGAGTGACAA & TGGGAGTAGACAAGGTACAACCC \\
SDF-1 & TGCCGGTTCTTCGAGAGC & CAGCCGTCAACAATCTGAA \\
Collagen la1 & CTTCACCTACAGCACCCTTGTG & CTTGGTGGTTTTGTATTCGATGAC \\
Collagen III & TCGGAACTGCAGAGACCTAAA & CCCCAGTTTCCATGTTACAGA \\
tTC & TGGAAGTCTCAGACCCGGTG & CCAATATCAGTCGGGAACAGGT \\
ARBP & GGACCCGAGAAGACCTCCTT & GCACATCACTCAGAATTTCAATGG \\
\hline
\end{tabular}

\section{Online supplemental Section III}

Baseline pro-MMP-2 or -9 zymographic activity levels did not differ significantly 
between Synd1 KO and WT mice (arbitrary units of lysis, Spec_OD/A.U. $\mathrm{mm}^{2}$ : proMMP-9, $0.7 \pm 0.1$ in WT versus $0.6 \pm 0.2$ in KO mice, $n=4, P=N S$; pro-MMP-2, $1.5 \pm$ 0.3 in Synd 1 KO versus $1.7 \pm 0.2$ in WT mice, $n=4, P=N S$ ).

Baseline pro-MMP-2 or -9 protein levels did not differ significantly between Synd1 WT and KO mice (arbitrary units: pro-MMP-9, $8 \pm 1.2$ in KO versus $6.8 \pm 2.1$ in WT mice, $n=4, P=N S$; pro-MMP-2: $4.0 \pm 0.5$ in Synd 1 KO mice versus $4.1 \pm 0.4$ in WT mice, $n=4, P=N S$ ).

Baseline protein or activity levels of tTG did not significantly differ in Synd1 WT compared with KO sham mice (tTG activity in arbitrary units at 14 days: $0.11 \pm 0.05$ in Synd1 WT versus $0.08 \pm 0.02$ in KO sham hearts; tTG protein levels in arbitrary units at 14 days: $0.7 \pm 0.2$ in Synd 1 WT versus $0.8 \pm 0.2$ in KO sham hearts; $n=4$ per group, $\mathrm{P}=\mathrm{NS}$ ).

\section{Online supplemental Section IV}

Increased expression of Synd1 at 7 days after intravenous injection of a replication deficient adenovirus overexpressing Synd1 (AdSynd1), as revealed by immunoblotting (representative blot of $n=3$ per group).

$65 \mathrm{kD}$

AdR5

AdSynd 1 



\section{Chapter 5}

\section{Syndecan-1 amplifies angiotensin II-mediated signalling and promotes cardiac fibrosis}

Mark WM Schellings, Davy Vanhoutte, Rick EW van Leeuwen, Gonda Konings, Joost J Leenders, Stephane Heymans, Yigal M Pinto

Submitted 


\section{Abstract}

Syndecan 1 (Synd1) is a transmembrane heparan sulfate proteoglycan that functions as a co-receptor for various growth factors, and modulates signal transduction. Recently, it has been shown that Synd1 expression increases after experimental myocardial infarction. Given its important role as a co-receptor we hypothesized that Synd1 plays a role in hypertension-induced cardiac fibrosis.

Synd1 knockout (KO) mice and their wild-type (WT) controls received angiotensin II (AngII) (1,5 mg/kg/day) for 14 days. After Angll infusion, systolic function was impaired in WT mice while Synd1 KO mice preserved systolic function (Fractional shortening; WT: $21.5 \pm 2.8 \%$ vs KO: $29.6 \pm 2.6 \%, \mathrm{P}<0.05, \mathrm{n}=8-14)$. Angll induced fibrosis in WT mice $(1018,3 \pm 214.2 \%$ compared to WT control $(100 \%), n=8)$ but significantly less in Synd1 KO mice $(581.1 \pm 92.2 \%, n=15)$, as measured by Sirius Red staining and Q-PCR. In vitro, Angll and transforming growth factor $ß$ (TGFß) induced connective tissue growth factor (CTGF), a mediator of Angll-induced fibrosis, expression in cardiac fibroblasts (CF). Knockdown of Synd1 by shRNA attenuated this increase of CTGF. In contrast, overexpression of Synd1 increased Angll mediated CTGF expression.

We show that hypertension-induced cardiac fibrosis and dysfunction is attenuated in Synd1 KO mice. Furthermore, we show that Synd1 amplifies CTGF expression by augmenting Angll-induced TGFß signaling, thereby enhancing the profibrotic effects of Angll. These findings suggest that inhibition of Synd1 may be an attractive adjuvant strategy to limit the ability of Angll to induce cardiac fibrosis. 


\section{Introduction}

Matrix accumulation, collagen deposition and stiffening hallmark the adverse remodeling in chronically overloaded myocardium ${ }^{1}$. The underlying mechanisms are not yet fully elucidated, but neurohormones and growth factors such as angiotensin II (AngII), endothelin and transforming growth factor ß1 (TGFß) are associated with enhanced synthesis of collagens and other matrix proteins, and have been implicated in the development of such adverse structural changes ${ }^{2}$. Apart from causing high blood pressure, Angll also may initiate adverse signaling in the heart, thereby causing cardiac hypertrophy and cardiac fibrosis ${ }^{3}$. The profibrotic signaling caused by Angll is importantly mediated via activation of the TGFß system, and concomitant activation of connective tissue growth factor (CTGF) expression ${ }^{4,5}$. Angll both induces the production of TGFß, CTGF and the expression of endoglin, a TGFß receptor, in cardiac fibroblasts, so that blockade of either TGFß signaling or of CTGF effectively decreases Angll-induced fibrosis ${ }^{4-6}$. Syndecans are heparan sulfate proteoglycans, which are present at the cell membrane where they modulate cell-matrix interactions ${ }^{7}$. They can bind to extracellular matrix proteins, growth factors, and other cell surface proteins. This allows syndecans to influence cellular migration and growth factor signaling, like fibroblast growth factor (FGF) and TGFß signaling ${ }^{8-10}$. Also, Angll-mediated signaling can be modulated by heparan sulfates ${ }^{11}$. Up to date, the precise role of syndecans in pathological remodeling of the hypertensive heart is unknown. Given its involvement in signal transduction modulation, we hypothesized that syndecan 1 (Synd1) is involved in Angll-induced cardiac remodeling.

Here, we show that Synd1 plays a crucial role in Angll-induced cardiac remodeling. Synd1 KO mice are protected against Angll-induced cardiac dysfunction and fibrosis. These findings were confirmed in vitro, where shRNA mediated knockdown of Synd1 significantly attenuates the ability of Angll and TGFß to increase CTGF expression, a known mediator of Angll-induced fibrosis. In reverse, overexpression of Synd 1 indeed increased CTGF expression. Our data show that Synd1 is an important regulator in the development of cardiac fibrosis, and therefore may be a new therapeutic target in pathological forms of cardiac fibrosis.

\section{Material and Methods}

\section{In vivo experiments}

We used 14- to 20-week-old male inbred BALB/c Synd1 knockout (KO) mice and their wild-type (WT) littermates. Synd1 mice were a gift from M.A. Stepp, PhD, Washington, DC. Angiotensin II (1,5 mg/kg/day) was administered for 14 days via osmotic minipumps (Alzet osmotic minipumps, Palo Alto, CA, USA; types 2ML4). At 
the end of experiment, echocardiography was performed under 2-4\% isofluorane anesthesia, as described previously ${ }^{12}$. Experiments were carried out according to the institutional guidelines for the experimental use of animals.

\section{Measurement of myocardial collagen content}

Myocardial collagen was stained with picrosirius-red as described earlier ${ }^{13}$. For the quantification of left ventricular collagen volume fraction (CVF), computerized planimetry was performed in at least 7 randomly selected fields per section per mouse.

\begin{tabular}{lllll} 
& Sham & \multicolumn{3}{c}{ 14 days Angll } \\
\hline & WT & KO & WT & KO \\
& $\mathrm{n}=4$ & $\mathrm{n}=5$ & $\mathrm{n}=8$ & $\mathrm{n}=14$ \\
\hline BW end (g) & $31 \pm 0.4$ & $23.2 \pm 1.0^{*}$ & $24.4 \pm 0.9^{*}$ & $20.9 \pm 0.6^{*} \dagger$ \\
LVW/BW & $4.1 \pm 0.1$ & $4.3 \pm 0.1$ & $5.4 \pm 0.2^{*}$ & $5.1 \pm 0.2^{*}$ \\
LW/BW & $6.0 \pm 0.2$ & $6.9 \pm 0.5$ & $7.7 \pm 0.8$ & $8.0 \pm 0.5$ \\
\hline
\end{tabular}

Table 1. General parameters of the mice at the end of the study.

${ }^{*} P<0.05$ vs corresponding sham orWTsham, $+P<0.05$ vsWTAngll LVW: left ventricular weight, BW: body weight, LW: lung BW: bodyht

\section{Cloning lentiviral Synd1 short hairpin RNA expressing constructs}

Small interfering RNA against Synd1 was designed by Eurogentec, Liège, Belgium. From this design oligo's with one hairpin loop (shRNA) were created (table 3). The oligo's were cloned into Xhol and Hpal site of the vector pLenti Lox 3.7 puro. This vector was modified from the pLenti Lox $3.7^{14}$ (pll3.7puro) by replacing the eGFP gene by puromycin. Constructs were verified by sequencing.

Lentiviral production was performed by co-transfection of $3 \mu \mathrm{g}$ shSynd1/pLL3.7 puro or empty pLL3.7puro and packaging vectors into $293 \mathrm{FT}$ cells by Lipofectamine 2000 (Invitrogen) and virus-containing supernatant was harvested after 48 hours.

\section{Adenoviral overexpression of Synd 1}

Replication deficient adenoviruses containing rat syndecan-1 CDNA (AdSynd1) or the control R5 gene (AdR5), all under control of the cytomegalovirus promoter, were generated and produced as described previously ${ }^{15}$.

\section{Cardiac fibroblast culture}

Dulbecco's modified eagle's medium (DMEM), and fetal bovine serum (FBS) were purchased from GIBCO BRL, Breda, the Netherlands. Culture plates were obtained from Costar, Badhoevendorp, the Netherlands. Cardiac fibroblasts were isolated from 2-day-old neonatal Lewis rats. All the experiments were performed on cells from the second passage. Cells were maintained in DMEM supplemented with $10 \%$ FBS along with $50 \mu \mathrm{g} / \mathrm{ml}$ gentamycin, and $100 \mathrm{units} / \mathrm{ml}$ penicillin/streptomycin, and were incubated at $37^{\circ} \mathrm{C}$ in a humidified chamber. Cells were allowed to attach, where after they were infected with lentivirus harboring shRNA against Synd1 
or control lentivirus, facilitated by Sequabrene (Sigma). After puromycin selection $(3 \mu \mathrm{g} / \mathrm{ml})$, cells were placed in low-serum medium (0.4\% FBS) for 24 hours. Synd 1 knockdown (KD) and wild type cells received Angll $(1 \mu \mathrm{M})$ or TGFß $(1 \mathrm{ng} / \mathrm{ml})$ for 24 hours. For adenoviral transfection, cells were transfected with AdR5 or AdSynd 1 for 48 hours. Hereafter, cells were placed on low-serum medium (0.4\% FBS) for 24 hours. After synchronization, cells received Angll $(1 \mu \mathrm{M})$ for 24 hours.

\section{RNA isolation and expression}

RNA was isolated from left ventricular tissue using the RNeasy Mini Kit (Qiagen) and stored in $-80^{\circ} \mathrm{C}$. RNA was reverse transcribed into CDNA using the iScript ${ }^{\mathrm{TM}}$ cDNA synthesis kit (BioRad). Real-time quantitative PCR was performed using $\mathrm{iQ}^{\mathrm{Tm}}$ SYBR green supermix (BioRad) and primers designed with Primer Express Software (PE Applied Biosystems, Foster City, CA). Tubulin was used as a housekeeping gene. Primers used are shown in table 3.

Table 2. Functional analysis of Syndecan-1 WT and KO mice

\begin{tabular}{lcccc}
\hline \multicolumn{2}{c}{ Sham } & \multicolumn{2}{c}{14 days Angll } \\
& WT & KO & WT & KO \\
& $n=4$ & $n=5$ & $n=8$ & $n=14$ \\
\hline FS, \% & $30.3 \pm 2.3$ & $29.7 \pm 1.2$ & $21.5 \pm 2.8^{*}$ & $29.6 \pm 2.6 \dagger$ \\
LVIDd, cm & $4.1 \pm 0.1$ & $3.7 \pm 0.1^{*}$ & $4.1 \pm 0.1$ & $3.5 \pm 0.1 \dagger$ \\
LVIDs, cm & $2.8 \pm 0.1$ & $2.7 \pm 0.1$ & $3.2 \pm 0.1$ & $2.5 \pm 0.2 \dagger$ \\
IVSd, cm & $0.93 \pm 0.05$ & $0.9 \pm 0.04$ & $1.09 \pm 0.1$ & $1.11 \pm 0.05^{*}$ \\
LVPWd, cm & $0.92 \pm 0.06$ & $0.9 \pm 0.04$ & $1.1 \pm 0.02^{*}$ & $1.12 \pm 0.06^{*}$ \\
\hline
\end{tabular}

Echocardiographical data obtained at the end of the study. FS, fractional shortening; LVIDd, left ventricular diameter diastole; LVIDs, left ventricular diameter systole; IVSd, intraventricular septum diastole; LVPWd, left ventricular posterior wall diastole.

${ }^{*} P<0.05$ vs corresponding sham or WT sham, $+P<0.05$ vs WT Angll

\section{Western blotting}

Western blotting was performed with the specific antibodies against CTGF, total SMAD3 (Abcam), and phospho-SMAD3 (CST). To ensure equal loading, the same membranes were probed with GAPDH (RDI). Bands were visualized by enhanced chemiluminiscence and quantified by the program Quantity One (Bio Rad).

\section{Statistical Analysis}

The data are expressed as mean \pm SEM. Data are derived from at least 2 different 
experiments performed in triplicate. Statistical analysis was performed using the Student $t$ test. Differences between the groups were considered to be significant when $\mathrm{P} \leq 0.05$.
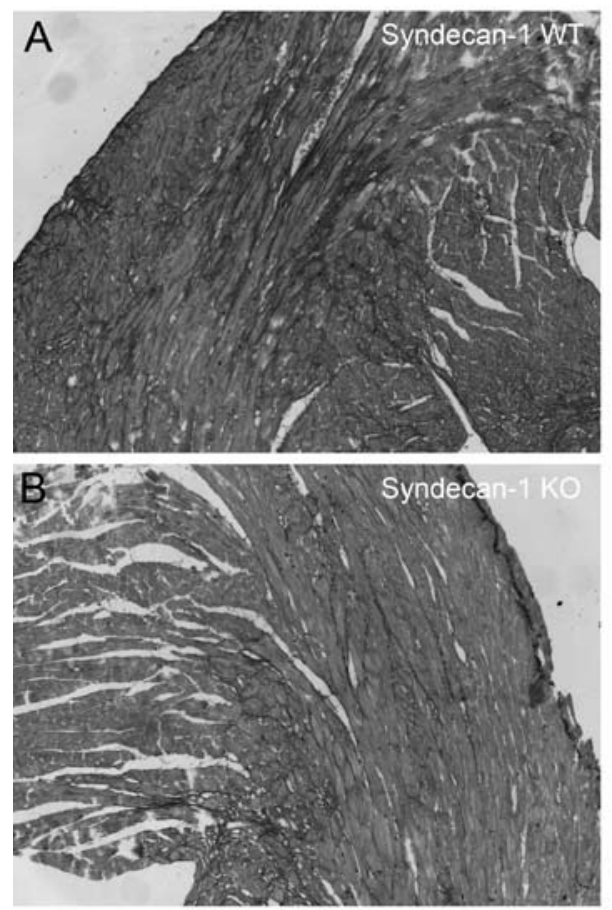

C

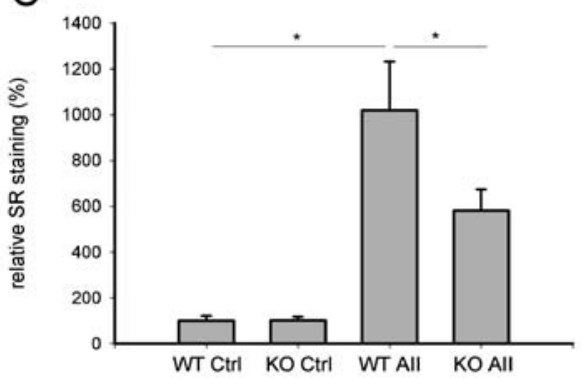

Figure 1. Cardiac fibrosis after Angll treatment is significantly attenuated in Synd $1 \mathrm{KO}$ mice as compared to Synd 1 WT mice. A, representative Sirius Red staining of a Synd 1 WT mouse treated with Angll. $B$, representative Sirius Red staining of a Synd 1 KO mouse treated with Angll. C, Quantification of Sirius Red staining. ${ }^{*} P<0.05, n=4-5$ in sham mice, $n=9-14$ in Angll treated mice.

\section{Results}

\section{Synd1 KO mice are protected against Angll-induced cardiac dysfunction}

To investigate the involvement of Synd1 in Angll-induced cardiac dysfunction, we treated Synd1 WT and KO mice with Angll for 2 weeks. Angll treatment resulted in cardiac hypertrophy in both Synd1 WT and Synd1 KO mice (table 1). 
Echocardiographic analysis at the end of the study revealed a significantly better systolic function in the Synd1 KO mice treated with Angll, as compared to the Angll-treated WT mice (Fractional Shortening, KO; 29,6 2 2.6 vs. WT; $21,5 \pm 2.8, n=8$ 14, $\mathrm{P}<0.05$, table 2).

\section{Cardiac fibrosis is attenuated in Synd1 KO mice after Angll infusion}

Quantification of total collagen with a computer-assisted densitometric analysis showed a significantly increased collagen content after Angll treatment, in both Synd1 KO and WT mice, as compared to placebo treated mice. However, Synd1 KO mice display significantly less collagen then WT mice after Angll treatment (581.1 $\pm 92.2 \%$ vs $1018.3 \pm 214.2 \%$, respectively, $\mathrm{P}<0.05$, SR staining compared to WT sham (100\%), Figure 1). These findings were confirmed by mRNA expression of collagen I, collagen III, and CTGF in the left ventricle, as measured by Q-PCR (Figure 2).

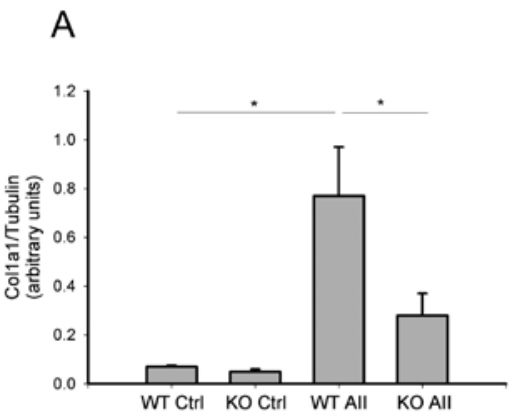

Figure 2. Col1, Col3, and CTGF transcript levels as measured by Q-PCR. A, Quantification of Col1 transcript levels. B, Quantification of $\mathrm{Col} 3$ transcript levels. C, Quantification of CTGF transcript levels. ${ }^{*} P<0.05, n=3$ in sham mice, $n=5-10$ in Angll treated mice.

B

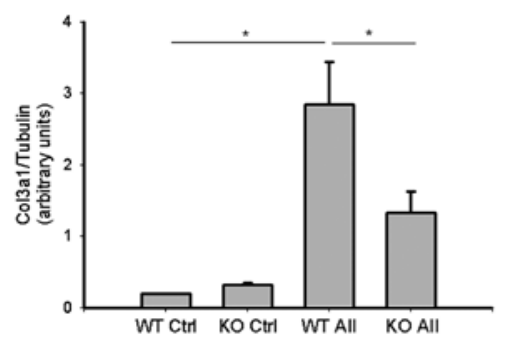

C

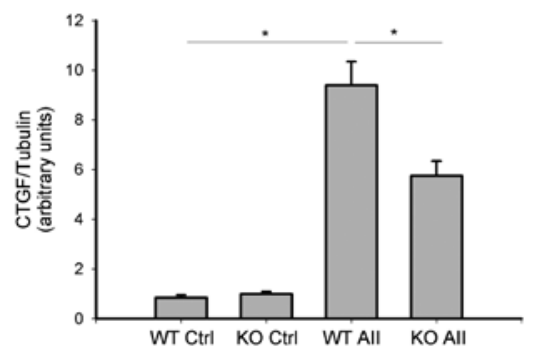




\section{Synd1 is essential for optimal CTGF expression after Angll or TGF $\beta$ stimulation in} cardiac fibroblasts

Since we showed that Synd 1 is important in the development of cardiac fibrosis in vivo, we investigated how Synd1 may influence profibrotic signaling in vitro. Using lentiviral-mediated shRNA against Synd1, we knocked-down Synd1 in cardiac fibroblasts ( $80 \%$ decrease in Synd1 levels, data not shown), and examined the expression of CTGF after Angll or TGFß stimulation. As expected, CTGF expression in cardiac fibroblasts increased after 24 hours of Angll or TGFß in control cells, as shown by Western blotting. This increase in CTGF expression was significantly attenuated by Synd 1 knockdown (Figure 3). In agreement, adenoviral overexpression of Synd 1 exaggerated the expression of CTGF after 24 hours of AngII stimulation, again indicating that Synd1 augments CTGF expression (Figure 5).

Table 3. Primers and ShRNA sequence

\begin{tabular}{lll}
\hline Gene & \multicolumn{1}{c}{ Fw primer 5' $-3^{\prime}$} & Rev primer 5 $^{\prime}-$ 3' $^{\prime}$ \\
\hline Collagen1 & CTTCACCTACAGCACCCTTGTG & CTTGGTGGTTTTGTATTCGATGAC \\
Collagen3 & TCGGAACTGCAGAGACCTAAA & CCCCAGTTTCCATGTTACAGA \\
CTGF & CACAGAGTGGAGCGCCTGTTC & GATGCACTTTTTGCCCTTCTTAATG \\
Tubulin & TGAGGGAAATCGTGCACATC & ATCGCTTATCACCTCCCAGAAC \\
& ShRNA Syndecan-1 & \\
\hline Fw & GACTTCACCTTTGAAACATTTCAAGAGAATGTTTCAAAGGTGAAGTCTTTTTC \\
Rev & TCGAGAAAAAGACTTCACCTTTGAAACATTCTCTTGAAATGTTTCAAAGGTGAAGTC \\
\hline
\end{tabular}

Synd1 modulates SMAD phosphorylation after Angll or TGF $\beta$ treatment in cardiac fibroblasts

Angll and TGFß are known to induce profibrotic signaling by recruiting SMAD signaling ${ }^{16-18}$. Accordingly, Synd1 knockdown and control cardiac fibroblasts were treated with Angll $(1 \mu \mathrm{M})$ or TGFß $(1 \mathrm{ng} / \mathrm{ml})$ for 24 hours, and the effects on SMAD signaling were investigated. Interestingly, loss of Synd1 significantly attenuated the increase in SMAD3 phosphorylation after Angll stimulation (Figure 4A). Also, SMAD3 phosphorylation was significantly attenuated in Synd1 knockdown fibroblasts after 24 hours of TGFß (1ng/ml) (Figure 4B). 
A
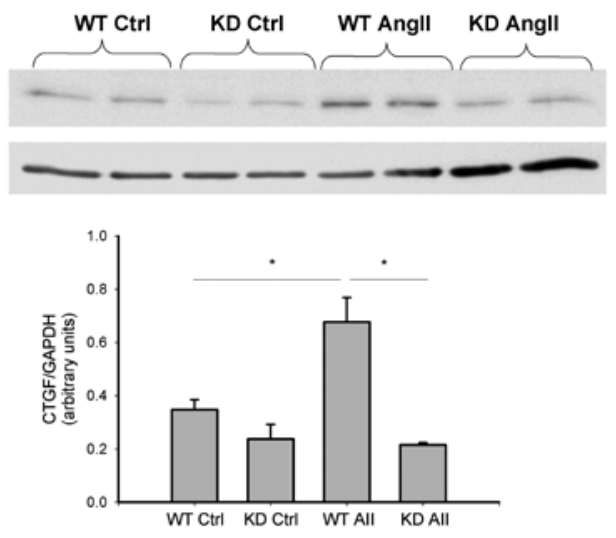

B

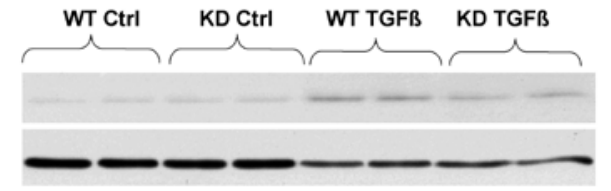

CTGF

GAPDH
Figure 3. Effects of Angll (1 $1 \mu \mathrm{M}$, 24 hours) or TGF $\beta$ (1ng/ml, 24 hours) treatment on CTGF protein expression in Synd1 wild-type (WT), and Synd 1 knockdown (KD) cardiac fibroblasts.

A. representative Western blot showing that CTGF levels are significantly increased after Angll treatment in Synd1 WT cardiac fibroblasts, whereas knockdown of Synd 1 significantly attenuates this increase.

B. representative Western blot showing that CTGF levels are significantly increased after TGF $\beta$ treatment in Synd1 WT cardiac fibroblasts, whereas knockdown of Synd1 significantly attenuates this increase. ${ }^{*} P<0.05, n=3$ per experiment, quantification of 3 experiments.

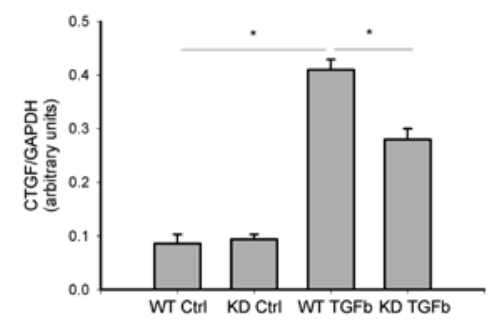

\section{Discussion}

The main finding of this study is that Synd1, a heparan sulfate proteoglycan, is an important amplifier of Angll-mediated cardiac dysfunction and fibrosis. This demonstrates for the first time that Synd 1 is involved in pathological hypertrophic cardiac remodeling. Synd1 KO mice are protected against Angll-induced cardiac dysfunction and cardiac fibrosis, and loss of Synd1 attenuates the effect of Angll on Col1 and CTGF mRNA expression in vivo. In vitro, loss of Synd 1 also attenuated the induction of CTGF by Angll or TGFß. Synd1 seems important to promote SMAD3 signaling as loss of Synd1 reduced the capability of Angll and TGFß to induce phosphorylation of SMAD3, an important pro-fibrotic downstream effector of TGFß signaling. These findings substantiate the idea that Synd1 acts as a coreceptor on the cell membrane. We speculate that Synd1 increases the efficiency for growth factor signaling by recruiting additional growth factors to its relevant receptors, thereby influencing signal transduction. 
A
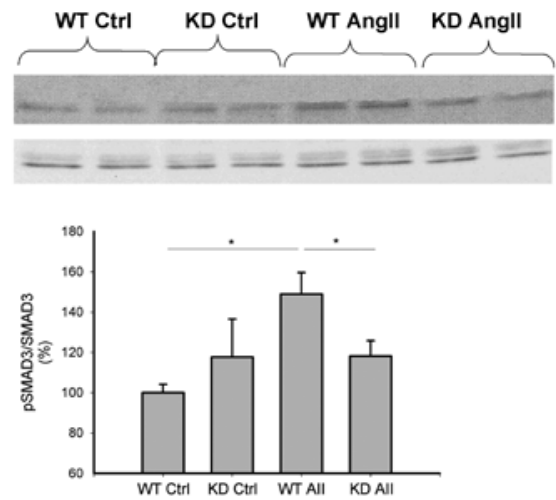

B

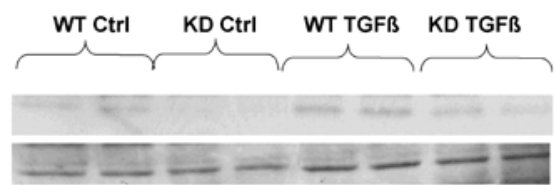

pSMAD3

SMAD3
Figure 4: Effects of Angll ( $1 \mu M, 24$ hours) or TGF $\beta$ (1ng/ml, 24 hours) on SMAD3 phosphorylation in Synd 1 WT and Synd1 $K D$ cardiac fibroblasts.

pSMAD3

SMAD3

A. Representative Western blot showing that SMAD3 phosphorylation levels are significantly increased in Synd1 WT cardiac fibroblasts after Angll treatment, whereas knockdown of Synd 1 significantly attenuates this increase.

B. Representative Western blot showing that SMAD3 phosphorylation levels are significantly increased in Synd 1 WT cardiac fibroblasts after TGF $\beta$ treatment, whereas knockdown of Synd1 significantly attenuates this increase. ${ }^{*} P<0.05, n=3$ per experiment, quantification of 2 experiments.

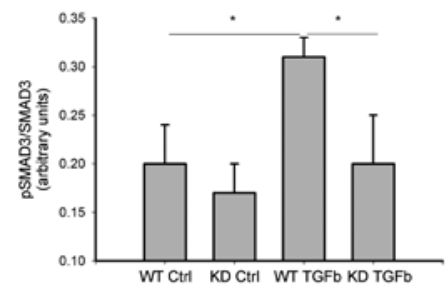

\section{Synd1 amplifies the induction of CTGF}

CTGF is a member of CCN family proteins that induce cell adhesion, migration, proliferation and synthesis of collagen and other ECM proteins ${ }^{19}$. CTGF is over-expressed in various fibrotic disorders such as renal fibrosis, myocardial infarction, and atherosclerosis ${ }^{20,21,22}$. Moreover, it has been shown that CTGF is a crucial regulator of Angll-induced fibrosis ${ }^{4,23}$. In agreement with these reports, we observed an increased CTGF expression in the myocardium of mice treated with Angll, which was paralleled by increased cardiac fibrosis. In vitro, we also confirmed that Angll can effectively induce CTGF expression, as shown previously both in vitro and in vivo ${ }^{4}$. Our study shows that Synd1 has an important role in this effect. In vivo, Angll mediated induction of CTGF is blunted in Synd $1 \mathrm{KO}$ mice. This was paralleled by decreased induction of Col1 and Col3 mRNA by Angll in these Synd $1 \mathrm{KO}$ mice. In vitro, these findings were confirmed as the induction of CTGF by Angll was impaired by knockdown of Synd1. This strongly suggests that Synd1 is important in vivo to enable Angll to recruit CTGF. We also were able to explore how Synd 1 enables the recruitment of CTGF. AngII might recruit CTGF via its ability to 
activate TGFß and concomiting SMAD signaling. We indeed show that Angll and TGFß induced SMAD3 phosphorylation in cultured fibroblasts. Importantly, this induction is decreased by knockdown of Synd1. These findings suggest that Synd1 serves to improve the ability of Angll and TGFß to activate SMAD3, which then can induce the profibrotic molecule CTGF, thereby activating Col1 expression.
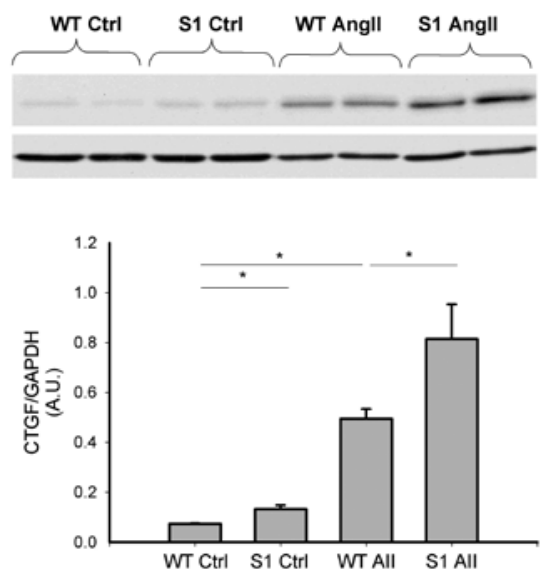

Figure 5: Effects of Angll treatment $(1 \mu \mathrm{M}$, 24 hours) on CTGF expression in Synd1 WT and Synd1 overexpressing cardiac fibroblasts. Representative Western blot showing that CTGF levels are significantly increased in Synd1 WT cardiac fibroblasts, whereas overexpression of Synd1 significantly exaggerates this increase. ${ }^{*} P<0.05, n=3$ per experiment, quantification of 2 experiments.

\section{Role of Synd 1 as a modulator of cell signaling}

Our study shows that Synd 1 has an important role as a mediator of Angll signaling. Syndecans are intriguing molecules, which seem to combine two major properties. Firstly, they contain an extracellular ectodomain with attached glycosaminoglycan (GAG) chains. This extracellular domain can be regarded as a 'sticky' part protruding into the ECM where it may trap signaling molecules and guide them to receptors on the membrane ${ }^{24}$. Secondly they contain a transmembrane domain with a short cytoplasmic tail, which may serve to promote signals directly intracellularly. They therefore seem to be able to act both as matricellular protein in the ECM yet at the same time may also have transmembrane functions ${ }^{25}$. Synd 1 has been shown to regulate bFGF dependent signalling, and, recently, Hayashida et al. showed its involvement in TGFß dependent signalling ${ }^{26,27}$. Also, heparan sulfates are able to regulate Angll-mediated signalling ${ }^{11}$. Our results show that decreased expression of Synd 1 decreases CTGF expression in cardiac fibroblasts after Angll or TGFß stimulation, whereas overexpression of Synd 1 has the opposite effect. Whether this response is dependent on signalling occurring through the cytoplasmic domain of Synd1, or on the Synd1 ectodomain, the 'sticky', extracellular part of Synd1 remains to be elucidated. Increasing ligand-receptor affinity may be a plausible explanation, and it is intuitive to surmise that Synd1 may function to increase the amount of TGFß that is presented at its receptors. TGFß is a profibrotic cytokine that is importantly involved in Angll- induced fibrosis. However, it is possible that 
the effects do not rely on increased TGFß being recruited to its receptors. Recently, Wang et al. showed that Angll may phosphorylate SMAD3 independent of TGFß in vascular smooth muscle cells ${ }^{28}$. Interestingly, our results indicate that absence of Synd1 also influences TGFß-induced CTGF expression, suggesting that Synd1 interferes with Angll-induced cardiac fibrosis by modulating TGFß signaling. In conclusion, the present study is the first to suggest that Synd1 regulates Angllinduced cardiac fibrosis by its ability to enhance profibrotic SMAD signalling culminating in increased levels of profibrotic molecules like CTGF and ultimately in increased expression of collagens. Our findings emphasize the important role of syndecans in modulating cellular signalling, and highlight Synd 1 as a potential target for anti-fibrotic treatments.

\section{References}

1. Weber KT. Extracellular matrix remodeling in heart failure: a role for de novo angiotensin II generation. Circulation. 1997;96:4065-4082.

2. Izumiya Y, Kim S, Izumi Y, Yoshida K, Yoshiyama M, Matsuzawa A, Ichijo $\mathrm{H}$, Iwao $\mathrm{H}$. Apoptosis signal-regulating kinase 1 plays a pivotal role in angiotensin II-induced cardiac hypertrophy and remodeling. Circ Res. 2003;93:874-883.

3. De Boer RA, Pokharel S, Flesch M, Van Kampen DA, Suurmeijer AJ, Boomsma F, Van Gilst WH, Van Veldhuisen DJ, Pinto YM. Extracellular signal regulated kinase and SMAD signaling both mediate the angiotensin II driven progression towards overt heart failure in homozygous TGR(mRen2)27. J Mol Med. 2004.

4. Ruperez M, Lorenzo O, Blanco-Colio LM, Esteban V, Egido J, Ruiz-Ortega M. Connective tissue growth factor is a mediator of angiotensin II-induced fibrosis. Circulation. 2003;108:1499-1505.

5. Chen K, Mehta JL, Li D, Joseph L, Joseph J. Transforming growth factor beta receptor endoglin is expressed in cardiac fibroblasts and modulates profibrogenic actions of angiotensin II. Circ Res. 2004;95:1167-1173.

6. Pinto YM, Pinto-Sietsma SJ, Philipp T, Engler S, Kossamehl P, Hocher B, Marquardt H, Sethmann S, Lauster R, Merker HJ, Paul M. Reduction in left ventricular messenger RNA for transforming growth factor beta(1) attenuates left ventricular fibrosis and improves survival without lowering blood pressure in the hypertensive TGR(mRen2)27 Rat. Hypertension. 2000;36:747-754.

7. Woods A. Syndecans: transmembrane modulators of adhesion and matrix assembly. J Clin Invest. 2001;107:935-941.

8. Volk R, Schwartz JJ, Li J, Rosenberg RD, Simons M. The role of syndecan cytoplasmic domain in basic fibroblast growth factor-dependent signal 
transduction. J Biol Chem. 1999;274:24417-24424.

9. Chen L, Klass C, Woods A. Syndecan-2 regulates transforming growth factor-beta signaling. J Biol Chem. 2004;279:15715-15718.

10. Tkachenko E, Rhodes JM, Simons M. Syndecans: new kids on the signaling block. Circ Res. 2005;96:488-500.

11. Koppel H, Yard BA, Christ M, Wehling M, van der Woude FJ. Modulation of angiotensin II-mediated signalling by heparan sulphate glycosaminoglycans. Nephrol Dial Transplant. 2003;18:2240-2247.

12. Schellings MW, Baumann M, van Leeuwen RE, Duisters RF, Janssen $\mathrm{SH}$, Schroen B, Peutz-Kootstra CJ, Heymans S, Pinto YM. Imatinib attenuates end-organ damage in hypertensive homozygous TGR(mRen2)27 rats. Hypertension. 2006;47:467-474.

13. Ammarguellat F, Larouche II, Schiffrin EL. Myocardial Fibrosis in DOCASalt Hypertensive Rats : Effect of Endothelin ET(A) Receptor Antagonism. Circulation. 2001;103:319-324.

14. Rubinson DA, Dillon CP, Kwiatkowski AV, Sievers C, Yang L, Kopinja J, Rooney DL, Ihrig MM, McManus MT, Gertler FB, Scott ML, Van Parijs L. A lentivirusbased system to functionally silence genes in primary mammalian cells, stem cells and transgenic mice by RNA interference. Nat Genet. 2003;33:401-406.

15. Vanhoutte D, Schellings MW, Gotte M, Swinnen M, Herias V, Wild MK, Vestweber D, Chorianopoulos E, Cortes V, Rigotti A, Stepp MA, Van de Werf F, Carmeliet P, Pinto YM, Heymans S. Increased expression of syndecan1 protects against cardiac dilatation and dysfunction after myocardial infarction. Circulation. 2007;115:475-482.

16. Hao J, Wang B, Jones SC, Jassal DS, Dixon IM. Interaction between angiotensin II and Smad proteins in fibroblasts in failing heart and in vitro. Am J Physiol Heart Circ Physiol. 2000;279:H3020-3030.

17. Schroder D, Heger J, Piper HM, Euler G. Angiotensin II stimulates apoptosis via TGF-beta1 signaling in ventricular cardiomyocytes of rat. J Mol Med. 2006;84:975-983.

18. Pokharel S, van Geel PP, Sharma UC, Cleutjens JP, Bohnemeier H, Tian XL, Schunkert H, Crijns HJ, Paul M, Pinto YM. Increased myocardial collagen content in transgenic rats overexpressing cardiac angiotensin-converting enzyme is related to enhanced breakdown of $\mathrm{N}$-acetyl-Ser-Asp-Lys-Pro and increased phosphorylation of Smad2/3. Circulation. 2004;110:31293135.

19. Brigstock DR. The CCN family: a new stimulus package. J Endocrinol. 2003;178:169-175.

20. Ito Y, Goldschmeding R, Bende R, Claessen N, Chand M, Kleij L, Rabelink T, Weening J, Aten J. Kinetics of connective tissue growth factor expression 
during experimental proliferative glomerulonephritis. J Am Soc Nephrol. 2001;12:472-484.

21. Ito Y, Aten J, Bende RJ, Oemar BS, Rabelink TJ, Weening JJ, Goldschmeding R. Expression of connective tissue growth factor in human renal fibrosis. Kidney Int. 1998;53:853-861.

22. Oemar BS, Werner A, Garnier JM, Do DD, Godoy N, Nauck M, Marz W, Rupp J, Pech M, Luscher TF. Human connective tissue growth factor is expressed in advanced atherosclerotic lesions. Circulation. 1997;95:831-839.

23. Ahmed MS, Oie E, Vinge LE, Yndestad A, Oystein Andersen G, Andersson $\mathrm{Y}$, Attramadal T, Attramadal $\mathrm{H}$. Connective tissue growth factor--a novel mediator of angiotensin II-stimulated cardiac fibroblast activation in heart failure in rats. J Mol Cell Cardiol. 2004;36:393-404.

24. Filla MS, Dam P, Rapraeger AC. The cell surface proteoglycan syndecan-1 mediates fibroblast growth factor-2 binding and activity. J Cell Physiol. 1998;174:310-321.

25. Carey DJ. Syndecans: multifunctional cell-surface co-receptors. Biochem J. 1997;327 ( Pt 1):1-16.

26. Kato $M$, Wang $H$, Kainulainen V, Fitzgerald ML, Ledbetter S, Ornitz DM, Bernfield $M$. Physiological degradation converts the soluble syndecan-1 ectodomain from an inhibitor to a potent activator of FGF-2. Nat Med. 1998;4:691-697.

27. Hayashida K, Johnston DR, Goldberger O, Park PW. Syndecan-1 expression in epithelial cells is induced by TGFbeta through a PKA-dependent pathway. J Biol Chem. 2006.

28. Wang W, Huang XR, Canlas E, Oka K, Truong LD, Deng C, Bhowmick NA, Ju W, Bottinger EP, Lan HY. Essential role of Smad3 in angiotensin II-induced vascular fibrosis. Circ Res. 2006;98:1032-1039. 


\section{Chapter 6}

\section{Imatinib attenuates end-organ damage in hypertensive homozygous TGR(mRen2)27 rats}

Mark WM Schellings*, Marcus Baumann*, Rick EW van Leeuwen, Rudy FJJ Duisters, Suzanne HP Janssen, Blanche Schroen, Carine J Peutz-Kootstra, Stephane Heymans, Yigal M Pinto

Hypertension

2006;47:467-474 


\section{Abstract}

Imatinib specifically inhibits receptor tyrosine kinase signaling and is clinically used to treat leukemia. Receptor tyrosine kinases not only mediate tumour growth, but also initiate adverse signaling in heart failure. We investigated whether imatinib, by inhibiting the platelet-derived growth factor receptor- $\beta$ (PDGFRß), prevents cardiac and renal damage in TGR(mRen2)27 (Ren2) rats.

Eight-week-old male homozygous Ren2 and Sprague Dawley rats were treated either with imatinib (30 mg/kg; STI-571) or placebo for 8 weeks (Ren2 $n=12$ for each group; Sprague Dawley $\mathrm{n}=6$ for each group). Imatinib did not affect blood pressure or left ventricular (LV) hypertrophy in both groups. Imatinib attenuated the decline in fractional shortening (imatinib versus Ren 2 placebo $45 \pm 4.5 \%$ versus $32 \pm 3 \% ; \mathrm{n}=7-11, \mathrm{P}<0.05$ ) and in diastolic function in Ren2 rats (baseline diastolic $\mathrm{dP} / \mathrm{dt}$ corrected for systolic blood pressure Ren2 imatinib versus Ren2 placebo, $38.6 \pm 0.67$ versus $35.3 \pm 0.41[1 \cdot s-1] ; n=7-11 ; P<0.05)$. This was associated with decreased cardiac fibrosis and decreased activation of PDGFRß and extracellular signal-regulated kinase 1/2. Renal microvascular hypertrophy and perivascular fibrosis in Ren2 rats were significantly decreased by imatinib. In vitro, imatinib blocked angiotensin II-induced activation of the PDGFRß and significantly decreased fibroblast proliferation and collagen production.

In conclusion, imatinib did not affect LV hypertrophy but attenuated the decline in cardiac function and reduced renal microvascular damage associated with reduced activation of the PDGFRß. The simultaneous improvement in both heart and kidneys suggests that inhibition of the PDGFRß has broad protective effects that may provide novel avenues for a blood pressure-independent protection against end-organ damage.

Keywords: End organ damage, PDGF receptor, angiotensin II, hypertrophy, fibrosis 


\section{Introduction}

Angiotensin II (AngII) mediated hypertension causes end-organ damage not only via increased blood pressure, but also via the direct effects of Angll. Angll is known to play a crucial role in the development of cardiomyocyte hypertrophy ${ }^{1,2}$ and interstitial cardiac fibrosis ${ }^{3,4}$, and sustained increases of Angll result in severe left ventricular (LV) dysfunction ${ }^{5-7}$. We have shown that the homozygous hypertensive TGR(mRen2)27 (Ren2) rat, a model of Angll-driven hypertension, develops accelerated heart failure accompanied by severe LV dysfunction and cardiac collagen accumulation ${ }^{8,9}$. Angll-mediated cardiac hypertrophy in Ren2 rats is associated with increased extracellular signal-regulated kinase (ERK) and Smad signaling ${ }^{7}$. ERK1/2 is an important downstream target of receptor tyrosine kinases, like the epidermal growth factor receptor (EGFR) and the platelet -derived growth factor receptors (PDGFRs). Recently, Angll-mediated transactivation of these receptor tyrosine kinases has gained much interest ${ }^{10}$, and we demonstrated that inhibition of the EGFR attenuates ERK1/2 activation in the Ren2 rat, which was paralleled by decreased cardiac fibrosis ${ }^{7}$. Imatinib mesylate (Gleevec), a specific tyrosine kinase inhibitor, is a novel, orally active drug used to treat chronic myeloid leukaemia ${ }^{11}$. Imatinib blocks the continuously increased tyrosine kinase activity of bcr/abl. Bcr/abl is a fusion protein resulting from a translocation between chromosome 9 and 22, which is the causative gene defect in chronic myeloid leukemia. However, imatinib blocks other tyrosine kinases as well, including the tyrosine kinase activity of the PDGFR $\alpha$, PDGFRß, and c-kit ${ }^{11}$. We therefore hypothesized that imatinib-mediated inhibition of PDGFRß tyrosine kinase activity may attenuate downstream ERK1/2 activation, thereby protecting against the direct adverse effects of Angll such as cardiac and renal fibrosis or dysfunction. The present study reveals that imatinib treatment in Ren2 rats protected against adverse cardiac and renal remodelling and dysfunction, associated with a decrease in PDGFRß phosphorylation and ERK1/2 activation. In concordance, administration of imatinib in vitro decreased collagen production and proliferation of cardiac fibroblasts and attenuated Angll-induced PDGFRß phosphorylation. In conclusion, imatinib treatment might provide a novel therapeutic tool to protect against cardiac dysfunction during Angll-mediated hypertension.

\section{Material and Methods}

\section{Drug Treatment}

Homozygous Ren2 and Sprague Dawley rats were purchased from the Moellegaard Breeding Company, Ry, Denmark. All described study protocols were approved by the animal care and use committee of the Universiteit Maastricht and were performed according to the official rules formulated in the Dutch law on care 
and use of experimental animals. At 8 weeks of age, 24 male Ren 2 rats and 12 nontransgenic Sprague Dawley rats were randomly assigned to receive placebo treatment (distilled water) or imatinib dissolved in distilled water (Novartis pharmaceuticals; $30 \mathrm{mg} / \mathrm{kg} /$ day; Ren2 $\mathrm{n}=12$; Sprague Dawley $\mathrm{n}=6$ per group). Daily treatment via oral gavage started at the age of 8 weeks and continued until the age of 16 weeks.

\section{Echocardiographical Analysis}

After sedation with $2 \%$ isoflurane, echocardiographical measurements were performed at day -1 (age 8 weeks), day 28 (age 12 weeks), and day 56 (age 16 weeks, end study). Standard views were obtained in 2D as well as M-mode by transthoracic echocardiography with a 12-MHz transducer (Hewlett Packard) on a Sonos 5500 (Hewlett Packard) echocardiograph.

Table 1. General Characteristics

\begin{tabular}{|c|c|c|c|c|}
\hline Parameter & SD pl & SD ima & R2 pl & R2 ima \\
\hline Body Weight, gr. & $452 \pm 14$ & $405 \pm 21$ & $319 \pm 14^{*} \ddagger$ & $325 \pm 12 * \ddagger$ \\
\hline LVW/Tibia Length & $25 \pm 0.5$ & $27 \pm 1.8$ & $33 \pm 1.3^{*} \ddagger$ & $34 \pm 1.4^{*} \ddagger$ \\
\hline Heart Rate, bpm & $297 \pm 18$ & $315 \pm 27$ & $304 \pm 10$ & $340 \pm 5$ \\
\hline Fractional Shortening, \% & $39 \pm 1.9$ & $44.5 \pm 1.7$ & $32.4 \pm 3 \ddagger$ & $45.1 \pm 4.5 \dagger$ \\
\hline Ejection Fraction, \% & $74.2 \pm 2.4$ & $80.5 \pm 1.7$ & $64.1 \pm 4.8 \ddagger$ & $79.4 \pm 3.9 \dagger$ \\
\hline + Dp/Dt / Sys & $47.7 \pm 5.4$ & $69.7 \pm 10.3$ & $57.6 \pm 0.94$ & $53.6 \pm 1.3$ \\
\hline - Dp/Dt / Sys & $52.8 \pm 5.8$ & $53.4 \pm 0.82$ & $35.3 \pm 0.41 * \ddagger$ & $38.6 \pm 0.67^{* \dagger \ddagger}$ \\
\hline
\end{tabular}

General characteristics of the rats at the end of the study (16 wks of age). ${ }^{*} P<0.05$ vs. SD pl, $+P<0.05 R 2 p /$ vs $R 2$ ima, $\neq$ $P<0.05$ vs Sprague Dawley ima; $n=4-6$ (Sprague Dawley); $n=7-11$ (Ren2).

\section{Functional Assessments}

Rats were anesthetized with urethane $(1,5 \mathrm{~g} / \mathrm{kg} \mathrm{IP})$ at 16 weeks. The right carotid artery was cannulated with a $2 \mathrm{~F}$ Millar microtip catheter and advanced into the left ventricle. The data were amplified, digitally stored and analyzed with IdeeO (IDEE; Maastricht University). The 0-pressure baseline was obtained by placing the pressure sensor in $37^{\circ} \mathrm{C}$ water before measurements. After a period of stabilization, maximal LV systolic pressure, diastolic pressure, and heart rate were recorded. The systolic $\mathrm{dP} / \mathrm{dt}$ and diastolic $\mathrm{dP} / \mathrm{dt}$ were corrected for peak systolic LV pressure and used as indices of contraction and relaxation. 
Figure 1

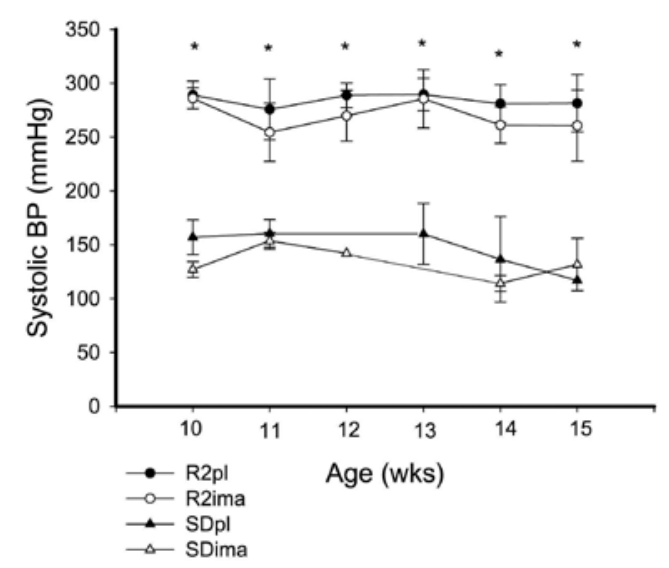

Figure 1. Systolic blood pressure. Homozygous Ren 2 rats show severe hypertension throughout the study as measured by tail-cuff. Imatinib treatment did not affect systolic blood pressure. ${ }^{*} P<0.05$, Ren 2 groups vs Sprague Dawley groups, $n=3-6$.

\section{Histological Analysis}

Rats were euthanized at 16 weeks. After perfusion with PBS, hearts and kidneys were taken out and prepared for further histological analysis. One half transverse midsection of the left ventricle and renal tissue were immersed in $1 \%$ paraformaldehyde for 4 to 6 hours, washed 3 times with PBS, and placed in 70\% ethanol for 24 hours, after which it was embedded in paraffin. LV sections were cut at $6 \mu \mathrm{m}$ and stained with Sirius Red to visualize collagen ${ }^{12}$. LV interstitial collagen was quantified by computerized planimetry. Transversal renal sections of $2 \mu \mathrm{m}$ were cut for investigation of glomerulosclerosis using periodic acid staining. Renal sections were cut at $4 \mu \mathrm{m}$ and stained with $\alpha$-smooth muscle actin and Sirius Red to investigate the renal microcirculation and to stain for collagen. The percentage of glomeruli that exhibited focal or global glomerulosclerosis was determined as described previously ${ }^{13}$. Tubulointerstitial injury was defined as inflammatory cell infiltrates, tubular dilation or atrophy, or interstitial fibrosis. Injury was graded according to Shih et $\mathrm{al}^{14}$ on a scale of 0 to 4 (0 normal; 0.5 small focal areas of damage; 1 involvement of $<10 \%$ of the cortex; 2 involvement of 10 to $25 \%$ of the cortex; 3 involvement of 25 to $75 \%$ of the cortex; 4 extensive damage involving $>75 \%$ of the cortex).

\section{Protein Isolation, Western Blotting, and Immunoprecipitation}

Protein was isolated after grinding frozen heart tissue with radioimmunoprecipitation assay (RIPA) buffer containing PBS, pH 7.4, Igepal (1\%), deoxycholic acid (0.5\%), sodium dodecyl sulfate (1\%), 2-mercapto-ethanol, and complete protease inhibitor tabs (Roche Diagnostics). 
Western blotting ${ }^{15}$ was performed on cultured fibroblasts to identify pPDGFRß ${ }^{751}$ PDGFRß, PEGFR ${ }^{1068}$, and EGFR (CST). Tyrosine phosphorylation state of PDGFRß (CST) and ERK1/2 (CST) in the heart homogenates was assessed by immunoprecipitation with an immobilized phosphotyrosine antibody (CST).

Protein samples were incubated with an immobilized phosphotyrosine antibody (1:10) at 4 -C overnight. Subsequently, the samples were centrifuged at $2000 \mathrm{rpm}$, $4^{\circ} \mathrm{C}$, and washed 3 times with RIPA buffer. Finally, the samples were prepared for Western blotting.

\section{Cell Culture}

DMEM and FBS were purchased from GIBCO BRL. Culture plates were obtained from Costar. Cardiac fibroblasts were isolated from 2-day-old neonatal Lewis rats. All the experiments were performed on cells from the second passage. Cells were maintained in DMEM supplemented with $10 \%$ FBS along with $0.1 \%$ gentamycin, incubated at $37^{\circ} \mathrm{C}$ in a humidified chamber, and grown to confluence, before synchronization in low-serum medium (0.1\% FBS) 48 hours before the experiments. For DNA synthesis determination, cells were put on high ( $10 \% \mathrm{FBS})$ or left on low (0.1\% FBS) serum for 24 hours after 30 minutes pretreatment with increased concentrations of imatinib (0 to $10 \mu \mathrm{mol} / \mathrm{L}$ ). Synthesis of DNA was assessed by radiolabeled $\left[{ }^{3} \mathrm{H}\right]$ thymidine incorporation assay. For collagen synthesis determination, cells were treated with imatinib (control 1 and $10 \mu \mathrm{mol} / \mathrm{L}$ ) for 24 hours. Hereafter, $\left[{ }^{3} \mathrm{H}\right]$ proline was added for 48 hours. The incorporated $\left[{ }^{3} \mathrm{H}\right]$ proline was corrected for cell density by dividing the radioactivity in disintegrations per minute by the total amount of cellular proteins.

For transactivation experiments, cardiac fibroblasts were treated with imatinib or placebo 30 minutes before the addition of Angll $(1 \mu \mathrm{mol} / \mathrm{L})$, PDGF-BB $(20 \mathrm{ng} / \mathrm{mL})$ or EGF $(10 \mathrm{ng} / \mathrm{mL})$. One minute or 10 minutes after growth factor stimulation, cells were harvested and prepared for Western blotting.

\section{Statistical analysis}

Data are presented as means \pm S.E.M. Statistical analysis was performed using paired and unpaired Student $t$ test. 
Figure 2

\section{A}

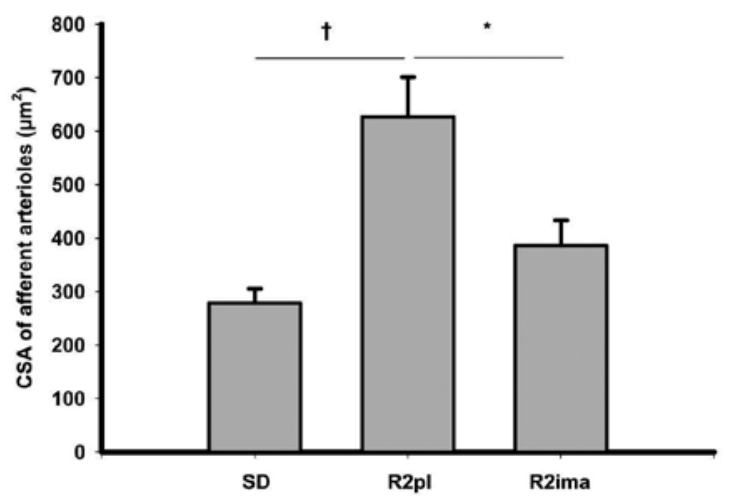

B

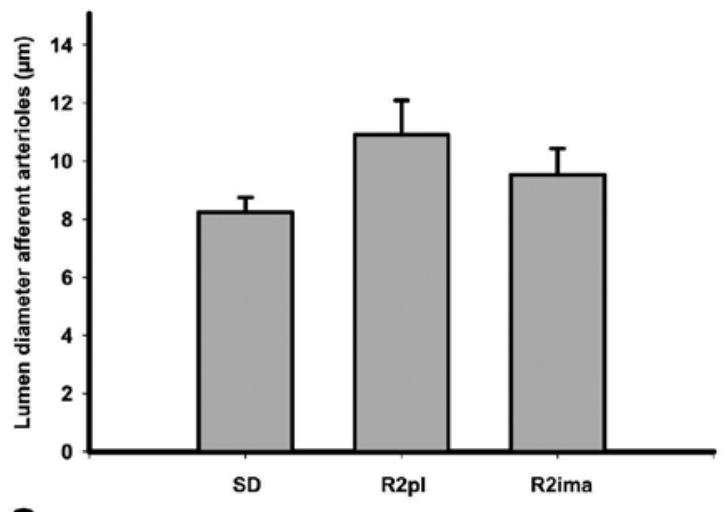

C

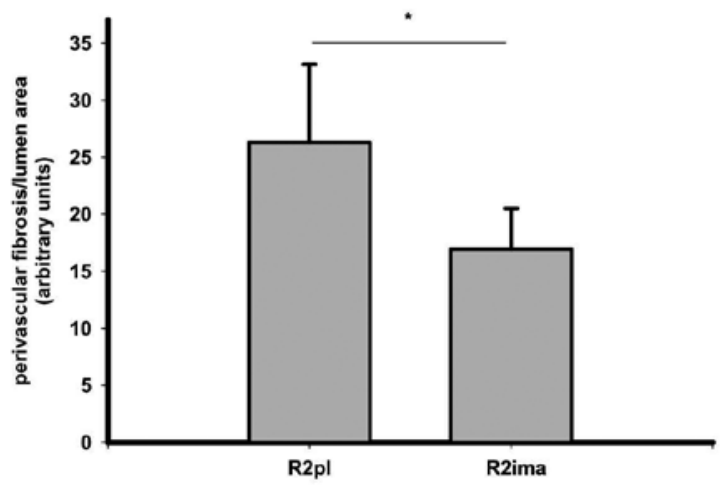

Figure 2. Effect of imatinib treatment on afferent arterioles cross sectional area, lumen and perivascular fibrosis.

A. Quantification of medial crosssectional area of afferent arterioles in Sprague Dawley, untreated and imatinib treated Ren2 rats. Imatinib treatment reversed media hypertrophy in homozygous Ren 2 rats. ${ }^{*} P<0.01 ;+P<0.001 ; n=7$.

B. Lumen diameter of afferent arterioles in Sprague Dawley, untreated, and imatinib-treated Ren2 rats shows no significant differences.

c. Imatinib treatment decreased perivascular fibrosis of afferent arterioles correlated with their lumen diameter in Ren 2 rats. ${ }^{*} P<0.01$. 


\section{Results}

Imatinib does not lower blood pressure but improves hemodynamics in the Ren2 rat After 8 weeks of treatment, body weight was significantly lower in the Ren 2 groups compared with the Sprague Dawley groups, but imatinib did not significantly alter body weight (Table). LV to body weight ratio was significantly increased in Ren2 rats compared with Sprague Dawley rats and was not altered by imatinib (Table). Ren 2 rats had severely elevated blood pressures. Imatinib did not affect systolic blood pressure (Figure 1).

To assess cardiac function of the rats during the study, we performed echocardiography as described above. In placebo-treated rats, fractional shortening decreased significantly. Imatinib significantly attenuated this decrease (Table). After 8 weeks of treatment, baseline diastolic dP/dt was significantly higher in imatinib treated Ren 2 rats compared to placebo-treated Ren 2 rats (Table). Imatinib treatment had no significant effects in Sprague Dawley rats (Table).

\section{Imatinib decreases cardiac interstitial fibrosis in Ren2 rats}

Heart sections were stained with Sirius Red to visualize total collagen. Quantification of myocardial collagen with a computer-assisted densitometric analysis revealed a significant decrease in interstitial collagen content in Ren 2 rats treated with imatinib compared with placebo-treated Ren 2 rats $(4.6 \pm 0.3 \%$ versus $5.5 \pm 0.3 \%$, respectively; $P<0.05)$.

\section{Imatinib decreases renal microcirculatory changes in Ren2 rats}

Renal afferent arterioles of Ren2 rats showed significant thickening of the vascular wall and a nonsignificant tendency toward a larger lumen (Figure 2). Imatinib fully prevented vascular thickening and normalized vascular thickness. Perivascular collagen was markedly increased in afferent arterioles of untreated rats, which was significantly decreased by imatinib treatment (Figures 2 and 3 ). 


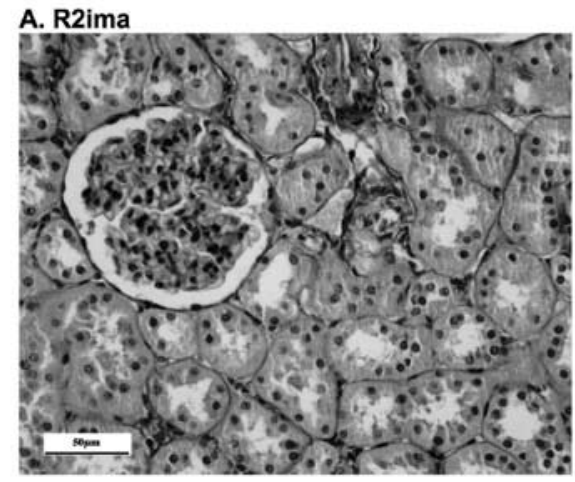

Figure 3. Decreased perivascular fibrosis and renal damage in Ren 2 rats treated with imatinib.

A. Representative Sirius Red staining of an imatinib-treated Ren 2 rat. B. Representative Sirius Red staining of a placebotreated Ren2 rat.

\section{B. R2pl}

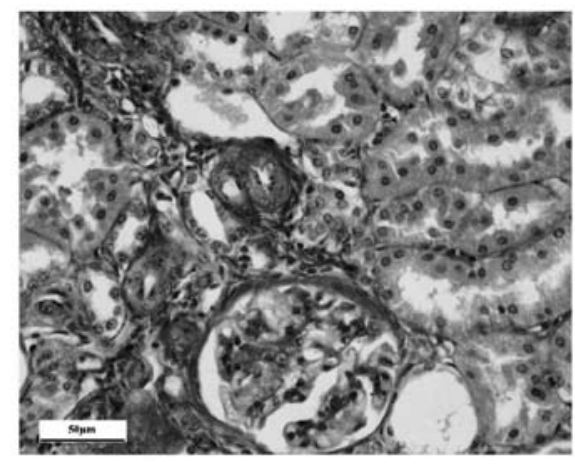

\section{Imatinib attenuates glomerular and tubular damage in Ren-2 rats}

Tubular atrophy was markedly attenuated by imatinib $(1.7 \pm 0.4$ R2pl versus $0.8 \pm 0.3$ R2ima; $n=7 ; P<0.05)$, whereas glomerulosclerosis index decreased nonsignificantly (0.6 \pm 0.2 R2pl versus $0.3 \pm 0.1$ R2ima) after imatinib in Ren2 rats (Figure 3). Glomeruli of Ren2 rats showed a slightly increased mesenchymal damage as semiquantitatively investigated, which was downregulated towards control level in imatinib-treated rats (0.5 $\pm 0.1 \mathrm{R} 2 \mathrm{pl}$ versus $0.3 \pm 0.1 \mathrm{R} 2 \mathrm{ima} ; \mathrm{n}=7$; $\mathrm{P}<0.05$; Figure 3 ).

Imatinib decreases cardiac fibroblast collagen production and proliferation in vitro Collagen production by cardiac fibroblasts, measured by $\left[{ }^{3} \mathrm{H}\right]$ proline incorporation, was significantly reduced by imatinib (Figure 4A).

Proliferation of neonatal rat cardiac fibroblasts on $10 \%$ FBS was dose-dependently inhibited by imatinib as determined by $\left[{ }^{3} \mathrm{H}\right]$ thymidine incorporation (Figure $4 \mathrm{~B}$, black bars). Proliferation of neonatal rat cardiac fibroblasts on $0.1 \%$ FBS was significantly inhibited by 0.1 to $10 \mu \mathrm{mol} / \mathrm{L}$ imatinib (Figure 4B, grey bars). 
Figure 4

A

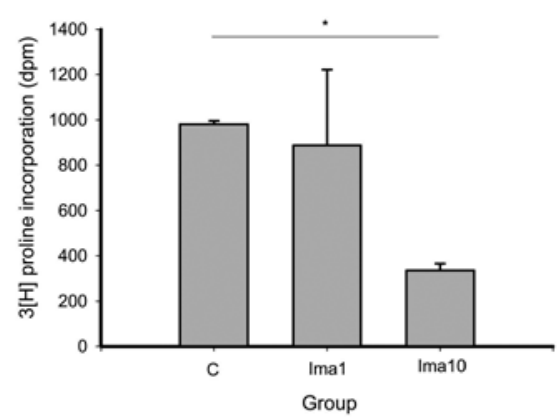

B

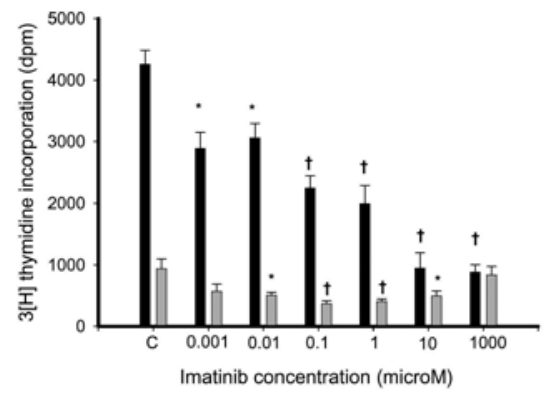

Figure 4. Effects of imatinib on DNA and collagen synthesis in cultured cardiac fibroblasts.

\begin{abstract}
A, synchronised cardiac fibroblasts were treated with imatinib (1 to $10 \mathrm{\mu mol} / \mathrm{L}$ ), and [3H]proline was added for 48 hours followed by scintillation counting. Untreated cells were used as controls. ${ }^{*} P<0.05$ vs control; $n=3$.

B, Synchronised cardiac fibroblasts were treated with imatinib (0.001 to $1000 \mu \mathrm{mol} / \mathrm{L})$ for 24 hours, and DNA synthesis was assessed with [3H]thymidine incorporation followed by scintillation counting. (black bars $10 \%$ FBS; grey bars $0.1 \% F B S){ }^{*} P<0.01,+P<0.001$ vs. control; $n=6$.
\end{abstract}

\section{Imatinib attenuates PDGFR signaling}

To assess the phosphorylation state of the PDGFRß and its downstream signaling protein ERK1/2 in LV homogenates, we immunoprecipitated proteins phosphorylated on their tyrosine residues and then immunoblotted for the PDGFRß and for ERK1/2. Phosphorylation of the PDGFRß was increased in Ren2 rats, but was significantly blunted by imatinib treatment (Figure 5A). Activation of ERK1/2 is dependent on threonine and tyrosine phosphorylation. Imatinib reduced tyrosine phosphorylation of ERK1/2, a downstream signaling protein in the PDGF pathway (Figure 5B). 
Figure 5

A
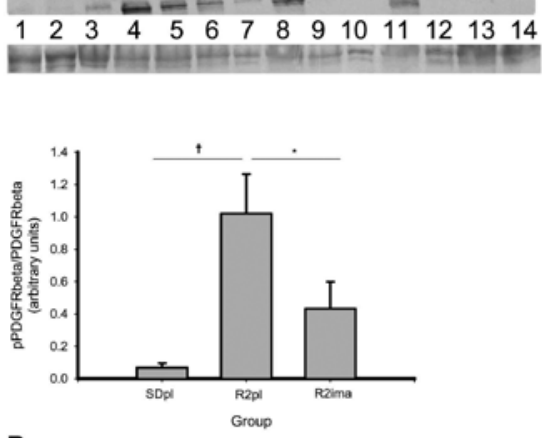

B

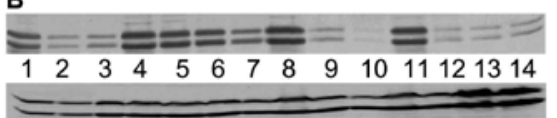

IP: pTyr WB: PDGFR $\beta$ WB: PDGFR $\beta$

IP: pTyr WB: ERK $1 / 2$ WB: ERK $1 / 2$
Figure 5. Effects of imatinib treatment on tyrosine phosphorylation levels of PDGFRß and ERK1/2 in Ren 2 rats. Tyrosine phosphorylation levels of PDGFR $\beta$ and ERK1/2 are increased in Ren2 rats compared with Sprague Dawley rats. Imatinib treatment decreased the tyrosine phosphorylation levels of PDGFRß and ERK1/2 in Ren 2 rats. A. Top, Representative blots showing tyrosine phosphorylation state of PDGFRß in Sprague Dawley (lanes 1 and 2), untreated (lanes 3 through 8), and imatinib-treated (lanes 9 through 14) Ren2 rats. Bottom, Quantification of blots from 2 experiments, corrected for total PDGFR $\beta$ ${ }^{*} P<0.05 ; \quad t P<0.01$. B. Top, Representative blots showing tyrosine phosphorylation state of ERK1/2 in Sprague Dawley (lanes 1 and 2), untreated (lanes 3 through 8), and imatinib-treated (lanes 9 through 14) Ren2 rats. Bottom, Ouantification of blots from 2 experiments, corrected for total ERK1/2, ${ }^{*} P<0.05$. WB indicates Western blot.

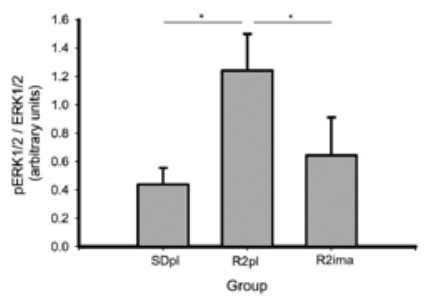

\section{Imatinib inhibits transactivation of receptor tyrosine kinases}

We examined whether phosphorylation of the PDGFRß or EGFR is increased in cardiac fibroblasts treated with Angll, PDGF-BB or EGF. Angll treatment for 1 minute resulted in both PDGFRß and EGFR phosphorylation, with imatinib only inhibiting PDGFRß phosphorylation (Figure 6A and 6B). Ten minutes of PDGF-BB treatment resulted in a marked increase in both PDGFRß and EGFR phosphorylation. In contrast, EGF treatment only activated the EGFR, but not the PDGFRß. Imatinib inhibited the PDGF-BB induced effects, but not the EGF induced phosphorylation of the EGFR (Figures 6C through 6F).

\section{Discussion}

The present study reveals that imatinib (Gleevec), a tyrosine kinase receptor blocker used to treat leukemia, attenuates the loss of cardiac function in a model of Angll-driven hypertensive LV hypertrophy. Furthermore, imatinib improved renal microvascular damage in these hypertensive homozygous Ren2 rats. This 
confirms that inhibition of growth factor signaling, such as specifically provided by imatinib, might represent a novel therapy to protect against cardiac and renal dysfunction in Angll-mediated hypertension.

Imatinib attenuated the loss of cardiac function in Ren2 rats as measured by echocardiography and direct LV pressure measurements. Furthermore, imatinib attenuated the accumulation of interstitial collagen in the heart and the kidney, reversed renal microvascular hypertrophy, and markedly reduced perivascular fibrosis in the renal microcirculation. To a smaller degree glomerular, and, in particular, mesenchymal and tubular, damage were attenuated by imatinib. The improvement in cardiac function and architecture in imatinib-treated Ren2 rats was associated with decreased cardiac PDGFRß-ERK1/2 signals. Apart from a general decreased collagen content in the heart, we were further able to distinguish an effect on renal perivascular collagen content, which may imply vascular localized action of imatinib. These in vivo findings were corroborated by the action of imatinib in vitro on fibroblasts where it inhibited collagen production and fibroblast proliferation. These findings substantiate the idea that targeted inhibition of growth factor systems, in particular tyrosine kinase inhibition, may have beneficial effects in hypertensive cardiac and renal damage ${ }^{16}$. 
Figure 6

A
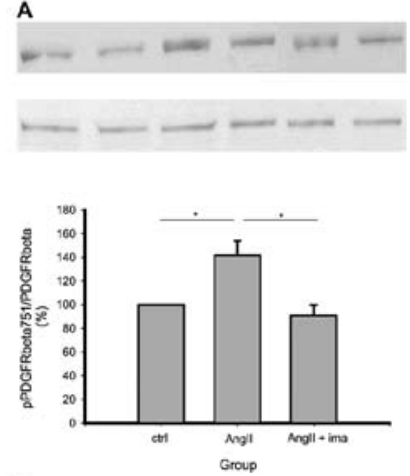

B
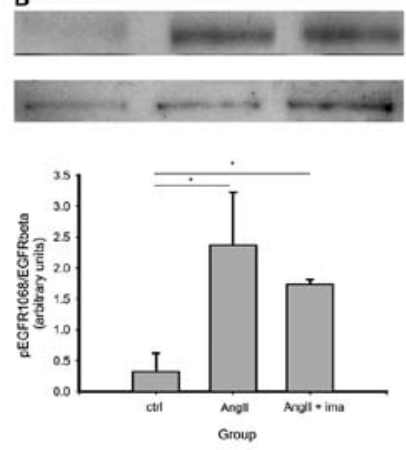

E

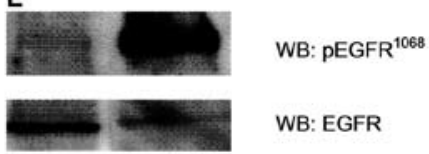

C

WB: pPDGF $\beta^{721}$

WB: PDGFR $\beta$
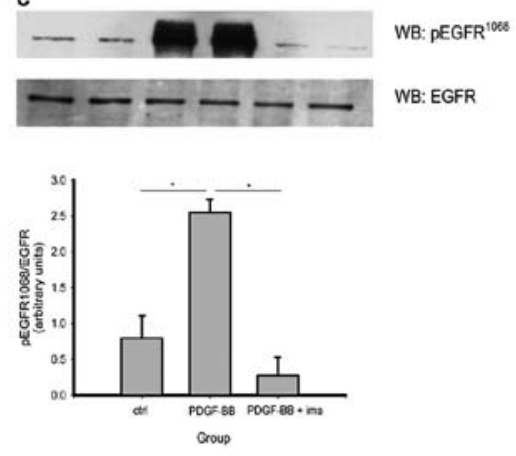

D

WB: pEGFR ${ }^{1068}$

WB: EGFR

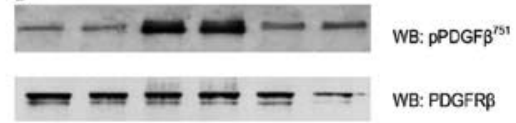

F

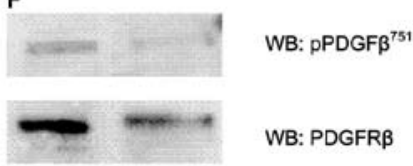

Figure 6. Effects of imatinib treatment on PDGFRß and EGFR phosphorylation in Angll-, PDGF-BB-, or EGF-treated neonatal rat cardiac fibroblasts. A: Representative blot showing that Angll treatment (1 $\mu \mathrm{mol} / \mathrm{L}$; 1 minute) increased PDGFRß phosphorylation in cardiac fibroblasts. Treatment with imatinib $(10 \mu \mathrm{mol} / \mathrm{L}) 30$ minutes before Angll blocked induced PDGFRß phosphorylation; ${ }^{*} P<0.05$; lanes 1 and 2 , control $(n=3)$; lanes 3 and 4 , Angll $(n=3)$; lanes 5 and 6 , Angll + imatinib (ima; $n=3$ ). B: Representative blot showing that Angll treatment (1 $\mu \mathrm{mol} / \mathrm{L} ; 1$ minute) increased EGFR phosphorylation in cardiac fibroblasts. Treatment with imatinib $(10 \mu \mathrm{mol} / \mathrm{L}) 30$ minutes before Angll did not block induced EGFR phosphorylation; ${ }^{*} P<0.05$. Left lane, control ( $\left.n=3\right)$; middle lane, Angll $(n=3)$; right lane, Angll + ima $(n=3)$. C: Representative blot showing that PDGF-BB treatment ( $20 \mathrm{ng} / \mathrm{mL} ; 10$ minutes) increased EGFR phosphorylation in cardiac fibroblasts. Treatment with imatinib $(10 \mu \mathrm{mol} / \mathrm{L}) 30$ minutes before PDGF-BB blocked induced EGFR phosphorylation; ${ }^{*} P<0.05$. Lanes 1 and 2, control $(n=2)$; lanes 3 and 4, PDGF-BB $(n=2)$; lane 5 and 6, PDGF-BB +ima $(n=2)$. D: Representative blot showing that PDGF-BB treatment (20 ng/mL; 10 minutes) increased PDGFRß phosphorylation in cardiac fibroblasts. Treatment with imatinib $(10 \mu \mathrm{mol} / \mathrm{L}) 30$ minutes before PDGF-BB blocked induced PDGFRß phosphorylation; ${ }^{*} P<0.05$. Lanes 1 and 2, control $(n=2)$; lanes 3 and 4, PDGF-BB $(n=2)$; lanes 5 and 6, PDGF-BB + ima $(n=2)$. E: Representative blot showing that $E G F$ treatment ( $10 \mathrm{ng} / \mathrm{mL} ; 10$ minutes) increased EGF phosphorylation in cardiac fibroblasts. ${ }^{*} P<0.05$. Left lane, control $(n=2)$; right lane, $\operatorname{EGF}(n=2)$. F: Representative blot showing that EGF treatment $(10 \mathrm{ng} / \mathrm{mL} ; 10$ minutes) did not increase PDGFRß phosphorylation in cardiac fibroblasts. ${ }^{*} P<0.05$. Left lane, control $(n=2)$; right lane, EGF $(n=2)$. WB indicates Western blot. 


\section{Effects of imatinib in an Angll driven model of cardiac hypertrophy and failure}

Homozygous Ren-2 rats have sustained local activation of the renin-angiotensin system, resulting in severe hypertension ${ }^{17}$. The elevated levels of AngII may directly or indirectly activate growth factor systems that can be inhibited by imatinib. First, Angll, by binding to its Angll type I receptor, can transactivate receptor tyrosine kinases, including the PDGFR $\beta^{10,18}$. The concept of transactivation by Angll has been reported in vitro ${ }^{19,20}$ and in vivo ${ }^{7,21,22}$. Here, we show that a 1-minute stimulation with Angll results in PDGFRß phosphorylation in neonatal cardiac fibroblasts, and that this transactivation can be inhibited by imatinib treatment. These findings suggest that imatinib efficiently blocks the activation of the PDGFRß in vitro as well and may explain the in vivo decreased cardiac fibrosis and improved cardiac function in imatinib-treated Ren2 rats.

Recently, our group showed that inhibition of EGFR signaling also has beneficial effects in this model ${ }^{7}$. Therefore, it is interesting to compare the role of these 2 growth factor receptors EGFR and PDGFRß that share tyrosine kinase activity. However, the effects of inhibition of either EGFR or the PDGFR differ quite substantially. Whereas EGF inhibition by tyrphostin decreased cardiac fibrosis, and also attenuated the development of LV hypertrophy (LVH), tyrphostin treatment did not significantly ameliorate cardiac function. In contrast, in our current study, although imatinib also decreased cardiac fibrosis, it failed to attenuate LVH, and, importantly, did improve cardiac dysfunction. Therefore, the effects of EGFR inhibition differ importantly from the here-described effects of inhibition of the PDGFRß. To analyze this discrepancy, we investigated how the PDGFRß transactivates the EGFR. Here, we show that when the PDGFRß is activated by its native ligand, PDGF, EGFR is transactivated, and this can be inhibited by imatinib. However, when the PDGFRß is activated by Angll, there is also concomitant activation of the EGFR, but this cannot be blocked by imatinib. This strongly suggests that Angll uses other pathways beside the PDGFRß to activate the EGFR, so that imatinib cannot block the effects of Angll on the EGFR. As a result, imatinib only blocks the PDGFRß effects in our model but not the EGFR effects. So, although seemingly related, EGFR or PDGFRß inhibition results in different protective effects in the Ren2 rat.

Given the efficacy of direct inhibition of the PDGFRß by imatinib, we propose that this activation of the PDGFRß is a crucial step in the development of cardiac and renal end-organ damage. This explains also that direct inhibition of the PDGFRß by imatinib is efficacious even without lowering blood pressure. Together, these findings implicate that imatinib attenuates the transition from LVH towards LV dysfunction by interrupting the Angll-induced PDGFRß activation. 


\section{Effects of imatinib in an Angll-driven model of accelerated nephropathy}

As mentioned above, homozygous Ren2 rats experience severe hypertension and high levels of local tissue Angll, which together result in accelerated nephropathy ${ }^{17}$. We show that imatinib treatment attenuates renal damage in the Ren2 rat. This result is in concordance with previous studies showing the protective effect of PDGFR inhibition on nephropathy ${ }^{23,24}$. Previous work of de Borst et $\mathrm{al}^{25}$ also revealed that ERK1/2 inhibition, using a mitogen-activated protein kinase blockade, protected against Angll-mediated renal damage. Here, we show combined beneficial effects of imatinib on renal parenchymal and renovascular level in imatinib-treated Ren2 rats.

Other studies also have demonstrated the important role for the PDGFR. Aberrant PDGF signaling has been implicated in various pathological conditions, such as oncogenesis, atherosclerosis, lung fibrosis, and kidney fibrosis ${ }^{26,27}$. Recently, Ponten et al showed that overexpression of PDGF-C results in dilated cardiomyopathy, cardiac fibrosis, and cardiac hypertrophy ${ }^{28}$, whereas PDGF-D overexpression activated the PDGFRß, and resulted in cardiac fibrosis ${ }^{29}$. These findings suggest that activation of PDGF signaling pathways plays an important role in the development of heart failure, in concordance with our finding of increased PDGFRß activation in our model.

In conclusion, the present study is the first to demonstrate that imatinib, an orally active tyrosine kinase inhibitor, attenuates the development of hypertensive endorgan damage in the hypertensive homozygous Ren2 rat, probably by inhibition of the Angll-related activation of the PDGFRß pathway.

\section{Perspectives}

The findings presented in this study may have important implications for future treatment of cardiovascular diseases. The use of specific kinase inhibitors, already widely appreciated in the treatment of cancer, may also be very successful in cardiovascular diseases. It is known that growth factor receptors, such as the transforming growth factor- $\beta$ (TGFß) receptor and the EGFR, play important roles in the development of cardiac fibrosis and hypertrophy, and targeted inhibition of TGFß and EGF signaling has beneficial effects ${ }^{7,30}$. Now we also show that inhibition of PDGFRß signaling has beneficial effects in a model of accelerated LV dysfunction. Because imatinib is already clinically successfully used for cancer therapy, our findings suggest that strategies aimed at inhibiting such tyrosine kinases may help to prevent hypertensive cardiac and renal damage. 


\section{References}

1. Sadoshima J, Xu Y, Slayter HS, Izumo S. Autocrine release of angiotensin II mediates stretch-induced hypertrophy of cardiac myocytes in vitro. Cell. 1993;75:977-984.

2. Sadoshima J, Izumo S. Molecular characterization of angiotensin II-induced hypertrophy of cardiac myocytes and hyperplasia of cardiac fibroblasts. Critical role of the AT1 receptor subtype. Circ Res. 1993;73:413423.

3. Schorb W, Booz GW, Dostal DE, Conrad KM, Chang KC, Baker KM. Angiotensin II is mitogenic in neonatal rat cardiac fibroblasts. Circ Res. 1993;72:1245-1254.

4. Weber KT, Brilla CG, Janicki JS. Myocardial fibrosis: functional significance and regulatory factors. Cardiovasc Res. 1993;27:341-348.

5. Wollert KC, Drexler H. The renin-angiotensin system and experimental heart failure. Cardiovasc Res. 1999;43:838-849.

6. Tan LB, Jalil JE, Pick R, Janicki JS, Weber KT. Cardiac myocyte necrosis induced by angiotensin II. Circ Res. 1991;69:1185-1195.

7. De Boer RA, Pokharel S, Flesch M, Van Kampen DA, Suurmeijer AJ, Boomsma F, Van Gilst WH, Van Veldhuisen DJ, Pinto YM. Extracellular signal regulated kinase and SMAD signaling both mediate the angiotensin II driven progression towards overt heart failure in homozygous TGR(mRen2)27. J Mol Med. 2004.

8. Schroen B, Heymans S, Sharma U, Blankesteijn WM, Pokharel S, Cleutjens JP, Porter JG, Evelo CT, Duisters R, van Leeuwen RE, Janssen BJ, Debets JJ, Smits JF, Daemen MJ, Crijns HJ, Bornstein P, Pinto YM. Thrombospondin-2 is essential for myocardial matrix integrity: increased expression identifies failure-prone cardiac hypertrophy. Circ Res. 2004;95:515-522.

9. Sharma UC, Pokharel S, van Brakel TJ, van Berlo JH, Cleutjens JP, Schroen B, Andre S, Crijns HJ, Gabius HJ, Maessen J, Pinto YM. Galectin-3 marks activated macrophages in failure-prone hypertrophied hearts and contributes to cardiac dysfunction. Circulation. 2004;110:3121-3128.

10. Yin G, Yan C, Berk BC. Angiotensin II signaling pathways mediated by tyrosine kinases. Int J Biochem Cell Biol. 2003;35:780-783.

11. Savage DG, Antman KH. Imatinib mesylate--a new oral targeted therapy. N Engl J Med. 2002;346:683-693.

12. Cleutjens JP, Verluyten MJ, Smiths JF, Daemen MJ. Collagen remodeling after myocardial infarction in the rat heart. Am J Pathol. 1995;147:325338.

13. Floege J, Hackmann B, Kliem V, Kriz W, Alpers CE, Johnson RJ, Kuhn KW, Koch $K M$, Brunkhorst R. Age-related glomerulosclerosis and interstitial fibrosis 
in Milan normotensive rats: a podocyte disease. Kidney Int. 1997;51:230243.

14. Shih W, Hines WH, Neilson EG. Effects of cyclosporin A on the development of immune-mediated interstitial nephritis. Kidney Int. 1988;33:11131118.

15. Negre-Aminou P, van Leeuwen RE, van Thiel GC, van den IP, de Jong WW, Quinlan RA, Cohen LH. Differential effect of simvastatin on activation of $\operatorname{Rac}(1)$ vs. activation of the heat shock protein 27-mediated pathway upon oxidative stress, in human smooth muscle cells. Biochem Pharmacol. 2002;64:1483-1491.

16. Force T, Kuida K, Namchuk M, Parang K, Kyriakis JM. Inhibitors of protein kinase signaling pathways: emerging therapies for cardiovascular disease. Circulation. 2004;109:1196-1205.

17. Lee MA, Bohm M, Paul M, Bader M, Ganten U, Ganten D. Physiological characterization of the hypertensive transgenic rat TGR(mREN2)27. Am J Physiol. 1996;270:E919-929.

18. Suzuki H, Motley ED, Frank GD, Utsunomiya H, Eguchi S. Recent progress in signal transduction research of the angiotensin II type-1 receptor: protein kinases, vascular dysfunction and structural requirement. Curr Med Chem Cardiovasc Hematol Agents. 2005;3:305-322.

19. Heeneman S, Haendeler J, Saito Y, Ishida M, Berk BC. Angiotensin II induces transactivation of two different populations of the platelet-derived growth factor beta receptor. Key role for the p66 adaptor protein Shc. J Biol Chem. 2000;275:15926-15932.

20. Murasawa S, Mori Y, Nozawa Y, Gotoh N, Shibuya M, Masaki H, Maruyama K, Tsutsumi Y, Moriguchi Y, Shibazaki Y, Tanaka Y, Iwasaka T, Inada M, Matsubara $\mathrm{H}$. Angiotensin II type 1 receptor-induced extracellular signalregulated protein kinase activation is mediated by $\mathrm{Ca} 2+/$ calmodulindependent transactivation of epidermal growth factor receptor. Circ Res. 1998;82:1338-1348.

21. Kim S, Zhan Y, Izumi Y, Yasumoto H, Yano M, Iwao H. In vivo activation of rat aortic platelet-derived growth factor and epidermal growth factor receptors by angiotensin II and hypertension. Arterioscler Thromb Vasc Biol. 2000;20:2539-2545.

22. Kelly DJ, Cox AJ, Gow RM, Zhang Y, Kemp BE, Gilbert RE. Platelet-derived growth factor receptor transactivation mediates the trophic effects of angiotensin II in vivo. Hypertension. 2004;44:195-202.

23. Lassila M, Jandeleit-Dahm K, Seah KK, Smith CM, Calkin AC, Allen TJ, Cooper ME. Imatinib attenuates diabetic nephropathy in apolipoprotein E-knockout mice. J Am Soc Nephrol. 2005;16:363-373.

24. Gilbert RE, Kelly DJ, McKay T, Chadban S, Hill PA, Cooper ME, Atkins RC, 
Nikolic-Paterson DJ. PDGF signal transduction inhibition ameliorates experimental mesangial proliferative glomerulonephritis. Kidney Int. 2001;59:1324-1332.

25. de Borst $M H$, Navis $G$, de Boer RA, Huitema S, Vis LM, van Gilst WH, van Goor H. Specific MAP-kinase blockade protects against renal damage in homozygous TGR(mRen2)27 rats. Lab Invest. 2003;83:1761-1770.

26. Lassila M, Allen TJ, Cao Z, Thallas V, Jandeleit-Dahm KA, Candido R, Cooper ME. Imatinib attenuates diabetes-associated atherosclerosis. Arterioscler Thromb Vasc Biol. 2004;24:935-942.

27. Heldin $\mathrm{CH}$, Westermark B. Mechanism of action and in vivo role of plateletderived growth factor. Physiol Rev. 1999;79:1283-1316.

28. Ponten A, Li X, Thoren P, Aase K, Sjoblom T, Ostman A, Eriksson U. Transgenic overexpression of platelet-derived growth factor- $C$ in the mouse heart induces cardiac fibrosis, hypertrophy, and dilated cardiomyopathy. Am J Pathol. 2003;163:673-682.

29. Ponten A, Folestad EB, Pietras K, Eriksson U. Platelet-derived growth factor $D$ induces cardiac fibrosis and proliferation of vascular smooth muscle cells in heart-specific transgenic mice. Circ Res. 2005;97:1036-1045.

30. Pinto YM, Pinto-Sietsma SJ, Philipp T, Engler S, Kossamehl P, Hocher B, Marquardt H, Sethmann S, Lauster R, Merker HJ, Paul M. Reduction in left ventricular messenger RNA for transforming growth factor beta(1) attenuates left ventricular fibrosis and improves survival without lowering blood pressure in the hypertensive TGR(mRen2)27 Rat. Hypertension. 2000;36:747-754. 


\section{Chapter 7}

\section{Another look at imatinib mesylate}

Mark WM Schellings, Bob Löwenberg, Yigal M. Pinto

\section{New England Journal of Medicine}

2007;356:1183 


\section{To the editors,}

Strebhardt and Ullrich (Dec. 7 issue) ${ }^{1}$ discuss the study by Kerkelä et al., which suggested that imatinib is cardiotoxic ${ }^{1,2}$. However, there are controversial data on the role of imatinib on cardiac function that are not discussed. We published data showing that a reduced dose of imatinib (30 mg per kilogram of body weight per day) was cardioprotective in hypertensive rats ${ }^{3}$. Kerkelä et al. examined various doses of imatinib but showed a loss of cardiac function only at higher doses than those used in other studies ${ }^{3-5}$. Furthermore, clinical evidence of the cardiotoxicity of imatinib is circumstantial. Only 3 of 10 selected patients who received imatinib and subsequently had cardiac dysfunction were free of underlying cardiac disease or risk factors. No detailed cardiac data are available for subjects receiving imatinib who did not have heart failure.

For the time being, the evidence of the clinical significance of the cardiotoxicity of imatinib remains thin. There is a need for studies to evaluate how frequently cardiotoxicity develops in patients receiving imatinib, taking into account dose levels of the drug, preexisting cardiac conditions, and the use of additional cardiotoxic drugs.

\section{Mark W. Schellings \\ Bob Löwenberg \\ Yigal M. Pinto}

\section{The author replies:}

There is no doubt that the kinase inhibitor imatinib has revolutionized the treatment of patients with chronic myeloiod leukaemia (CML). In a recent randomized study of 553 patients, the 5 -year estimated survival rate was $89 \%$ for patients receiving initial imatinib therapy at a daily dose of $400 \mathrm{mg}^{6}$. Congestive heart failure was an extremely rare event in this study. Other trials involving patients with CML have also shown that imatinib greatly improves the risk-benefit ratio ${ }^{6,7}$. The 10 patients described by Kerkelä et al. ${ }^{2}$ had preexisting conditions, including hypertension in 7 patients, diabetes in 4 , and coronary artery disease in 3 . Seven patients received elevated daily doses of imatinib (600 to $800 \mathrm{mg}$ ); all 10 patients had normal left ventricular function before treatment, and cardiac dysfunction developed after 1 to 14 months of therapy ${ }^{2}$. Recent recommendations call for a 400-mg dose of imatinib as standard treatment for CML; the dose may be increased to 600 to 800 $\mathrm{mg}$ if patients have a suboptimal response or if treatment fails ${ }^{8}$. Careful, long-term monitoring of individual patients is required to answer the question of whether elevated doses of imatinib substantially increase the risk of cardiotoxicity, as Kerkelä et al. observed in humans and mice.

\section{Klaus Strebhardt}




\section{References}

1. Strebhardt K, Ullrich A. Another look at imatinib mesylate. N Engl J Med. 2006;355:2481-2482.

2. Kerkela R, Grazette L, Yacobi R, Iliescu C, Patten R, Beahm C, Walters B, Shevtsov S, Pesant S, Clubb FJ, Rosenzweig A, Salomon RN, Van Etten RA, Alroy J, Durand JB, Force T. Cardiotoxicity of the cancer therapeutic agent imatinib mesylate. Nat Med. 2006;12:908-916.

3. Schellings MW, Baumann M, van Leeuwen RE, Duisters RF, Janssen $\mathrm{SH}$, Schroen B, Peutz-Kootstra CJ, Heymans S, Pinto YM. Imatinib attenuates end-organ damage in hypertensive homozygous TGR(mRen2)27 rats. Hypertension. 2006;47:467-474.

4. Lassila M, Allen TJ, Cao Z, Thallas V, Jandeleit-Dahm KA, Candido R, Cooper ME. Imatinib attenuates diabetes-associated atherosclerosis. Arterioscler Thromb Vasc Biol. 2004;24:935-942.

5. Schermuly RT, Dony E, Ghofrani HA, Pullamsetti S, Savai R, Roth M, Sydykov A, Lai YJ, Weissmann N, Seeger W, Grimminger F. Reversal of experimental pulmonary hypertension by PDGF inhibition. J Clin Invest. 2005;115:28112821.

6. Druker BJ, Guilhot F, O'Brien SG, Gathmann I, Kantarjian H, Gattermann N, Deininger MW, Silver RT, Goldman JM, Stone RM, Cervantes F, Hochhaus A, Powell BL, Gabrilove JL, Rousselot P, Reiffers J, Cornelissen JJ, Hughes T, Agis H, Fischer T, Verhoef G, Shepherd J, Saglio G, Gratwohl A, Nielsen JL, Radich JP, Simonsson B, Taylor K, Baccarani M, So C, Letvak L, Larson RA. Five-year follow-up of patients receiving imatinib for chronic myeloid leukemia. N Engl J Med. 2006;355:2408-2417.

7. Kantarjian H, Sawyers C, Hochhaus A, Guilhot F, Schiffer C, GambacortiPasserini C, Niederwieser D, Resta D, Capdeville R, Zoellner U, Talpaz M, Druker B, Goldman J, O’Brien SG, Russell N, Fischer T, Ottmann O, ConyMakhoul P, Facon T, Stone R, Miller C, Tallman M, Brown R, Schuster M, Loughran T, Gratwohl A, Mandelli F, Saglio G, Lazzarino M, Russo D, Baccarani M, Morra E. Hematologic and cytogenetic responses to imatinib mesylate in chronic myelogenous leukemia. N Engl J Med. 2002;346:645652.

8. Baccarani M, Saglio G, Goldman J, Hochhaus A, Simonsson B, Appelbaum F, Apperley J, Cervantes F, Cortes J, Deininger M, Gratwohl A, Guilhot F, Horowitz M, Hughes T, Kantarjian H, Larson R, Niederwieser D, Silver R, Hehlmann R. Evolving concepts in the management of chronic myeloid leukemia: recommendations from an expert panel on behalf of the European LeukemiaNet. Blood. 2006;108:1809-1820. 



\section{Chapter 8}

General discussion and conclusions 
Despite increasing insight into the diseases that cause heart failure, it remains a major health problem. Cardiac remodeling is one of the changes that hallmark the continuous and relentless progression of left ventricular dysfunction towards overt heart failure. Therefore, deeper understanding of the molecular factors that determine cardiac remodeling are bound to yield novel opportunities to alter this adverse change. Recent studies have identified previously unsuspected players in cardiac remodeling, like matricellular proteins (chapter 2). This thesis describes the func-tions of several matricellular proteins during cardiac remodeling, including their signaling effects. In addition, it describes the potential beneficial effects of directinhibition ofcardiacsignaling byimatinibtreatment. Thefollowing paragraphs will discuss the presented findings, and new data on the role of other matricellular proteins (osteopontin, thrombospondin 1 and 2) during cardiac remodeling.

\section{SPARC}

As described for several other matricellular proteins, secreted protein acidic and rich in cysteine (SPARC) expression is high during development, but low during normal postnatal life. SPARC has been implicated in matrix remodeling during pathological stress, as shown by its increased expression after injury ${ }^{1,2}$. Concerning the heart, increased expression has been shown after myocardial infarction (MI $)^{3-5}$ or $ß$-adrenergic stimulation ${ }^{6}$. Also, SPARC may regulate fibroblast migration after $\mathrm{MI}^{7}$. In concordance with the results of Komatsubara et al., we also showed an increased expression of SPARC, peaking 14 days after MI (chapter 3). Moreover, we investigated the function of SPARC during cardiac remodeling after MI by inducing MI in SPARC null and WT mice. Strikingly, almost $40 \%$ of the SPARC null mice died within 5 days after the induction of $\mathrm{Ml}$ due to cardiac rupture, which indeed suggests an important role for SPARC in regulating matrix remodeling. Surviving SPARC null mice displayed aberrant infarct healing 7 and 14 days after MI, with deposition of a less mature collagen matrix, as shown by Sirius Red polarization. Also, SPARC null infarcts contained more myofibroblasts, indicating that SPARC indeed may regulate (myo)fibroblast migration. The abnormal wound healing in SPARC null mice resulted in cardiac dysfunction, as evidenced by an attenuated response to dobutamine. These results support the general idea that SPARC is involved in regulating the formation of a collagen matrix.

The precise role that SPARC exerts is not fully identified. SPARC has been shown to activate transforming growth factor $B$ (TGFß) signaling in mesengial cells and fibroblasts, by binding to the TGFß receptor type $\|{ }^{8,9}$. Since TGFß is necessary for early infarct healing ${ }^{10}$, we investigated whether the lack of SPARC resulted in decreased SMAD2 phosphorylation, a major downstream mediator of TGFß signals. Indeed, we showed that SMAD2 phosphorylation was decreased after 
TGFß stimulation in shRNA-mediated SPARC knockdown cardiac fibroblasts. This prompted the question whether additional TGFß could overcome the defective signaling in SPARC null mice, thereby protecting against cardiac rupture. Indeed, only 1 out of 7 SPARC KO males died due to cardiac rupture, when pretreated with TGFß 1 day before the onset of MI. TGFß treatment in these mice resulted in thick infarcts, hardly containing necrotic myocytes, suggesting an accelerated wound healing with increased extracellular matrix deposition. Taken together, we showed that the absence of SPARC resulted in an increased incidence of cardiac rupture after MI, probably caused by the deposition of an immature collagen matrix. Our data strongly suggest that defective TGFß signaling is one of the mechanisms involved in this defective collagen maturation.

\section{Syndecan-1}

Syndecan-1 is a heparan sulfate proteoglycan, which contains an extracellular ectodomain with glycosaminoglycan chains, a transmembrane domain, and a short cytoplasmic tail. Syndecan-1 has been implicated as a central regulator of inflammation and matrix remodeling ${ }^{11,12}$, and therefore is an interesting candidate to play a role in cardiac remodeling. In 2004, Finsen et al. for the first time showed an increased expression of syndecan-1 after MI, suggesting a functional role during cardiac remodeling after $\mathrm{MI}^{13}$. In chapter 4 of this thesis, we confirmed this upregulation, and, in addition, showed that syndecan1 expression after $\mathrm{Ml}$ indeed is important to maintain cardiac function ${ }^{14}$.

Syndecan-1 mRNA and protein levels increase within 4 days after MI, and reach their peak 7 days after MI. Seven-day-old syndecan-1 null infarcts contain more inflammatory cells and myofibroblasts, and have less necrotic myocytes, as compared to WT mice, indicating an accelerated infarct healing in these mice. Moreover, syndecan-1 null mice have an increased collagen deposition in the infarct 7 and 14 days after MI, but of an impaired quality, which may be due to an increased MMP activity. The accelerated infarct healing together with the altered deposition of immature collagen results in an increased cardiac dilatation and dysfunction 14 days after MI. Interestingly, adenoviral-mediated overexpression of syndecan-1 in WT mice resulted in an improved cardiac function as compared to WT mice treated with control virus. These data indicate that increased syndecan-1 after MI might act as a barrier against inflammatory cells and also may modulate matrix deposition and quality. In conclusion, syndecan-1 upregulation protects against cardiac dilatation and dysfunction after MI.

In chapter 5 we describe the role of syndecan-1 during hypertensive cardiac hypertrophy, showing that syndecan-1 null mice are protected against cardiac 
dysfunction due to decreased cardiac fibrosis. These results were confirmed in vitro using short hairpin mediated knockdown of syndecan-1, and overexpression of syndecan-1. Stimulation with angiotensin II (AngII) or transforming growth factor $\beta$ (TGFß) resulted in increased protein expression of CTGF in normal cardiac fibroblasts, which was significantly attenuated in syndecan-1 knockdown fibroblasts. In contrast, overexpression of syndecan-1 resulted in an exaggerated CTGF expression after AngII treatment. These results clearly indicate that syndecan1 is able to modulate Angll induced CTGF expression, probably by acting as a coreceptor, thereby increasing ligand-receptor affinity.

These results are seemingly opposite to the results obtained in the MI model of remodeling: syndecan-1 is protective after MI, but harmful during Angll-induced cardiac remodeling. During wound healing after MI, syndecan-1 predominantly acts as a modulator of inflammation by controlling the migration of inflammatory cells towards the infarct area, and subsequent stages of infarct healing ${ }^{14}$. The increased shedding of syndecan-1 may play a crucial role herein. During Angllinduced cardiac remodeling, we hypothesize that syndecan-1 shedding is not increased, and syndecan-1 rather acts as an amplifier of cellular signaling ${ }^{15}$, by showing that the absence of syndecan-1 decreases pro-fibrotic signaling in cardiac fibroblasts. Therefore, one could speculate that inhibition of syndecan-1 only during the late phase of infarct healing might be beneficial, by decreasing the amount of cardiac fibrosis. In conclusion, syndecan-1 seems to have an adverse role in general cardiac remodeling, yet to have a beneficial role only in the acute phase of MI, when it limits infarct expansion.

\section{Osteopontin}

Osteopontin (OPN) is a mulitfunctional protein expressed by various celltypes, including macrophages and fibroblasts. OPN is highly expressed during embryogenesis, but its expression declines after birth, and is low in the normal, postnatal heart. However, OPN expression strongly increases after injury, where it regulates inflammatory cell migration, adhesion, and cytokine release ${ }^{16-18}$. Also, OPN has been implicated in the regulation of collagen deposition ${ }^{19}$.

Recently, several studies have been published investigating the role of OPN during diabetic cardiomyopathy, chronic pressure overload, angiotensin II and aldosterone induced cardiac remodeling ${ }^{20-24}$. Together with the article of Trueblood and co-workers ${ }^{25}$, which focused on the role of OPN after MI, these articles grossly describe the primary functions of osteopontin in the stressed heart.

OPN expression is increased in the myocardium during all above-described 
injuries, clearly indicating that OPN is involved in remodeling of the stressed heart. With respect to $\mathrm{MI}, \mathrm{OPN}$ mRNA strongly increases in the infarct region three days after $\mathrm{MI}$, and is still modestly increased 28 days after MI. OPN null mice develop exaggerated left ventricular dilation after MI due to a defect in collagen synthesis, implicating an important role for OPN in post-MI remodeling ${ }^{25}$. Decreased collagen deposition in OPN null mice also has been demonstrated after Angll infusion, and aldosterone infusion ${ }^{22-24}$. In these models, the decrease in fibrosis was associated with a decreased cardiac function in OPN KO mice. Especially for the Angll and aldosterone model this is surprising, since cardiac fibrosis is thought to have detrimental effects on cardiac function. Interestingly, no difference in fibrosis was found after chronic pressure overload between OPN WT and KO mice ${ }^{21}$. Moreover, left ventricular hypertrophy was attenuated in OPN KO mice after aortic banding compared to WT mice, a phenomenon which was not present after Angll or aldosterone treatment. This strongly suggests that OPN may exert different functions during mechanical and neurohormonal hypertension.

In conclusion, the upregulation of OPN in the stressed heart is necessary to regulate collagen deposition, thereby preventing cardiac dilation.

\section{Thrombospondin $1 \& 2$}

Thrombospondins (TSPs) are extracellular glycoproteins, and exert their function by binding to membrane proteins or cytokines, thereby regulating the structure of the extracellular matrix and cell function ${ }^{26}$. As for other matricellular proteins, their expression is high during embryogenesis, but declines after birth ${ }^{27,28}$.

Recently, Frangogiannis et al. showed that TSP1 prevents expansion of healing myocardial infarcts ${ }^{29}$. First, they showed that ischemia increases TSP1 mRNA and protein. Lack of TSP1 increases transcript levels of several cytokines, and presence of macrophages and myofibroblasts in the infarct zone, as well as in remote, non-infarcted myocardium. This suggests that TPS1 null mice have an increased inflammatory response after ischemia-reperfusion, which correlated with an increased infarct expansion. Also, TSP1 is known to be an activator of TGFß, an important regulator of post-MI remodeling. Indeed, TSP1 null mice showed a tendency to a decreased phosphorylation of SMAD2, a known mediator of TGFß signaling, which in part could explain the altered myocardial remodeling after $\mathrm{MI}$ in these mice. Since TSP1 is selectively expressed in the infarct border zone, it might control infarct remodeling, by protecting the non-infarcted zone from remodeling ${ }^{29}$. The role of TSP1 in chronic pressure overload or angiotensin II mediated hypertension has not been studied to date, although this may be very interesting, since TSP1 is a potent activator of TGFß, as mentioned above. In fact, 
Zhou et al. showed that TSP1 is an important mediator of angiotensin II-induced TGFß activation ${ }^{30}$. Angiotensin II stimulated TGFß activity in rat cardiac fibroblasts was totally blocked when they were co-treated with TSP1 neutralizing antibodies or TSP1 antagonistic peptides. Therefore, it would be interesting to see whether this is also the case in an in vivo setting.

With respect to TSP2, our group has shown that TSP2 is upregulated in hypertrophic hearts that are prone to fail, and that lack of TSP2 results in cardiac rupture or severe cardiac dysfunction after Angll infusion ${ }^{31}$. Interestingly, TSP2 null mice do not display any cardiac abnormalities at baseline. The mechanism behind the increased cardiac rupture and dysfunction in TSP2 null mice after Angll infusion was suggested by the exaggerated activation of matrix metalloproteinase (MMP) 2 and 9 in these mice. It is known that TSP2 is capable of binding proMMP2 and MMP2, which than may be endocytosed via the LRP1 receptor ${ }^{32}$. Lack of TSP2 would therefore result in an uncontrolled activation of MMP2 and MMP9, contributing to the disorganization of the matrix, as seen in TSP2 null mice.

Taken together, TSP1 and TSP2 have important roles in cardiac remodeling. Lack of these proteins disturbs the normal inflammatory response or weakens the cardiac matrix, thereby accelerating cardiac dysfunction after injury.

\section{Matricellular proteins as extracellular mediators of intracellular signal transduction}

Matricellular proteins perform various functions during wound healing, as described above, but one of the most intruiging is their ability to modulate outsidein cellular signaling. Matricellular proteins seem to be fine-tuners of cellular signaling, thereby optimizing the signal brought to the cell by either increasing ligand-receptor affinity or increasing the amount of ligands presented to the receptor. For instance, SPARC, Syndecan-1, and TSP-1 have been shown to modulate TGFß signaling through different ways. While SPARC increases the ligand-receptor affinity, Syndecan-1 may increase the amount of ligand presented to the receptor. Additionally, TSP-1 is involved in the activation of TGFß. This shows that matricellular proteins are involved in various steps of signal transduction, which is one of the mechanisms by which they control wound healing. The importance of knowing crucial signal transduction pathways involved in the progression of a disease is immense. Recently, drugs inhibiting the activity of specific signal transduction proteins have been developed. One of these drugs is imatinib mesylate, which is successfully used to treat patients with chronic myeloid leukemia (CML). Imatinib blocks the constant tyrosine kinase activity of the fusion protein bcr/abl, thereby neutralizing the molecular defect that causes CML. Since imatinib is also able to 
block the activity of the platelet-derived growth factor receptor, a receptor known to be involved in cardiovascular disease, we investigated whether imatinib also is useful for the treatment of cardiovascular diseases, like hypertension.

\section{Imatinib as a possible anti-fibrotic agent}

In chapter 6 of this thesis, we describe the potential beneficial effects of imatinib treatment, especially its ability to inhibit cardiac fibrosis during hypertension. Our findings with respect to the anti-fibrotic properties of imatinib are confirmed in many other tissues, like liver, lung, and skin ${ }^{33-35}$. These studies all suggest that imatinib is a well-fit candidate for clinical trials examining its anti-fibrotic properties. However, recently Kerkelä et al. suggested that imatinib may have cardiotoxic effects ${ }^{36}$. They describe ten patients who developed heart failure after the initiation of imatinib treatment. However, only three were devoid of cardiac disease or risk factors. Therefore, their data cannot establish the claimed 'imatinib-induced heart failure' as suggested in their discussion. Also, they only showed a decreased cardiac function after administration of the highest dose of imatinib (200 mg/kg/day), being reasonably high as compared to other animal studies. A large-scale animal study investigating the cardiac effects of a longterm administration of different doses of imatinib should be conducted to provide answers regarding the potential cardiotoxicity of imatinib. Meanwhile, patients taking imatinib should be closely monitored with respect to cardiac function.

Table 1: Cardiac phenotypes of several matricellular protein null mice after myocardial infarction (MI) or angiotensin II (Angll) infusion.

\begin{tabular}{cccc}
\hline $\begin{array}{c}\text { Matricellular } \\
\text { protein }\end{array}$ & Cardiac phenotype after MI & $\begin{array}{c}\text { Cardiac phenotype after } \\
\text { Angll infusion }\end{array}$ & References \\
\hline Osteopontin & Exaggerated LV dilatation & Decreased cardiac fibrosis & $22,23,25$ \\
SPARC & $\begin{array}{c}\text { Increased incidence of } \\
\text { cardiac rupture } \\
\text { Exaggerated post-MI } \\
\text { remodeling }\end{array}$ & No studies & \\
TSP2 & $\begin{array}{c}\text { Increased incidence of } \\
\text { cardiac rupture }\end{array}$ & $\begin{array}{c}\text { Increased LV dysfunction } \\
\text { and cardiac rupture }\end{array}$ & 31,37 \\
& Exaggerated LV dilatation & Decreased cardiac fibrosis & 14 \\
\hline
\end{tabular}




\section{Matricellular proteins are crucial regulators of cardiac remodeling; implications of the presented findings}

The summary of cardiac phenotypes in SPARC, syndecan-1, osteopontin, TSP1 and TSP2 null mice as presented above clearly shows that these proteins play crucial roles when the myocardium is subjected to (hemodynamic) stress (table 1). All these proteins are members of the family of matricellular proteins, an evolving family of proteins, which have the ability to regulate cell-matrix interactions.

Strikingly, none of the respective null mice display any cardiac abnormalities at baseline. However, after MI, the lack of matricellular proteins induces an evident phenotype. This is indicated by the increased incidence of cardiac rupture, increased cardiac dilatation, and increased cardiac dysfunction in comparison to WT mice, as described in this thesis. A shared phenotype seen by these matricellular protein null mice is their inability to produce a collagen matrix of adequate quality. The lack of matrix quality may be present under baseline conditions, but does not seem to influence normal cardiac performance. In contrast, defective collagen maturation in the infarct scar seems to be a very important cause for the phenotypes described in this thesis.

Apart from their ability to influence collagen maturation, matricellular proteins also influence intracellular signaling. For instance, both loss of SPARC and syndecan-1 decreases phosphorylation of SMAD2. Finally, several matricellular proteins are able to control the inflammatory response, possibly through the above effects on intracellular signaling, thereby allowing cardiac remodeling in the infarct scar, but protecting the healthy, non-infarcted myocardium from infiltrating inflammatory cells. This especially is the case for TSP1 and syndecan1, since the TSP1 null mice display infarct expansion with increased numbers of inflammatory cells invading in the healthy myocardium, and syndecan-1 null mice show an increased abundance of inflammatory cells after MI.

\section{Matricellular proteins as biomarkers}

The findings described in this thesis have important implications for the prevention and treatment of heart failure. Recently, serum syndecan-1 has been identified as a marker of poor prognosis in myeloma patients, and inhibition of syndecan-1 is a viable target for myeloma treatment ${ }^{38}$. Whether serum syndecan-1 levels are correlated with the severity of heart disease remains to be determined. Based on our results, serum syndecan-1 levels may be a biomarker for the inflammatory response after $\mathrm{MI}$, whereas syndecan-1 inhibition might be beneficial during hypertension by blocking the development of cardiac fibrosis. SPARC seems to act as a biomarker for melanoma, as increased SPARC and glypican-3 serum levels 
can detect early stage melanoma ${ }^{39}$. Moreover, high levels of SPARC were found in the blood of patients with severe heart failure, and used as a marker of platelet activation ${ }^{40}$. The increased serum levels of SPARC may not only indicate platelet activation, but also ongoing cardiac remodeling, as we showed increased SPARC expression after MI.

\section{Genetic variation in matricellular proteins}

Since we showed that SPARC expression is crucial during wound healing after $\mathrm{MI}$, this protein is an attractive target for clinical investigation regarding infarct healing. For instance, SPARC mutations may cause impaired wound healing, resulting in decreased cardiac function or even cardiac rupture. Indeed, SPARC mutations can influence collagen binding ${ }^{41,42}$, which may lead to decreased collagen quality. Therefore, screening for SPARC mutations could be of benefit, by possibly predicting adverse cardiac remodeling. Based on our results, syndecan1 mutations could lead to an altered inflammatory response after injury, which may lead to impaired wound healing, and subsequent cardiac failure. On the other hand, mutated syndecan-1 may also have implications on the development of cardiac fibrosis during hypertension. Currently, no reports are available linking syndecan-1 mutations with cardiovascular diseases.

In conclusion, our recent efforts in unraveling the role of matricellular proteins during cardiac remodeling have yielded important new insights. These novel concepts on the cardiac role of matricellular proteins can trigger clinical research investigating the correlation between the quality of the cardiac matrix and the development of heart failure after MI, or during hypertension. In addition, we have shown that matricellular proteins are important modulators of signal transduction, and that drugs inhibiting specific signaling pathways are useful in the treatment of cardiovascular disease, with matricellular proteins as potential new therapeutic targets.

\section{References}

1. Porter PL, Sage EH, Lane TF, Funk SE, Gown AM. Distribution of SPARC in normal and neoplastic human tissue. J Histochem Cytochem. 1995;43:791800.

2. Ledda F, Bravo Al, Adris S, Bover L, Mordoh J, Podhajcer OL. The expression of the secreted protein acidic and rich in cysteine (SPARC) is associated with the neoplastic progression of human melanoma. J Invest Dermatol. 1997;108:210-214.

3. Komatsubara I, Murakami T, Kusachi S, Nakamura K, Hirohata S, Hayashi J, Takemoto S, Suezawa C, Ninomiya Y, Shiratori Y. Spatially and temporally 
different expression of osteonectin and osteopontin in the infarct zone of experimentally induced myocardial infarction in rats. Cardiovasc Pathol. 2003;12:186-194.

4. Stanton LW, Garrard LJ, Damm D, Garrick BL, Lam A, Kapoun AM, Zheng Q, Protter AA, Schreiner GF, White RT. Altered patterns of gene expression in response to myocardial infarction. Circ Res. 2000;86:939-945.

5. Dobaczewski M, Bujak M, Zymek P, Ren G, Entman ML, Frangogiannis NG. Extracellular matrix remodeling in canine and mouse myocardial infarcts. Cell Tissue Res. 2006;324:475-488.

6. Masson S, Arosio B, Luvara G, Gagliano N, Fiordaliso F, Santambrogio D, Vergani C, Latini R, Annoni G. Remodelling of cardiac extracellular matrix during beta-adrenergic stimulation: upregulation of SPARC in the myocardium of adult rats. J Mol Cell Cardiol. 1998;30:1505-1514.

7. Wu RX, Laser M, Han H, Varadarajulu J, Schuh K, Hallhuber M, Hu K, Ertl $\mathrm{G}$, Hauck CR, Ritter O. Fibroblast migration after myocardial infarction is regulated by transient SPARC expression. J Mol Med. 2006;84:241-252.

8. Francki A, McClure TD, Brekken RA, Motamed K, Murri C, Wang T, Sage EH. SPARC regulates TGF-beta1-dependent signaling in primary glomerular mesangial cells. J Cell Biochem. 2004;91:915-925.

9. Zhou X, Tan FK, Guo X, Arnett FC. Attenuation of collagen production with small interfering RNA of SPARC in cultured fibroblasts from the skin of patients with scleroderma. Arthritis Rheum. 2006;54:2626-2631.

10. Ikeuchi M, Tsutsui H, Shiomi T, Matsusaka H, Matsushima S, Wen J, Kubota T, Takeshita A. Inhibition of TGF-beta signaling exacerbates early cardiac dysfunction but prevents late remodeling after infarction. Cardiovasc Res. 2004;64:526-535.

11. Gotte M, Joussen AM, Klein C, Andre P, Wagner DD, Hinkes MT, Kirchhof B, Adamis AP, Bernfield M. Role of syndecan-1 in leukocyte-endothelial interactions in the ocular vasculature. Invest Ophthalmol Vis Sci. 2002;43:1135-1141.

12. Elenius V, Gotte M, Reizes $O$, Elenius K, Bernfield M. Inhibition by the soluble syndecan-1 ectodomains delays wound repair in mice overexpressing syndecan-1. J Biol Chem. 2004;279:41928-41935.

13. Finsen AV, Woldbaek PR, Li J, Wu J, Lyberg T, Tonnessen T, Christensen G. Increased syndecan expression following myocardial infarction indicates a role in cardiac remodeling. Physiol Genomics. 2004;16:301-308.

14. Vanhoutte D, Schellings MW, Gotte M, Swinnen M, Herias V, Wild MK, Vestweber D, Chorianopoulos E, Cortes V, Rigotti A, Stepp MA, Van de Werf F, Carmeliet P, Pinto YM, Heymans S. Increased expression of syndecan1 protects against cardiac dilatation and dysfunction after myocardial infarction. Circulation. 2007;115:475-482. 
15. Carey DJ. Syndecans: multifunctional cell-surface co-receptors. Biochem J. 1997;327 ( Pt 1):1-16.

16. Nasu K, Ishida T, Setoguchi M, Higuchi Y, Akizuki S, Yamamoto S. Expression of wild-type and mutated rabbit osteopontin in Escherichia coli, and their effects on adhesion and migration of P388D1 cells. Biochem J. 1995;307 ( Pt 1):257-265.

17. Giachelli CM, Lombardi D, Johnson RJ, Murry CE, Almeida M. Evidence for a role of osteopontin in macrophage infiltration in response to pathological stimuli in vivo. Am J Pathol. 1998;152:353-358.

18. Ashkar S, Weber GF, Panoutsakopoulou V, Sanchirico ME, Jansson M, Zawaideh S, Rittling SR, Denhardt DT, Glimcher MJ, Cantor H. Eta-1 (osteopontin): an early component of type-1 (cell-mediated) immunity. Science. 2000;287:860-864.

19. Liaw L, Birk DE, Ballas CB, Whitsitt JS, Davidson JM, Hogan BL. Altered wound healing in mice lacking a functional osteopontin gene (spp1). J Clin Invest. 1998;101:1468-1478.

20. Subramanian V, Krishnamurthy P, Singh K, Singh M. Lack of osteopontin improves cardiac function in streptozotocin-induced diabetic mice. Am J Physiol Heart Circ Physiol. 2007;292:H673-683.

21. Xie Z, Singh M, Singh K. Osteopontin modulates myocardial hypertrophy in response to chronic pressure overload in mice. Hypertension. 2004;44:826831.

22. Collins AR, Schnee J, Wang W, Kim S, Fishbein MC, Bruemmer D, Law RE, Nicholas S, Ross RS, Hsueh WA. Osteopontin modulates angiotensin IIinduced fibrosis in the intact murine heart.J Am Coll Cardiol. 2004;43:16981705.

23. Matsui Y, Jia N, Okamoto H, Kon S, Onozuka H, Akino M, Liu L, Morimoto J, Rittling SR, Denhardt D, Kitabatake A, Uede T. Role of osteopontin in cardiac fibrosis and remodeling in angiotensin II-induced cardiac hypertrophy. Hypertension. 2004;43:1195-1201.

24. Sam F, Xie Z, Ooi H, Kerstetter DL, Colucci WS, Singh M, Singh K. Mice lacking osteopontin exhibit increased left ventricular dilation and reduced fibrosis after aldosterone infusion. Am J Hypertens. 2004;17:188-193.

25. Trueblood NA, Xie Z, Communal C, Sam F, Ngoy S, Liaw L, Jenkins AW, Wang J, Sawyer DB, Bing OH, Apstein CS, Colucci WS, Singh K. Exaggerated left ventricular dilation and reduced collagen deposition after myocardial infarction in mice lacking osteopontin. Circ Res. 2001;88:1080-1087.

26. Bornstein P. Thrombospondins as matricellular modulators of cell function. J Clin Invest. 2001;107:929-934.

27. Iruela-Arispe ML, Liska DJ, Sage EH, Bornstein P. Differential expression of thrombospondin 1, 2, and 3 during murine development. Dev Dyn. 
1993;197:40-56.

28. Kyriakides TR, Zhu YH, Yang Z, Bornstein P. The distribution of the matricellular protein thrombospondin 2 in tissues of embryonic and adult mice. J Histochem Cytochem. 1998;46:1007-1015.

29. Frangogiannis NG, Ren G, Dewald O, Zymek P, Haudek S, Koerting A, Winkelmann K, Michael LH, Lawler J, Entman ML. Critical role of endogenous thrombospondin-1 in preventing expansion of healing myocardial infarcts. Circulation. 2005;111:2935-2942.

30. Zhou Y, Poczatek MH, Berecek KH, Murphy-Ullrich JE. Thrombospondin 1 mediates angiotensin II induction of TGF-beta activation by cardiac and renal cells under both high and low glucose conditions. Biochem Biophys Res Commun. 2006;339:633-641.

31. Schroen B, Heymans S, Sharma U, Blankesteijn WM, Pokharel S, Cleutjens JP, Porter JG, Evelo CT, Duisters R, van Leeuwen RE, Janssen BJ, Debets JJ, Smits JF, Daemen MJ, Crijns HJ, Bornstein P, Pinto YM. Thrombospondin-2 is essential for myocardial matrix integrity: increased expression identifies failure-prone cardiac hypertrophy. Circ Res. 2004;95:515-522.

32. Yang Z, Kyriakides TR, Bornstein P. Matricellular proteins as modulators of cell-matrix interactions: adhesive defect in thrombospondin 2-null fibroblastsisaconsequence ofincreased levels of matrixmetalloproteinase2. Mol Biol Cell. 2000;11:3353-3364.

33. Yoshiji H, Noguchi R, Kuriyama S, Ikenaka Y, Yoshii J, Yanase K, Namisaki T, Kitade M, Masaki T, Fukui H. Imatinib mesylate (STI-571) attenuates liver fibrosis development in rats. Am J Physiol Gastrointest Liver Physiol. 2005;288:G907-913.

34. Daniels CE, Wilkes MC, Edens M, Kottom TJ, Murphy SJ, Limper AH, Leof EB. Imatinib mesylate inhibits the profibrogenic activity of TGF-beta and prevents bleomycin-mediated lung fibrosis. J Clin Invest. 2004;114:13081316.

35. Distler JH, Jungel A, Huber LC, Schulze-Horsel U, Zwerina J, Gay RE, Michel BA, Hauser T, Schett G, Gay S, Distler O. Imatinib mesylate reduces production of extracellular matrix and prevents development of experimental dermal fibrosis. Arthritis Rheum. 2007;56:311-322.

36. Kerkela R, Grazette L, Yacobi R, Iliescu C, Patten R, Beahm C, Walters B, Shevtsov S, Pesant S, Clubb FJ, Rosenzweig A, Salomon RN, Van Etten RA, Alroy J, Durand JB, Force T. Cardiotoxicity of the cancer therapeutic agent imatinib mesylate. Nat Med. 2006;12:908-916.

37. Cleutjens J, Huynen F, Smits J, Bornstein P, Daemen M. Thrombospondin2 deficiency in mice results in cardiac rupture early after myocardial infarction. Circ Res. 1999;100 (Suppl.):156.

38. Yang Y, Macleod V, Dai Y, Khotskaya-Sample Y, Shriver Z, Venkataraman 
G, Sasisekharan R, Naggi A, Torri G, Casu B, Vlodavsky I, Suva LJ, Epstein J, Yaccoby S, Shaughnessy JD, Jr., Barlogie B, Sanderson RD. The syndecan1 heparan sulfate proteoglycan is a viable target for myeloma therapy. Blood. 2007.

39. Ikuta Y, Nakatsura T, Kageshita T, Fukushima S, Ito S, Wakamatsu K, Baba $\mathrm{H}$, Nishimura $\mathrm{Y}$. Highly sensitive detection of melanoma at an early stage based on the increased serum secreted protein acidic and rich in cysteine and glypican-3 levels. Clin Cancer Res. 2005;11:8079-8088.

40. Serebruany VL, Murugesan SR, Pothula A, Atar D, Lowry DR, O'Connor CM, Gurbel PA. Increased soluble platelet/endothelial cellular adhesion molecule-1 and osteonectin levels in patients with severe congestive heart failure. Independence of disease etiology, and antecedent aspirin therapy. Eur J Heart Fail. 1999;1:243-249.

41. Pottgiesser J, Maurer P, Mayer U, Nischt R, Mann K, Timpl R, Krieg T, Engel J. Changes in calcium and collagen IV binding caused by mutations in the EF hand and other domains of extracellular matrix protein BM-40 (SPARC, osteonectin). J Mol Biol. 1994;238:563-574.

42. Sasaki T, Hohenester E, Gohring W, Timpl R. Crystal structure and mapping by site-directed mutagenesis of the collagen-binding epitope of an activated form of BM-40/SPARC/osteonectin. Embo J. 1998;17:16251634. 



\section{Summary}

Myocardial infarction (MI) and chronic hypertension are two main risk factors for the development of heart failure, a disease that represents a major cause of mortality and morbidity in the Western world. Although treatment of $\mathrm{MI}$ and hypertension is improving, there is still need to gain more insight into the changes occuring in the heart due to these diseases. Recently, a new group of extracellular matrix proteins, the matricellular proteins, has been implicated in the regulation of wound healing. This thesis describes the role of a subset of matricellular proteins in the injured heart, and shows the anti-fibrotic properties of imatinib, an already clinically used anti-cancer drug. Overall, this thesis adds new knowledge regarding cardiac remodeling after Ml or during hypertension, which may improve treatment of cardiac diseases.

In chapter 2, available literature on the function of matricellular proteins in the stressed heart is summarized. It discusses the potential roles of the matricellular proteins tenascin C, tenascin X, thrombospondin 1, thrombospondin 2, secreted protein acidic and rich in cysteine (SPARC), and osteopontin in the stressed heart. Today, several questions regarding the role of these proteins in the injured heart are answered and discussed in chapter $\mathbf{8 .}$

Chapter 3 describes the function of the matricellular protein SPARC after MI. First, we show that SPARC protein expression is increased 3 days after MI, while peaking 14 days after MI. Strikingly, the absence of SPARC resulted in a significantly increased mortality after MI, due to cardiac rupture. Additionally, surviving SPARC KO mice have an impaired response to hemodynamic stress, as compared to wild-type mice. These features may be the consequence of the deposition of less qualitative collagen in the infarcts of SPARC KO mice, as shown by Sirius Red polarization. Also, MMP activity is increased in SPARC KO infarcts. In addition, TGFß signalling was impaired in SPARC knockdown fibroblasts, confirming SPARC as a modulator of TGFß signalling. Infusion of TGFß in SPARC KO animals improved survival after $M I$ by preventing cardiac rupture. These findings show the crucial role of SPARC in regulating infarct healing through its effects on collagen maturation as well as on intracellular signalling.

In chapter 4, the function of the matricellular protein syndecan-1 after MI is described. Syndecan-1 expression readily increases after $\mathrm{Ml}$, reaching its maximum 7 days post-MI. The inflammatory response after MI was severely increased in syndecan-1 KO mice, resulting in an accelerated removal of necrotic cardiomyocytes, and replacement by granulation tissue. This was confirmed in vitro, by showing increased adhesion and transmigration of syndecan-1 KO 
inflammatory cells. The increased inflammation and accelerated wound healing in syndecan-1 KO mice resulted in increased collagen deposition, but of impaired quality, which is related to increased matrix metalloproteinase activity. Together, this resulted in cardiac dilatation and dysfunction in syndecan-1 KO mice after MI. In contrast, syndecan-1 overexpression in WT mice decreased inflammation, and improved the quality of collagen deposition, resulting in an improved cardiac function. This study reveals an important role for syndecan-1 in mediating cardiac healing after $\mathrm{Ml}$.

The importance of syndecan-1 as a modulator of cardiac remodelling was confirmed in a model of chronic hypertension, as described in chapter 5. Importantly, lack of syndecan-1 is beneficial in this model of cardiac stress, by decreasing the amount of cardiac fibrosis. The direct involvement of syndecan-1 in profibrotic signalling was confirmed in vitro. Knockdown of syndecan-1 in cardiac fibroblasts significantly attenuated the expression of the profibrotic protein connective tissue growth factor (CTGF) after angiotensin II of TGFß stimulation, whereas overexpression of syndecan-1 increased CTGF expression. Therefore, syndecan-1 might be a new therapeutic target for decreasing cardiac fibrosis during hypertension.

After investigating the modulatory role of matricellular proteins on intracellular signalling, we addressed the importance of intracellular signalling in the development of cardiac fibrosis more directly in chapter 6 . Imatinib, a successful anti-cancer drug, directly inhibits the kinase activity of the platelet-derived growth factor receptor- $\beta$. Hypertensive homozygous Ren2 rats treated with imatinib developed less cardiac fibrosis than placebo-treated Ren2 rats, which was accompanied by a better cardiac function. Also, kidneys of Ren2 rats were protected by imatinib treatment. The anti-fibrotic properties of imatinib were confirmed in vitro. The clinical implications of these results are highlighted in chapter 7.

In conclusion, this thesis describes the importance of matricellular proteins during cardiac remodeling after MI or during hypertension. It also highlights the potential of matricellular proteins to influence intracellular signalling, and shows that specific inhibition of signalling pathways has beneficial effects. This newly obtained knowledge increases our insight in the development of these diseases, which may have important therapeutic implications. 


\section{Samenvatting}

Het krijgen van een hartinfarct en chronische hypertensie zijn twee belangrijke risicofactoren voor de ontwikkeling van hartfalen, een ziekte die een grote oorzaak is van mortaliteit en morbiditeit in de westerse wereld. Hoewel de behandeling van een hartfinfarct en hypertensie steeds beter wordt, is het nog steeds nodig om meer inzicht te krijgen in de veranderingen die door deze ziekten optreden in het hart. Recentelijk is aangetoond dat een nieuwe groep extracellulaire matrix eiwitten, de matricellulaire eiwitten, betrokken is bij de regulatie van wondheling. Dit proefschrift beschrijft de rol van enkele matricellulaire eiwitten in het zieke hart en toont aan dat imatinib, een geneesmiddel tegen kanker dat al in de kliniek gebruikt wordt, anti-fibrotische eigenschappen heeft. Dit proefschrift voegt nieuwe kennis toe over cardiale remodelering na een hartinfarct of tijdens chronische hypertensie, waardoor de behandeling van deze ziekten verbeterd kan worden.

In hoofdstuk 2 wordt de beschikbare literatuur over de functie van matricellulaire eiwitten in het zieke hart samengevat. De potentiële functies van de matricellulaire eiwitten tenascin $\mathrm{C}$, tenascin $\mathrm{X}$, thrombospondin 1 , thrombospondin 2 , secreted protein acidic and rich in cysteine (SPARC) en osteopontin in het zieke hart worden ook besproken. Verschillende vragen omtrent de functie van deze eiwitten in het zieke hart zijn inmiddels beantwoord en worden besproken in hoofdstuk 8 .

Hoofdstuk 3 beschrijft de functie van het matricellulaire eiwit SPARC na een hartinfarct. Om te beginnen tonen we aan dat de eiwitexpressie van SPARC toeneemt 3 dagen na het infarct en maximaal is op dag 14 na het infarct. De afwezigheid van SPARC zorgt voor een toename van de mortaliteit na een hartinfarct, veroorzaakt door een toename in cardiale ruptuur. Ook vertonen overlevende SPARC KO muizen, vergeleken met wildtype muizen, een gebrekkige respons op hemodynamische stress. Deze zaken kunnen het gevolg zijn van de depositie van minder kwalitatief collageen in het infarctgedeelte van de SPARC KO muizen, zoals we aantonen met Sirius Rood polarisatie. Ook de activiteit van MMP's is verhoogd in de SPARC KO infarcten. SPARC knockdown fibroblasten vertoonden een verminderde TGFß signalering, daarmee bevestigend dat SPARC een modulator van TGFß signalering is. Infusie van TGFß in SPARC KO dieren verbeterde de overlevingskansen na een infarct door cardiale ruptuur te voorkomen. Samen laten deze bevindingen zien dat SPARC een cruciale rol speelt in de regulatie van infarctheling door zijn effecten op collageenmaturatie en intracellulaire signalering.

In hoofdstuk 4 wordt de functie van het matricellulaire eiwit syndecan-1 na een hartinfarct beschreven. De expressie van syndecan-1 neemt snel toe na een 
infarct en piekt na 7 dagen. De inflammatoire respons na een hartinfarct was ernstig verhoogd in syndecan-1 KO muizen, resulterend in een versnelde ruiming van necrotische cardiomyocyten en vervanging door granulatieweefsel. Deze bevindingen werden in vitro bevestigd door verhoogde adhesie en transmigratie aan te tonen in syndecan-1 KO inflammatoire cellen. De verhoogde inflammatie en versnelde wondheling in syndecan-1 KO muizen resulteerde in een verhoogde depositie van collageen, maar van een slechtere kwaliteit, wat is gerelateerd aan de verhoogde matrix metalloproteinase activiteit in syndecan-1 KO infarcten. Samen zorgden deze veranderingen voor cardiale dilatatie en dysfunctie in syndecan-1 KO dieren na een hartinfarct. Tegenovergesteld zorgde syndecan-1 overexpressie in WT muizen voor een verlaagde inflammatie en een betere collageen kwaliteit, resulterend in een verbeterde cardiale functie. Deze studie laat een belangrijke rol zien voor syndecan-1 in de regulatie van wondheling na een hartinfarct.

Het belang van syndecan-1 als een modulator van cardiale remodelering werd bevestigd in een model van chronische hypertensie, zoals beschreven in hoofdstuk 5. Interessant genoeg is het missen van syndecan-1 juist goed in dit model van cardiale stress door het verminderen van de hoeveelheid cardiale fibrose. De directe betrokkenheid van syndecan-1 in profibrotische signalering werd bevestigd in vitro. Syndecan-1 knockdown in cardiale fibroblasten verminderde de expressie van het profibrotische eiwit connective tissue growth factor (CTGF) significant na angiotensine II of TGFß stimulatie, terwijl overexpressie van syndecan-1 CTGF expressie verhoogde. Deze resultaten tonen aan dat syndecan-1 een nieuw therapeutisch doel kan zijn om de ontwikkeling van cardiale fibrose te verminderen tijdens hypertensie.

Na de modulerende rol van matricellulaire eiwitten op intracellulaire signalering hebben we het belang van intracellulaire signalering in de ontwikkeling van cardiale fibrose meer direct bestudeerd in hoofdstuk 6. Imatinib, een succesvol medicijn tegen kanker, blokkeert specifiek de kinase activiteit van de plateletderived growth factor receptor-ß (PDGFR-ß). Hypertensieve homozygote Ren2 ratten die behandeld werden met imatinib ontwikkelden minder cardiale fibrose dan Ren 2 ratten met een controle behandeling en hadden ook een betere cardiale functie. Ook beschermde behandeling met imatinib tegen nierschade in de Ren2 ratten. De antifibrotische eigenschappen werden bevestigd in vitro. De klinische implicaties van deze resultaten worden belicht in hoofdstuk 7.

Concluderend beschrijft dit proefschrift het belang van matricellulaire eiwitten tijdens cardiale remodelering na een hartinfarct of tijdens hypertensie. Daarnaast benadrukt dit proefschrift de potentie van matricellulaire eiwitten om intracellulaire signalering te beinvloeden en toont aan dat specifieke remming 
van PDGFR-ß een gunstig effect heeft. Deze nieuw verkregen kennis vergroot ons inzicht in de ontwikkeling van deze ziekten en kan daarom belangrijke therapeutische implicaties hebben. 



\section{Dankwoord}

Een proefschrift komt tot stand door vele mensen, zeker niet alleen door de schrijver ervan. Daarom wil ik op deze plaats alle mensen bedanken die aan dit boekwerk hebben bijgedragen.

Professor Doctor Pinto, beste Yigal. Ik kan me nog als de dag van gisteren herinneren dat ik ietwat zenuwachtig de staf Cardiologie binnenliep, wachtend op toen nog dr. Pinto. De zenuwen verdwenen meteen toen jij, enthousiast als altijd, over het toenmalige onderzoek begon te vertellen. Je hebt de klasse om altijd alles positief in te zien en mensen te enthousiasmeren voor klinisch dan wel basaal onderzoek. Daarnaast ben je ook nog een man van de wereld, waarmee je de hele avond kunt praten over totaal uiteenlopende zaken. Van een ding heb je echter iets minder verstand, en gelukkig ben ik daarin in ieder geval de bovenliggende partij geweest de afgelopen jaren. Ik wil je van harte bedanken voor alle steun in de afgelopen jaren en ik hoop dat we samen nog mooie dingen kunnen verwezenlijken.

Dr. Heymans, beste Stephane, jij bent zeker de mede-initiator van dit proefschrift. In de zomer van 2003 kwam je je voorstellen tijdens onze 'traditionele' barbecue bij Yigal, met de nu vanzelfsprekende champagne. Ondertussen had ik via de mail al veel met je te maken gehad, ik had namelijk de taak om al jouw KO muizen de CPV binnen te loodsen, wat natuurlijk een uitgelezen kans was voor mij om kennis te maken met de matricellulaire eiwitten. Tijdens mijn onderzoeken vroeg je altijd geinteresseerd naar de gang van zaken en gaf je nuttige tips. Jouw kennis van histologie en proefdieronderzoek is van groot belang voor ons lab. Hartelijk bedankt voor de fijne jaren!

Rick van Leeuwen: Westernblotkoning, celcultuurprins, beursgorilla, vinoloog, achtergronddanser van Re-play, ex-ploeggenoot van Rene van der Gijp! Woorden schieten te kort om jouw rol in ons lab aan te geven. Labmentor en cultuurbewaarder komen het dichtst in de buurt, denk ik. Altijd kritisch op de resultaten en nooit te beroerd om zelf mee te denken, heb je een groot aandeel gehad in de totstandkoming van dit proefschrift. Ik ben er trots op dat je mijn paranimf bent. Mijn dank is groot!

Rudy Duisters: kloneringskoning, Brabander en PSV'er! Vanaf dag 1 zat het snor tussen ons, het is goed om iemand te hebben die tijdens de lunch het meestal met je eens is! Ik heb je waarschijnlijk helemaal gek gemaakt met mijn vele vragen, maar gelukkig kon/kun je daar goed tegen. De laatste jaren ben je zelf meer onderzoek gaan doen en met jouw kwaliteiten moet daar zeker iets goeds uitkomen! 
Mirjam van Loon (West-Brabander), de vele uren die je samen met mij en voor mij op het muizenlab van farmacologie hebt doorgebracht staan aan de basis van dit proefschrift! Heel veel dank daarvoor! Ook heb je aan het begin gestaan van alle IHC protocollen, nu mooi geordend op onze share. Kortom, jouw bijdrage aan dit proefschrift is levensgroot! $\mathrm{Na}$ een aantal jaren in ons lab ging je je eigen weg om te gaan studeren in Utrecht. Ik wens je hierbij heel veel succes!

Blanche Schroen, Blanchie Panchie. Ik ben er trots op dat ik jouw opvolger mag zijn. Je hebt met jouw prachtige proefschrift een standaard gezet, waaraan iedereen zich op kan trekken. Je bent natuurlijk mijn eigenlijke congresmaatje en ik zal onze belevenissen in the States nooit meer vergeten. Van de merlot met nachos in Orlando naar shots in New Orleans tot en met Toto in Chicago, bedankt voor alle gezelligheid! Tegen de tijd dat ik promoveer, heb jij Londen al veroverd! Veel succes met al wat komen gaat!

Geert van Almen, weer een Brabander! Lang, heel lang, heb ik tegen je aan moeten zeuren om toch maar eens bij ons in het lab te komen kijken voor een eventuele stageplaats tijdens je studie gezondheidswetenschappen. Maar ik hoop (en denk) dat je het uiteindelijk wel hebt gewaardeerd. Na een fantastische stage als 'Tweezerman' ben je nu gepromoveerd tot AiO binnen onze groep. Je houdt je nu bezig met de meest evidente vraag in de wereld; hoe veroudert een hart? Ik weet zeker dat hieruit mooie publicaties zullen volgen! Geert, jouw humor en langdradigheid zijn ongeëvenaard! Bedankt voor alles en we zullen elkaar nog vaak treffen in de toekomst!

Joost Leenders: mede-student \& wielrenner, halve Brabander, overbuurman! Ik denk dat je de meest sociale kerel bent op het oostelijk halfrond (en dus ook op het westelijk)! Je bent de cel-isolatiekoning van ons lab en hebt verder prachtige resultaten behaald met KLF15. Daarnaast ben je ook een cruciale factor in het slagen van een lab-uitje! Befaamd zijn jouw woorden: "Ik ga het niet te laat maken vanavond", om vervolgens iedereen op sleeptouw te nemen en er een geweldige avond van te maken! Joost, ook jij heel veel succes in de toekomst!

N.A.R.D. Kubben, the man with the plan. Hoe kan een Limburgse jongen overleven tussen al dat Brabantse geweld? Nard doet het al 3 jaar met verve! Nard, jouw experimenten zijn grotesk en nu al een begrip in het EMC lab. Binnenkort worden ze uitbetaald in prachtige artikelen! En natuurlijk kan ik hier de befaamde rabarberchampagne uit Munstergeleen niet onbenoemd laten, een onmisbaar onderdeel van onze AiO-uitjes.

Melissa en Davy, the Leuven connection. Jullie verdienen samen een meer dan 
eervolle vermelding in dit dankwoord! Mede dankzij jullie inzet zijn er een paar mooie artikelen verschenen. Naast onze samenwerking hebben jullie zelf ook prachtige resultaten met andere projecten. Hartelijk bedankt voor alles!

Esther Creamers! Vanuit Dallas, TX, ben je ons lab binnengevlogen als een ware wervelwind. Samen met Joost en Viola terroriseer je de labtafels en pipetten, op zoek naar nieuwe data. Je enthousiasme werkt aanstekelijk op de hele groep. Of de hierboven genoemde eigenschappen het gevolg zijn van overmatig koffiegebruik laat ik in het midden...In ieder geval bedankt voor alles en nog veel succes hier in het EMC lab!

Terwijl u dit dankwoord aan het lezen bent, kunt $u$ zich vast niet voorstellen dat ons EMC lab in 2003 nog maar uit 7 mensen bestond. En dan te bedenken dat er nog wat namen aankomen! Laat ik verdergaan met iemand die heel veel goed werk heeft afgeleverd en mede daardoor een baan binnen ons lab heeft verdiend. Gonda, bedankt voor alle Westerns en Q-PCR's die je hebt verricht en ik ben blij dat je nog steeds in onze groep zit. Verder wil ik ook de drie kroonprinsen Kevin 'kefkef', Wouter en Frank 'bonobo' bedanken voor al het werk! Ook jullie zullen nog terugkeren in het warme nest van het EMC lab. Viola, de stille kracht, keep up the good work! Arie, als bioinformaticus creëer je steeds weer nieuwe targets voor het lab, hiermee maak je je onmisbaar. Succes met je promotie! Verder wil ik ook de mensen van het eerste uur bedanken, Suzanne, Sara, Umesh en Jop. Bedankt voor alle steun in de eerste jaren op het EMC lab. Ook de secretaresses van de vakgroep Cardiologie kan ik niet onvermeld laten! Bianca, Barbara en de overigen, heel erg bedankt voor alles!

Ik wil de leden van de leescommissie hartelijk bedanken voor het beoordelen van mijn proefschrift, in het bijzonder de voorzitter van de leescommissie prof. dr. Harry Crijns. U heeft altijd interesse getoond voor het onderzoek in het lab 'aan de overkant'. Ik wil u hiervoor hartelijk bedanken en vind het een eer dat $u$ de voorzitter van mijn leescommissie was.

Tijdens mijn promotie-onderzoek heb ik niet alleen in het lab van Cardiologie gezongen, maar ook diverse andere laboratoria hebben van mijn zangkunsten kunnen genieten. Een heel bijzonder woord van dank gaat uit naar de medewerkers van het dierenlab van Farmacologie: Jacques, Agnieszka, Peter, Helma, Nicole. Zij stonden altijd klaar wanneer ik in de problemen raakte. Vooral Jacques en Agnieszka hebben mij de fijne kneepjes van het dierenwerk bijgebracht en stonden altijd klaar om toch nog wat extra dieren in te zetten voor een bepaalde studie. Mijn dank is groot! Ook de leden van onze 'dinsdagochtendclub' wil ik van harte bedanken voor alle vruchtbare ontmoetingen en alle hulp die zij hebben geboden. Tijdens 
deze bijeenkomsten op dinsdagochtend ontmoet je als AiO ook collega-AiO's van andere vakgroepen, sommigen hiervan KAN ik eenvoudigweg niet onbenoemd laten. Pascal Smeets, onze proefballonnetjes over de toekomst van België zal ik nooit vergeten. Bedankt voor alle fibroblasten die je mij schonk (ook dank aan Birgit hiervoor!). Susanne en Veerle, tja...eigenlijk zijn jullie geen Farmaco-AiO's maar Cardio-AiO's! Bedankt voor alle gezelligheid! Rest mij om jullie veel succes te wensen met het schrijven van jullie proefschrift. De mensen van de vakgroep Pathologie wil ik bedanken voor hun gastvrijheid en hulp de afgelopen jaren. Veronica, als ex-cardio verdien je natuurlijk een speciaal plaatsje in dit dankwoord, bedankt voor de prachtige ISH. Ook Jack nogmaals bedankt voor het verhelpen van de vele microscoopproblemen. Bij de vakgroep Anatomie \& Embryologie kon ik altijd terecht voor het nodige snijwerk, hartstikke bedankt hiervoor. Verder wil ik de mensen van de CPV ontzettend bedanken voor alle hulp die ik in de afgelopen jaren heb gekregen! Natuurlijk mag ik onze buren van Fysiologie niet vergeten, zij hebben namelijk nog het meeste last van de voortdurende Cardio-terror. Peter en consorten, beter een goede buur is hier helemaal op zijn plaats, bedankt!

Dr. Martin Götte and Dr. Helene Sage, thank you very much for your cooperation on the syndecan-1 and SPARC projects, respectively.

Zonder ontspanning geen inspanning! Hein, bedankt dat je mijn paranimf wilt zijn! Je hebt het Zuiden verlaten voor Amsterdam. Maar de lokroep van het ware bourgondische leven, waar jij goed bekend mee bent, zal niet lang op zich laten wachten.... Verder wil ik natuurlijk Randy, Jacco, Jeroen, Jacques, Henk, Jaro en alle (oud-)Heeren van Abraxas, BMC6 en alle anderen niet vergeten. Bedankt voor alles en ik hoop nog veel plezier met jullie te hebben in de toekomst.

Ik wil mijn familie bedanken voor de niet aflatende interesse en steun die ik de afgelopen jaren heb gekregen. Pap en mam, jullie hebben ervoor gezorgd dat ik niets tekort kwam en hebben mij altijd gesteund. Het is altijd heerlijk om weer thuis te komen! Frank, van twee broers moet er een de technicus zijn en dat ben jij! lk ben trots op alles wat je doet!

Marjolein: I can't stop loving you! Jij weet precies welke melodie hierbij hoort. De afgelopen jaren was je mijn steun en toeverlaat, mijn rustpunt, maar bovenal mijn meisje! En ik hoop dat dat nog lang zo mag blijven! 



\section{List of Publications}

1. Rouwet EV, Tintu AN, Schellings MW, van Bilsen M, Lutgens E, Hofstra L, Slaaf DW, Ramsay G, Le Noble FA. Hypoxia induces aortic hypertrophic growth, left ventricular dysfunction, and sympathetic hyperinnervation of peripheral arteries in the chick embryo. Circulation. 2002;105:27912796.

2. Schellings $\mathbf{M W}$, Pinto $\mathrm{YM}$, Heymans S. Matricellular proteins in the heart: possible role during stress and remodeling. Cardiovasc Res. 2004;64:24-31.

3. Vanhoutte D, Schellings $\mathbf{M W}$, Pinto $\mathrm{Y}$, Heymans S. Relevance of matrix metalloproteinases and their inhibitors after myocardial infarction: a temporal and spatial window. Cardiovasc Res. 2006;69:604-613.

4. Schellings $\mathbf{M W ^ { * }}$, Baumann $\mathbf{M}^{*}$, van Leeuwen RE, Duisters RF, Janssen SH, Schroen B, Peutz-Kootstra CJ, Heymans S, Pinto YM. Imatinib attenuates end-organ damage in hypertensive homozygous TGR(mRen2)27 rats. Hypertension. 2006;47:467-474.

5. Vanhoutte $D^{*}$, Schellings $\mathbf{M W}^{*}$, Gotte $M$, Swinnen $M$, Herias V, Wild MK, Vestweber D, Chorianopoulos E, Cortes V, Rigotti A, Stepp MA, Van de Werf F, Carmeliet P, Pinto YM, Heymans S. Increased expression of syndecan1 protects against cardiac dilatation and dysfunction after myocardial infarction. Circulation. 2007;115:475-482.

6. de Borst $\mathrm{MH}$, Diks $\mathrm{SH}$, Bolbrinker J, Schellings $\mathbf{M W}$, van Dalen $\mathbf{M B}$, Peppelenbosch MP, Kreutz R, Pinto YM, Navis G, van Goor H. Profiling of the renal kinome: a novel tool to identify protein kinases involved in angiotensin II-dependent hypertensive renal damage. Am J Physiol Renal Physiol. 2007.

7. Schellings $\mathbf{M W}$, Lowenberg B, Pinto YM. Another look at imatinib mesylate. N Engl J Med. 2007;356:1183; author reply 1183.

8. Schroen B, Leenders JJ, van Erk A, Bertrand AT, van Loon M, van Leeuwen RE, Kubben N, Duisters RF, Schellings MW, Janssen BJ, Debets JJ, Schwake M, Hoydal MA, Heymans S, Saftig P, Pinto YM. Lysosomal integral membrane protein 2 is a novel component of the cardiac intercalated disc and vital for load-induced cardiac myocyte hypertrophy. J Exp Med. 2007;204:1227-1235. 



\section{Curriculum Vitae}

Mark Schellings was born on August 23, 1980 in Berlicum, The Netherlands. In 1992, he attended Gymnasium Bernrode in Heeswijk-Dinther, where he graduated in 1998. The same year, he started studying Health Sciences at Maastricht University. From 2001-2002, he performed an internship at the department of Physiology, investigating the influence of hypoxia on aortic remodeling. In 2002, he obtained his MSc degree in Biological Health Sciences. January 2003, he started his $\mathrm{PhD}$ at the department of Cardiology at Maastricht University. His main goal was to investigate the role of matricellular proteins during cardiac remodeling. In 2004 and 2005 he received the Young Investigator Award from the European Council for Cardiovascular Research. Also in 2005, he received the Best Poster Award in Cardiac Biology at the $10^{\text {th }}$ European Council for Cardiovascular Research. 

